\begin{tabular}{|c|c|c|}
\hline Beitr. Ent. & Berlin & ISSN 0005-805X \\
\hline $49(1999) 1$ & S. 3-96 & 6.04 .1999 \\
\hline
\end{tabular}

\title{
A revision of Othius STEPHens, 1829. VII. The species of the Eastern Palaearctic region east of the Himalayas
}

\section{(Coleoptera: Staphylinidae)}

With 31 figure plates, 7 diagrams, and 1 map

\section{VOLKER ASSING}

\begin{abstract}
Summary
Types and additional material of Othius from the Eastern Palaearctic region east of the Himalayas as well as from southern China and Taiwan are revised. 31 valid species and 2 subspecies are recognized; the identity of a further 3 species, whose types were not made available, remains dubious. The following new synonymies are established: $O$. medius SHARP $=O$. medius kusuii $\mathrm{ITO}_{\text {, }}$ syn. n., $=$ O. medius yakushimanus ITO, syn. n.; O. rosti BERNHAUER $=O$. ussuriensis COIFFAT, syn. n.; O. latus SHARP $=O$. stoetzneri BERNHAUER, syn. n., $=O$. chongqingensis ZHENG, syn. n., $=O$. latus ozakii ITO, syn. n.; O. punctatus BERNHAUER $=O$. arisanus (SHIBATA), syn. n. Lectotypes are designated for O. medius SHARP, O. rosti BERNHAUER, O. stoetzneri BERNHAUER, and $O$. rufipennis SHARP. 19 new species and one new subspecies are described: $O$. bordonii sp. n. (China), O. latus gansuensis ssp. n. (China: Gansu), O. atavus sp. n. (China: Yunnan), O. lubricus sp. n. (China: Yunnan), O. discrepans sp. n. (China: Sichuan), O. excisus sp. n. (China: Sichuan), O. sculptipennis sp. n. (China: Sichuan), O. tuberipennis sp. n. (China: Yunnan), O. fibulifer sp. n. (China: Sichuan), O. wrasei sp. n. (China: Sichuan), O. smetanai sp. n. (Taiwan), O. aequabilis sp. n. (Taiwan), $O$. hamatus sp. n. (Taiwan), O. acutus sp. n. (Taiwan), O. reticulatus sp. n. (Taiwan), O. praecisus sp. n. (Taiwan), $O$. collapsus sp. n. (Taiwan), O. contumax sp. n. (Taiwan), and $O$. coniceps sp. $\mathbf{n}$. (Taiwan). Comparative diagnoses are given for the species and subspecies treated and complemented by comments on phylogenetic relationships; revised biogeographical and the available bionomical data are compiled. The primary and secondary sexual characters are figured; for several species, the distribution and intraspecific morphological variation are illustrated. A diagnostic key is presented for the Othius species of the Eastern Palaearctic region east of the Himalayas. There is some evidence that both the Western Palaearctic and the Eastern Palaearctic species of Othius are monophyla; the former is distributed west and the latter east of the Caspian Sea, the only exception being the Western Himalayan $O$. kashmirica subgroup, which is closely related to the Western Palaearctic O. laeviusculus group. In the region east of the Himalayas, species diversity is highest in Yunnan and Sichuan (mainland China), and in Taiwan. The phylogenetics of the Taiwanese species are discussed, and conclusions regarding the colonization of the island are presented.
\end{abstract}

Key words

Coleoptera - Staphylinidae - Xantholininae - Othiini - Othius - Eastern Palaearctic - Taiwan - China - Japan distribution - ecology - taxonomy - revision - new species - lectotype designation - new synonyms 


\section{Zusammenfassung}

Eine Revision der Typen und weiteren Sammlungsmaterials von Othius-Arten aus der Paläarktis östlich des Himalayas sowie aus Südchina und Taiwan ergab 31 valide Arten und 2 Unterarten; die Identität dreier weiterer Arten bleibt ungeklärt, da die Typen nicht verfügbar waren. Die folgenden Taxa werden neu synonymisiert: $O$. medius SHARP $=O$. medius kusuii ITO, syn. n., $=O$. medius yakushimanus ITO, syn. n.; $O$. rosti BERNHAUER $=0$. ussuriensis COIFFAT, syn. n.; O. latus $\mathrm{SHARP}=O$. stoetzneri BERNHAUER, syn. $\mathbf{n} .,=O$. chongqingensis ZHENG, syn. n., $=O$. latus ozakii ITO, syn. n.; $O$. punctatus BERNHAUER $=O$. arisanus (ShIBATA), syn. n. Für $O$. medius SharP, $O$. rosti BERnHAUER, $O$, stoetzneri BernHAUER und $O$. rufipennis SHARP werden Lektotypen designiert. 19 neue Arten und eine neue Unterart werden beschrieben: $O$. bordoni sp. n. (China), O. latus gansuensis ssp. n. (China: Gansu), O. atavus sp. n. (China: Yunnan), O. lubricus sp. n. (China: Yunnan), O. discrepans sp. n. (China: Sichuan), O. excisus sp. n. (China: Sichuan), O. sculptipennis sp. n. (China: Sichuan), O. tuberipennis sp. n. (China: Yunnan), O. fibulifer sp. n. (China: Sichuan), O. wrasei sp. n. (China: Sichuan), O. smetanai sp. n. (Taiwan), O. aequabilis sp. n. (Taiwan), $O$. hamatus sp. n. (Taiwan), O. acutus sp. n. (Taiwan), O. reticulatus sp. n. (Taiwan), $O$. praecisus sp. n. (Taiwan), $O$. collapsus sp. n. (Taiwan), $O$. contumax $\mathbf{s p}$. n. (Taiwan) und $O$. coniceps $\mathbf{s p}$. n. (Taiwan). Die Diagnosen der behandelten Arten und Unterarten werden durch Angaben zur Phylogenie, Verbreitung und Bionomie ergänzt; primäre und sekundäre Sexualmerkmale werden abgebildet. Für einige Arten werden die intraspezifische Variablität und die Verbreitung anhand von Diagrammen bzw. Karten veranschaulicht. Für die Arten der Ostpaläarktis ostlich des Himalayas wird eine Bestimmungstabelle vorgelegt. Morphologische Merkmale deuten darauf hin, daß die westpaläarktischen und ostpaläarktischen Othius-Arten jeweils Monophyla darstellen, wobei erstere - mit Ausnahme der im westlichen Himalaya vorkommenden O. kashmiricaArtengruppe - im Gebiet westlich und letztere östlich des Kaspischen Meeres verbreitet sind. In der Ostpaläarktis östlich des Himalayas zeichnen sich Yunnan und Sichuan (China) sowie Taiwan durch bemerkenswert hohe Artendiversität aus. Auf der Grundlage der phylogenetischen Beziehungen der Arten Taiwans werden Schlußfolgerungen hinsichtlich der Besiedlung der Insel abgeleitet.

\section{Table of contents}

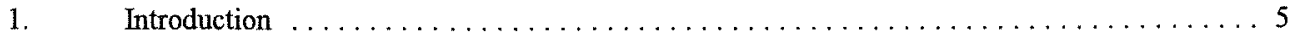

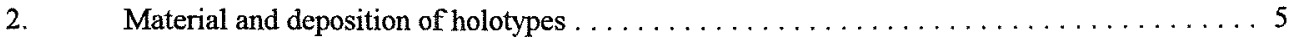

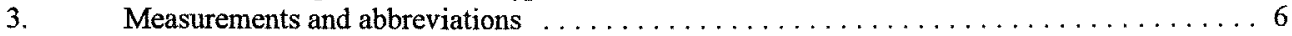

4. The Othius species of the Eastern Palaearctic region east of the Himalayas . . . . . . . . 6

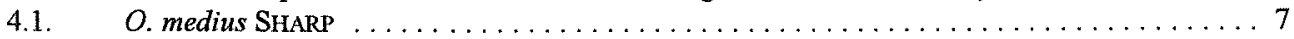

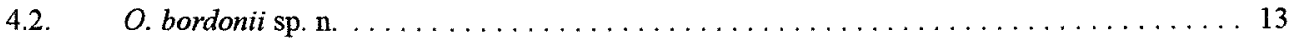

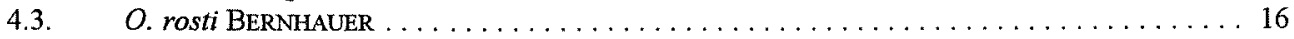

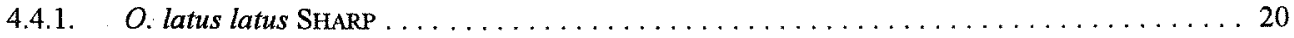

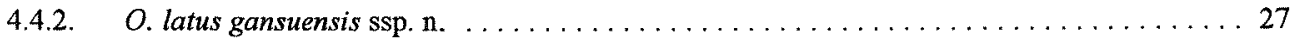

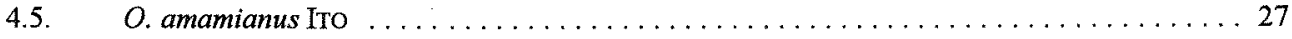

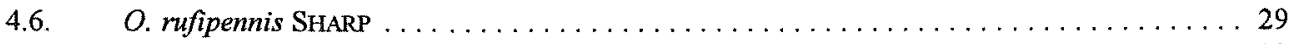

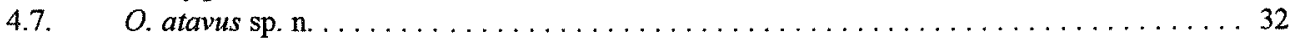

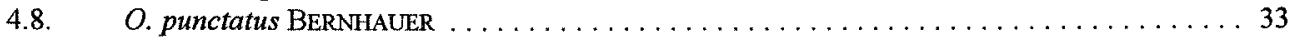

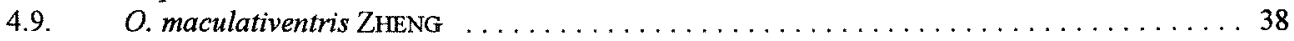

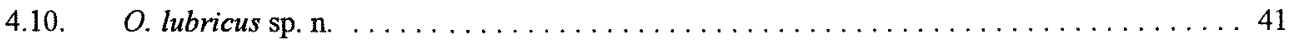

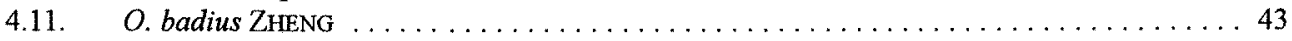

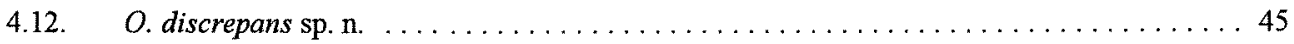

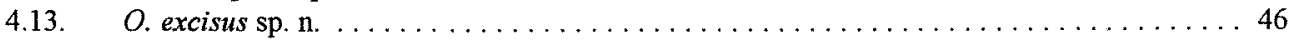

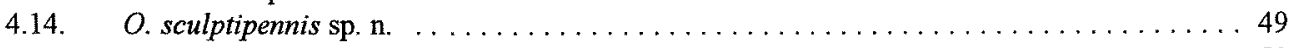

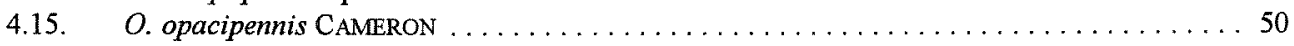

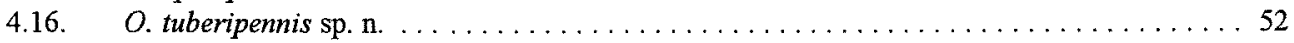

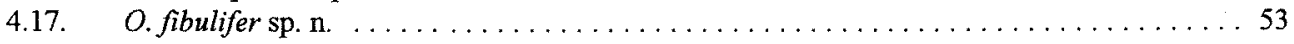

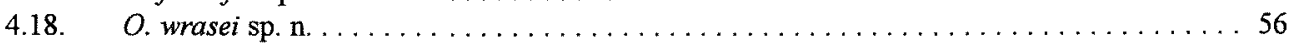

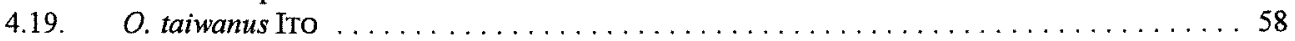




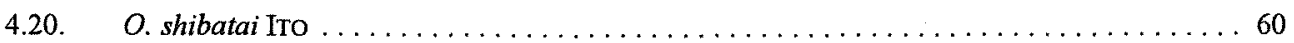

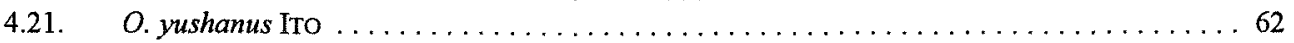

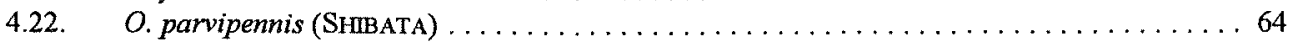

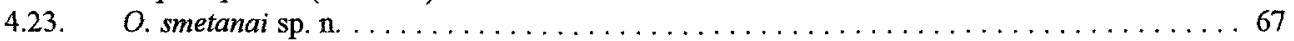

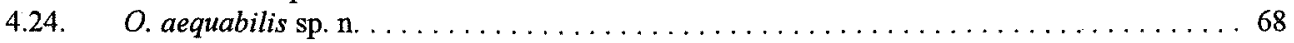

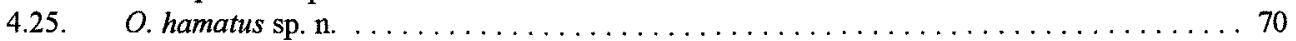

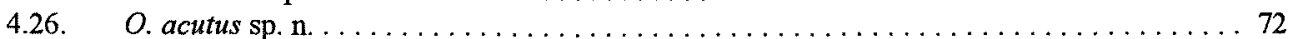

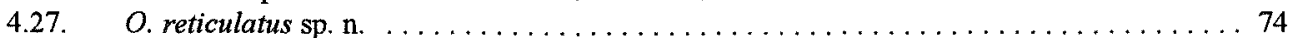

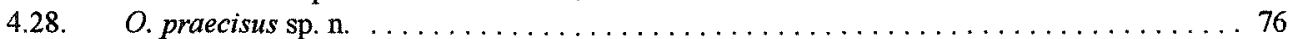

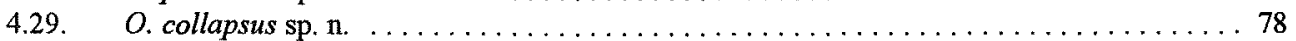

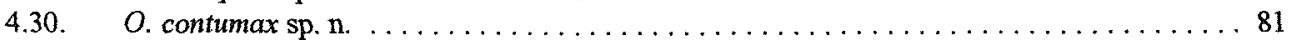

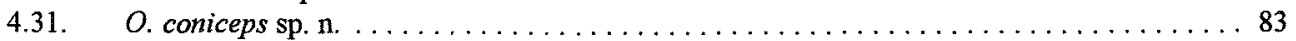

5. The Othius species of Taiwan: diversity, phylogenetics and colonization $\ldots \ldots \ldots \ldots 5$

6. Key to the species of Othius of the Eastern Palaearctic region east of the Himalayas . . . . 88

Acknowledgements . . . . . . . . . . . . . . . . . . . . . . 95

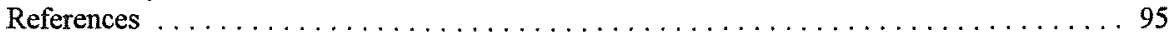

\section{Introduction}

After the Othius species of the Western Palaearctic, the Central Asian and of the Himalayan region have been revised in six previous contributions (ASSING, 1997a, b; 1998a, b; AsSING \& SOLODOVNIKOV, 1998; ASSING \& WUNDERLE, 1995), the object of the present paper is to treat the species of the remainder of the Palaearctic region, i. e. the Russian Far East, the Japanese archipelago, northern China, and adjacent regions. Strictly speaking, the mountainous areas of southern China and Taiwan belong to the Oriental region. Nevertheless, they are here treated as Palaearctic, because at higher altitudes, a considerable proportion of the flora and fauna is of Palaearctic affiliations; this is also true for the genus Othius, as will be shown below.

Apart from the Palaearctic and adjacent Oriental regions, species of Othius have only been reported from New Zealand (KLIMASZEWSKI et al., 1996); these species, however, have not yet been revised. Such an amphipolar distribution would suggest that the genus is phylogenetically old, particularly since, in Coleoptera, amphipolar vicariance patterns are usually observed at the level of tribus or subtribus (CROWSON, 1980).

BERNHAUER \& SCHUBERT (1914) list four species from the Eastern Palaearctic region east of the Himalayas, all of them from Japan. Since then, 16 further species and three subspecies have been described: nine species from China (BERNHAUER, 1916, 1922, 1931; CAMERON, 1939b; ZHENG, 1995), five species from Taiwan (ITO, 1989; SHIBATA, 1973), one species and three subspecies from Japan (ITO, 1993), and one species from the Russian Far East (COIFFAIT, 1974). One further species, O. javanus, was described from Java by CAMERON (1937), but shortly afterwards referred to Metolinus CAMERON of the Xantholinini (CAMERON, 1939a).

\section{Material and deposition of holotypes}

Types and further material from the following institutions and private collections were examined:

BMNH The Natural History Museum, London (M. BRENDELL)

DEI Deutsches Entomologisches Institut, Eberswalde (L. ZERCHE)

FMNH Field Museum of Natural History, Chicago (A. F. NEwTON JR., P. P. PARRILLO)

IRSNB Institut Royal des Sciences Naturelles de Belgique, Bruxelles (D. DrugMaND)

MHNG Muséum d'Histoire Naturelle, Genève (I. LōBL)

MNHNP Muséum National dHistoire Naturelle, Paris (N. BERTI)

MNHUB Museum für Naturkunde der Humboldt-Universität, Berlin (M. UHLIG) 


$\begin{array}{ll}\text { MZS } & \text { Museo Zoologico de "La Specola", Firenze (A. BORDONI) } \\ \text { NHMB } & \text { Naturhistorisches Museum Basel (M. BRANCUCCI, E. SPRECHER) } \\ \text { NHMC } & \text { Natural History Museum and Institute, Chiba (S.-I. NAOMI) } \\ \text { NHMW } & \text { Naturhistorisches Museum Wien (H. SCHILHAMMER) } \\ \text { NMNST } & \text { National Museum of Natural Science, Taichung, Taiwan } \\ \text { SMNS } & \text { Staatliches Museum für Naturkunde in Stuttgart (W. SCHAWALLER) } \\ \text { SMTD } & \text { Staatliches Museum fur Tierkunde, Dresden (O. JÄGER) } \\ \text { TUA } & \text { Tokyo University of Agriculture, Laboratory of Entomology (Y. WATANABE) } \\ \text { cAss } & \text { author's private collection } \\ \text { cBor } & \text { Private collection A. BorDON, Firenze } \\ \text { cIto } & \text { Private collection T. ITO, Kyoto } \\ \text { cRou } & \text { Private collection G. DE RoUGEMONT, London } \\ \text { cSch } & \text { Private collection M. ScHÜLKE, Berlin } \\ \text { cShT } & \text { Private collection T. SHIBATA, Hyogo } \\ \text { cShY } & \text { Private collection Y. SHIBATA, Tokyo } \\ \text { cSme } & \text { Private collection A. SMETANA, Ottawa } \\ \text { cSol } & \text { Private collection A. SOLODOVNIKOV, St. Petersburg }\end{array}$

Deposition of holotypes of species described in this paper:

In accordance with the owner's wishes, the holotypes from the private collection of A. SMETANA will be deposited in the NMNST (Taiwanese species) and the MHNG (remaining species). For the holotypes of the remaining species, the respective public institution is indicated in the species sections.

\section{Measurements and abbreviations}

The measurements in the descriptions and the key are indicated in mm and abbreviated as follows:

HW: $\quad$ maximal head width

HL: $\quad$ head length from front margin of clypeus to neck

PW: $\quad$ maximal width of pronotum

PL: $\quad$ length of pronotum along median line

EL: $\quad$ length of elytra from apex of scutellum to elytral hind margin

TiL: $\quad$ length of metatibiae (external aspect, from knee to insertion of first metatarsomere)

TaL: $\quad$ length of metatarsi (claws not included)

TL: $\quad$ total length from apex of mandibles to hind margin of tergum VIII.

For the calculation of the relative eye size, the postgenae were measured from the hind margin of the eye to the neck (lateral view).

\section{The Othius species of the Eastern Palaearctic region east of the Himalayas}

As has already been shown for the previously revised species from other Palaearctic regions (ASSING, 1997a), intraspecific variation in the genus is remarkable. This particularly applies to the widespread species, in which gene flow is hampered by a distribution which is both extensive and fragmented by various barriers (ocean, stretches of land without suitable habitats). (Note, however, that the sea barriers between and within the Eastern Palaearctic archipelagos and those separating them from China, South Korea and the Ussuri region of the East Asian mainland (e. g. Tatarskiy Proliv, Korea Strait, Yellow Sea) are either very narrow or mostly less than $100 \mathrm{~m}$ deep, so as to allow colonization even of short-distance dispersers in various directions at least during the glacial periods of the Quaternary period.) All the synonymies recognized below refer to such species; they are in most cases a result of an underestimation of the intraspecific variation of external characters and, at the same time, of the fact that sexual characters, especially the structures in the internal sac of the aedeagus, were not or not sufficiently considered. 
Evidently, a taxonomic revision is strongly dependent on the study and availability of type material. There has been no difficulty in arranging loans of types deposited in Europe, Japan, and North America. Unfortunately, the same cannot be said for the types of the six species described by ZHENG (1995), which are, according to the original descriptions, deposited in the Sichuan Teachers College, China. Repeated requests to the author for a loan of the type material have remained unanswered. It was A. BORDONI who provided me with paratypes of two of the species previously sent to him by ZHENG; a third species could be identified based on the illustration of the outline of the aedeagus in the original description. The remaining three species, however, had to be neglected and their identity must remain dubious, also because the descriptions mainly rely on variable and/or subjective external characters and because the rough sketches of the aedeagi are inadequate.

After the revision, 31 valid species with two subspecies are recognized for the Eastern Palaearctic region east of the Himalayas (the three dubious species described by ZHENG (1995) and referred to above are here neglected). Together with 38 species (with two subspecies) from the Western Palaearctic region (ASSING, 1997a, 1998b; ASSING \& SOLODOVNIKOV, 1998), two species from the Central Asian republics, and 24 species from the Himalayas (AssING, 1998a), the total number of known species of Othius STEPHENS in the Palaearctic region - including the mountainous areas of southern China and Taiwan (see section 1) - currently amounts to 95.

The Russian Far East, the Japanese archipelago with one exception (O. amamianus), and most of eastern China are exclusively inhabited by relatively few and widespread species, whereas the mountain ranges of Yunnan and Sichuan in mainland China and of Taiwan apparently host numerous, more or less endemic species. With one exception, all the new taxa described below are from these regions; many of them are brachypterous and show further reductions, such as relatively small eyes and a reduced palisade fringe, usually found in species with restricted areas of distribution. Judging from the little material available and the number of new species it contained, it can safely be assumed that the actual species diversity in Yunnan, Sichuan and Taiwan is far higher than is currently known (see also section 5 ).

My earlier hypothesis that the Central Asian species $O$. chrysurus REITTER and $O$. turcmenus FAUVEL are more closely related Eastern Palaearctic congeners than to Western Palaearctic species (AssING, 1997a) is here confirmed. Western and Eastern Palaearctic Othius are morphologically distinguished by several characters, the most prominent of them being the different punctation pattern of the pronotum and the different arrangement of internal structures of the aedeagus. Geographically, they are separated by the Caspian Sea, a border crossed only by the $O$. kashmirica subgroup, which is distributed in the western Himalayas, but phylogenetically belongs to the Western Palaearctic O. laeviusculus group (AssING, 1998 a).

Geographical names of countries, regions, provinces etc. are in accordance with the Times Atlas. The localities indicated on the labels of types are cited in the original spelling.

\subsection{Othius medius SHARP, 1874}

Figs $1 \mathrm{a}-\mathrm{h}, 2,3$

Othius medius SHARP, 1874: 50f

Othius medius kusuii ITo, 1993: 147, syn. n.

Othius medius yakushimanus ITO, 1993: 148, syn. n.

\section{Types examined}

O. medius SHARP: Lectotype o [aedeagus dissected prior to present study], here designated: Type [red curator label]/ Japan. Lewis/ Sharp Coll. 1905-313/ Othius medius type D.S./ Lectotypus Othius medius Sharp, V. Gusarov des. 1993/ Othius medius Sharp, V. I. Gusarov det. 1993 (BMNH). 

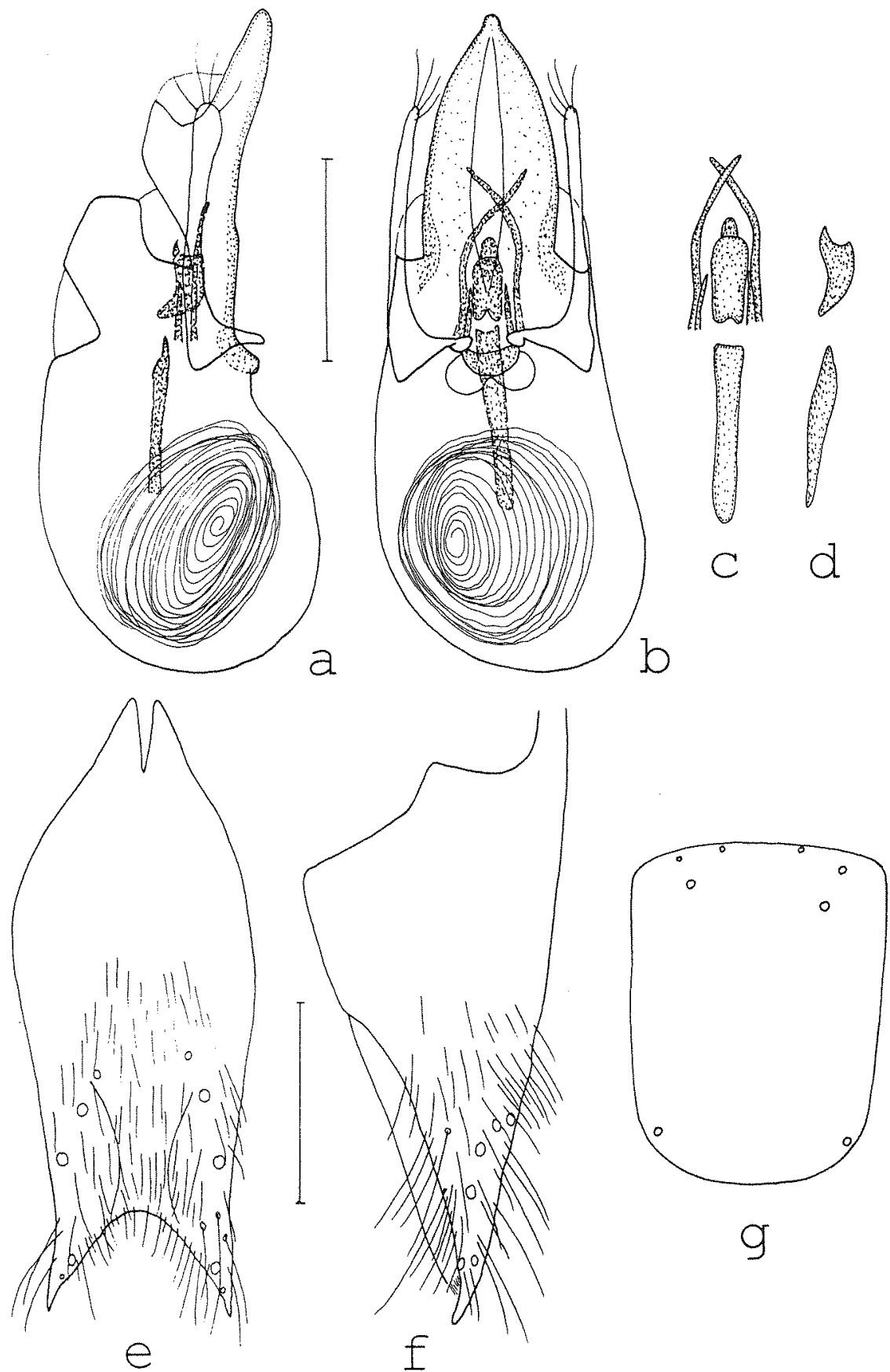
Figs 1 a - h.: 0 . medius SHARP: aedeagus in lateral and in ventral view (a, b); internal structures of HT of $O$. medius yakushimanus ITo in ventral view (c); apical and basal median structure of the same in lateral view $(d) ; 0^{\circ}$ sternum IX (e); $\sigma^{n}$ lateral tergal sclerite IX and tergum X in lateral view (f); schematic representation of pronotal punctation pattern $(\mathbf{g}) ;$ $\&$ terminalia (h); long setae partly or completely omitted in e, $\mathrm{f}, \mathrm{h}$. Scales: $0.5 \mathrm{~mm}$; g without scale.

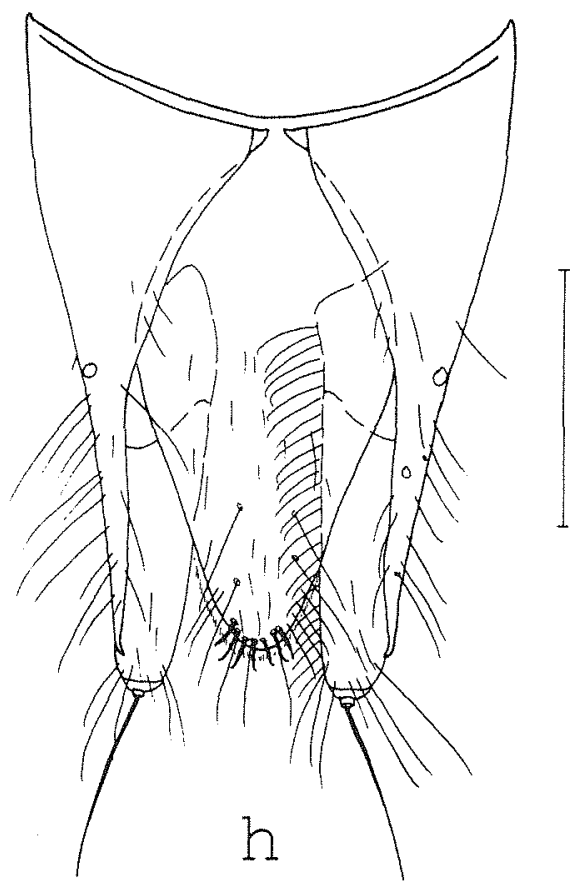

Paralectotype 0": Japan. G. Lewis, 1910-320/ Exchange ex Collection British Mus. (N.H.) (FMNH).

The original description is based "on eight individuals of this species" (SHARP, 1874). Since only two of them could be located and the possibility of confusion with the similar $O$. latus cannot be ruled out for the remaining six syntypes, a lectotype designation was considered necessary.

O. medius kusuii ITO: Holotype ơ [aedeagus dissected]: Tamaura, Okushiri Is., Hokkaido, 11.X. 1986, Y. Kusui leg./ Holotype Othius medius kusuii ssp. nov. T. Ito (cShT).

O. medius yakushimanus ITO: Holotype $\sigma^{*}$ [aedeagus dissected prior to present study]: Miya-NoUra, Yaku Is., 26. VII.1966, leg. Nomura/ Holotype Othius medius yakushimanus ssp. nov. T. Ito (cShT).

\section{Additional material examined}

Japan: Hokkaidō: 1 $\sigma^{\circ}$, Higashi-mokoto, 45m, 30.VII.1991, leg. Smetana (cSme); 40 $0^{\circ}, 3 q q$, Ishikari, 6.VIII.1962, leg. Y. Shibata (cShY, cAss). Honshū: $20^{\pi} 0^{*}, 19$, Yokohama, Kanazawa Nat. Park, 16.XI.1987,

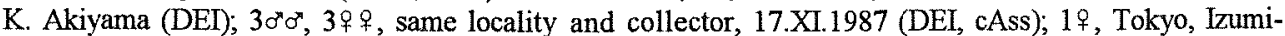
Tamagawa, 2.V.1958, leg. Nonaka (NHMW); 19, Tokyo, Chta-ku, Chi Umetatechi, 23.V.1982, leg. Y. Shibata (cShY); 1ㅇ, Gifu, 1.VI.1953, coll. Fagel (IRSNB); 1ㅇ, Hyogo (NHMW); 1 ${ }^{*}$, Hyogo, Kobe, Maiko, Tarumi, 24.V.1983, leg. Matsumoto (cShY); 2 우, Kobe, 13.IX.1952 (NHMW); 1 ㅇ, Kobe (NHMW); 2 우, Kobe ['latus Shrp. det. Bernh.] (FMNH); 10", 19, Hyogo, Hamasaka, Sashikui, 30.V.1986, leg. Matsumoto (cShY); 10, Fukasatoge, Echizen, IX.1896, coll. Fauvel (IRSNB); 1\%, Sagamura, Kadagori, Yamashiro, VI.1897, coll. Fauvel (IRSNB); 10", Kyoto, 23.DX.1906, leg. Sauter ['latus Shrp. det. Bernh.] (FMNH); $20^{\circ} 0^{*}$, $2 \%$, Kyoto, Riv. Yodo, Yawata, 12.X.1986, 16.V.1992, 16.V.1993, leg. N. Ito (DEI, cAss); $10^{\circ}, 29$ \%, Kyoto, Yaseyuen, 4. VIII.1980, leg. Besuchet (MHNG, cAss); 1 \% , Kyoto, 7.-8.VIII.1980, leg. Besuchet (MHNG); $10^{\circ}$, Kyoto, 2.VIII.1982, leg. Masaki (cAss); 10", Kyoto, Kuze, 2.VIII.1982, leg. Masaki (cSol); 10", Kyoto, Mizuho T., 22.XI.1992, leg. Hayashi (cSol); 40º, 2q, Osaka, Riu. Yodo, 24. VII.1952, leg. Shibanai 
(NHMW, cAss); 19, Kanagawa, Yokohama, Tsurumi-ku, 26.IX.1982, leg. Tao (NHMC); 19, same data, 7.X.1984 (NHMC); 10", same data, 10.VII.1983 (NHMC); $20^{\circ} 0^{\prime \prime}$, Yokohama, Minatokitaku, 23.IX.1986, leg. Tao (NHMC); 1 9, Yokohama, 6.V.1976, leg. Tao (NHMC); 1 \%, Yokohama, Midori-ku, 5.V.1987, leg. Tao (NHMC); $1 \sigma^{\circ}$, Kanagawa, Noborito, 1.X.1978, leg. Tao (NHMC); $2 \sigma^{\circ} \sigma^{\circ}$, Kanagawa, Yokohama-shi, 26.VII. 1987, leg. Tao (NHMC); 10", Kanagawa, Asahi-ku, 3.XI.1982, leg. Tao (cAss); 19, Kanagawa, Hiratsuka, 12.VIII. 1960, leg. Y. Shibata (cShY); 10", Yamato [=Nara], Tonomine, IX.1895, coll. Fauvel (IRSNB); $10^{*}$, 29 ․, Yamato, Hase, 8.X.1967, leg. Ito (cIto, cSol); $10^{*}$, Yamato, Riv. Yoshino, 2.VI.1984, leg. Ito (cIto); 1 , Saitama, Urawa, 23.IX.1983, leg. Tao (NHMC); 1 \%, Chiba-shi, Aoba-cho, 21.IX.1994, leg. Hagino(NHMC); $20^{\circ} 0^{*}$, Chiba, Ichihara, Anegasaki beach, 29. VIII.1986, leg. Inagawa (cShY); 2 우, Ibaraki, Toride, Tone riv., 6.VIII.1986, leg. Tao (NHMC); 10", Tochigi, Oyama, 28.VI.1978, leg. Nishida (NHMC); $10^{7}$, Tochigi, Nogimachi, 10.X.1977, leg. Tao (NHMC); 10", same locality, 31.V.1976, leg. Niizato (cAss); 10", Tottori, Mt. Hisamatsu, 9.VI.1984, leg. Nomura (NHMC); 19, Tottori, Koyama, 12.IX.1991, leg. Tsurusaki (NHMC); 10", Okayama, leg. Sauter [ latus Shrp. det. Bernh.] (FMNH); 2 우, Okayama, 5.V.1978, leg. Ito (cIto); 1 우, Okayama, 19.XI.1978, leg. Ito (cIto); 1\%, Okayama, Mt. Misao, 3.V.1978, leg. Naomi (NHMC); $20^{\circ} 0^{\circ}, 29 \%$, Okayama, Shomura, 6./28.VII.1969, leg. Watanabe (NHMC); 10", Okayama, Bizenhara, 5.VII.1976, leg. Yamazi (NHMC); 19, same locality, 31.V.1976, leg. Naomi; 10", Okayama, Mt. Ryuou, Kojima, 22.X.1992, leg. Yamazi (NHMC); 299 , Okayama, Nonoguchi, 1.V.1971, leg. Naomi (NHMC); 10", Okayama, Takahashi, Mt. Gagyu, 27.V.1979, leg. Naomi (NHMC); 10, Okayama, Bizen Mara, 31.V.1976, leg. Naomi (cAss); 19. Fukui, Samri-hama, 16.VI.1963, leg. Kamiya (NHMC); 10", Harima, 25.V.1912 ['latus Shrp. det. Bernh.'] (FMNH). Shikoku: $20^{\circ} 0^{\circ}, 39$ \%, Ehime, Matsuyama, Ishide-gawa, 29.IX.1991, leg. Okamoto (cShY, cAss). Kyüshü: $20^{*} 0^{*}$, Mt. Kasuga, Nara, 3.XI.1993, N. Ito leg. (DEI, cAss); $10^{\circ}$, Nagasaki, leg. Hilgendorf (MNHUB); $20^{\circ} 0^{\circ}$, Nagasaki, Tobaru, 12.XI.1980, leg. Imasaka (cIto, cAss); 10\%, $2 \%$ \% , Nagasaki, Shimabara, Kueyama, 26.IX.1977, leg. Imasaka (NHMC); 10", Nagasaki, Kitaarima, 2.XI. 1977, leg. Imasaka (NHMC); 10, Nagasaki, Shimabara, Mizunashi riv., 5.XI.1977, leg. Imasaka (NHMC); 19, same data, 19.IV.1977 (NHMC); 19, Nagasaki, Shimabara, Unzendake, 28.IX.1977, leg. Imasaka (NHMC); 20 $0^{\circ} 0^{\circ}, 1$, , Nagasaki, Mizuho-cho, 6.XI.1980, leg. Imasaka (NHMC, cAss); 1 ㅇ, Nagasaki, Obama-cho, 2.XI.1977, leg. Imasaka (NHMC); 10", Nagasaki, Kuchinotsu, 25.XI.1977, leg. Imasaka (cAss); 10", 19, Nagasaki, Azuma-cho, 18.XI.1980, leg. Imasaka (NHMC); 10", Imari, 15.IX. 1976, leg. Osiho (NHMC); 19, Kumamoto, Hitoyoshi, 6.X.1977, leg. Naomi (NHMC); 2q9, same locality, 16.X.1977, leg. Ohishi (NHMC); 1q, Kumamoto, Hitoyoshi-shi, 6.IV.1977, leg. Naomi (NHMC); 10", Kumamoto, Obiyama, 11. V.1970, leg. Naomi (NHMC); 10", Kumamoto, Kawachi, 14.VIII.1977, leg. Naomi (cAss); 20"07, Fukuoka, Hakozaki, 8. VI.1979, leg. Yamasishi (NHMC); 10", 29ㅇ, Fukuoka, Mt. Hiko, 24.V.1970, leg. Takeno (NHMC); 1 , Fukuoka, Mt. Tahibana, 7.V.1980, leg. Naomi (NHMC); 19, Kagoshima, Korimoto, 10.V.1913 (NHMC); 10", Onzen, Hikonan, 20.IX.1943, leg. Shibata (NHMC). Smaller Islands: 1\%, Nagasaki, Tsushima, leg. Fruhstorfer, coll. Fauvel (IRSNB); 10", 1\%, Tsushima (FMNH); 1\%, Tsushima Is., Tsu Tsu, 6.X.1981, leg. Nomura (NHMC); $10^{7}$ [teneral], Iō-Jima Island, Nishisonoki, 10.V.1992, leg. Kusui (cIto).

Locality not specified: $10^{\prime \prime}, 29 \%$, 'Japonia' (DEI, NHMW); 19, 'Japon' (IRSNB); 10", Japan, G. Lewis (BMNH); 10", [locality in Japanese] 29.VI.1993 (cShY).

South Korea: 1웅, Cheju-do, 12.XI.1992, leg. Kusui (cîto).

China: $20^{\circ} 0^{\circ}, 49 \circ$, Gansu, Maijishan, VIII.1985, leg. Rougemont (cRou, cAss); 10", Gansu, Dalijia Shan, 46km W Linxia, 2980m, 10.VII.1994, leg. Smetana (cAss); 1ㅇ, Shanghai, 21./25.V.1934, leg. Svenson (FMNH, NHMW); 10", Zhejiang, Ningbo (NHMW).

\section{Diagnosis}

Measurements (range, arithmetic mean; $\mathrm{n}=133$ ): $\mathrm{HL}: 1.62-2.07,1.86$; HW: $1.34-1.80,1.62$; PW: 1.65 - 2.17, 1.94; PL: 2.01 - 2.62, 2.32; EL: 1.31 - 1.83, 1.57; TiL: 1.40 - 1.80, 1.62; TaL: $1.10-1.59,1.32$; TL: $9.3-15.9,12.4$.

Measurements and ratios of holotypes (O. medius kusuii, O. medius yakushimanus): HL: 2.10 , 1.83; HW: 1.89, 1.59; PW: 2.23, 1.89; PL: 2.53, 2.32; EL: 1.77, 1.56; TiL: 1.74, 1.59; TaL: 1.40, 1.31; TL: 13.6, 12.3; HL/HW: 1.11, 1.15; HW/PW: 0.85, 0.84; PL/PW: 1.14, 1.23; EL/PL: 0.70, 0.67 ; TiL/TaL: $1.24,1.21$. 
Highly variable species. Usual coloration: head, pronotum, most of elytra and abdomen, mandibles and antennomeres IV - XI dark brown to blackish; suture and hind margins of elytra, hind margins of posterior abdominal segments, legs, mouthparts and antennomeres I - III lighter, reddish to brown. Sometimes elytra or, rarely, most of the body reddish or brown; all the specimens from Gansu had red elytra.

Head of highly variable shape, weakly to distinctly oblong, $1.08-1.24 x$ (mean: 1.15 ) longer than wide; HW/PW: $0.69=0.88$ (mean: 0.84 ); eyes in lateral view usually $0.42=0.48 \mathrm{x}$ the length of postgenae; temples behind eyes sometimes slightly widened, usually \pm parallel or slightly narrowed in dorsal view; microsculpture on dorsal surface extremely fine and usually \pm indistinct, in posterior half composed of transverse striae and/or tranverse meshes; punctation absent in median and moderately dense in lateral area; near occiput only narrowly and sparsely punctured; frons with two pairs of punctures in \pm quadrate arrangement, the anterior punctures mostly distinctly deeper, larger, usually situated in oval or transverse impressions and accompanied by further often confluent - punctures; posterior pair of frontal punctures normally present and distinct, occasionally minute or even absent; frontal furrows variable, distinct to very indistinct, not reaching front margin; antennae slender, antennomeres IV and V usually weakly oblong, VI \pm subquadrate and VII - X weakly transverse.

Pronotum of variable shape, $1.09-1.26 x$ (mean: 1.20) longer than wide; maximal width in anterior half, but usually at some distance behind anterior angles; in median line posteriorly with a scratchlike impression; dorsal surface with microsculpture similar to head; position of discal punctures similar to $O$. chrysurus REITTER, i. e. posterior discal punctures near hind angles (Fig. 1g).

Elytra relatively long, but length subject to considerable variation (see measurements and Fig. 3); EL/PL: $0.61-0.78$, mean: 0.68 ; punctation highly variable, usually very dense with predominantly well-defined punctures of moderate strength and rugose punctures only near suture and scutellum; sometimes, however, all of the elytra nugose; surface without distinct microsculpture, somewhat opaquely shining; scutellum with distinct microsculpture composed of isodiametric and short transverse meshes; (always?) macropterous; legs relatively long and slender; TiL/TaL: 1.06 - 1.36, mean: 1.23 .

Abdomen with the area near the anterior margins of the terga, i. e. in tergum III - VI the anterior transverse impressions, with distinct microsculpture and mat; the remaining tergal surfaces at most with very indistinct transverse microsculpture and somewhat iridescent; punctures relatively dense and of moderate strength; palisade fringe at hind margin of tergum VII present.

$\sigma^{*}:$ protarsomeres I - IV extremely dilated, clearly more so than in $o q$; sternum V and VI each centrally with relatively large, \pm semicircular to subcircular flattened area, with tomentose yellowish pubescence and rasp-like sculpture; sternum VII posteriorly with shallow median impression and weakly concave to truncate hind margin; sternum VIII posteriorly with shallow impression and \pm truncate or weakly concave hind margin; lateral tergal sclerites of segment IX long, protruding over hind margin of tergum $X$, apically with a spine-like process (often broken off in older material), whose tip is bent upwards (Fig. 1f); shape of hind margin of sternum IX somewhat variable, but deeply concave, hind angles with tooth-like processes (Fig. 1e); ventral process of aedeagus with pair of distinct long carinae; internal sac with 6 sclerotized structures: a long median basal, a short charactistically shaped median apical, a pair of short straight lateral and a pair of long, curved and apically crossed lateral structures; flagellum very long and thin, with ca. $40-60$ coils (Figs $1 \mathrm{a}-\mathrm{d}$ ).

q: lateral tergal sclerites of segment IX apically with spine-like processes similar to of $0^{\prime \prime}$; tergum $X$ with narrow basis, near hind margin with $4-10$ apically curved modified setae; styli of roughly conical shape, their inner margin with fringe of numerous long and rather stout setae (Fig. Ih). 
Comparative notes and phylogenetics: $O$. medius is readily distinguished from other macropterous Eastern Palaearctic congeners, except for $O$. bordonii sp. n. (see below), especially by the apical spine-like processes of the lateral tergal sclerites IX and of the hind angles of the $\sigma^{*}$ sternum IX, and by the shape and internal structures of the aedeagus. For remarks on phylogenetics see below the following species.

Comments: According to the original description of $O$. medius kusuii, which is based on $20^{\prime \prime} 0^{\prime \prime}$ and 3 우 from Okushiri island, the subspecies is characterized by a "slightly coarsened" ventral process of the aedeagus, the wider and posteriorly dilated head, the coarser punctation of the elytra, the more regular and more distinct microsculpture of head and pronotum, and finally the larger size. The distinguishing characters indicated for $O$. medius yakushimamus, whose description is based on $10^{7}$ and 1 ㅇ from Yakushima island, are a "shallower and less clearly defined" ventral depression of the aedeagus, relatively shorter parameres, the denser and coarser elytral punctation and slightly shorter penultimate antennomeres (ITO, 1993).

A comparison of the holotypes of both taxa with numerous specimens collected in other Japanese localities, South Korea and China, however, showed that, apart from the slightly larger size of $O$. medius kusuii, the distinguishing characters indicated above are within the range of intraspecific variation of $O$. medius SHARP. I have seen specimens with posteriorly dilated and relatively even wider heads (see measurements) also from the Japanese mainland and from China. Elytral punctation, the microsculpture of the forebody, and the shape of the antennomeres are highly variable in $O$. medius. The shape of the aedeagus (including the ventral carinae, surface sculpture, and the relative length of the parameres), too, is subject to some intraspecific variation, a phenomenon also encountered in other species of Othius (ASSING, 1997a). The slightly larger size of the head and the greater pronotal width of the holotype of $O$. medius kusuii (no overlap in HL, HW, and PW; see measurements) is here confirmed; in addition, the aedeagus was found to be somewhat larger than in average $O$. medius. On the other hand, size shift is a well-known phenomenon in island populations (GRANT, 1998), and measurements showed that the size of the median lobe is subject to some allometric variation. The length of the median lobe was $1.55-1.59 \mathrm{~mm}$ in very small $\sigma^{\prime \prime} \sigma^{\prime \prime}$, $1.66-1.73$ in $\sigma^{\prime \prime} \sigma^{7}$ of average size, and $1.86 \mathrm{~mm}$ in the holotype of $O$. medius kusuii.

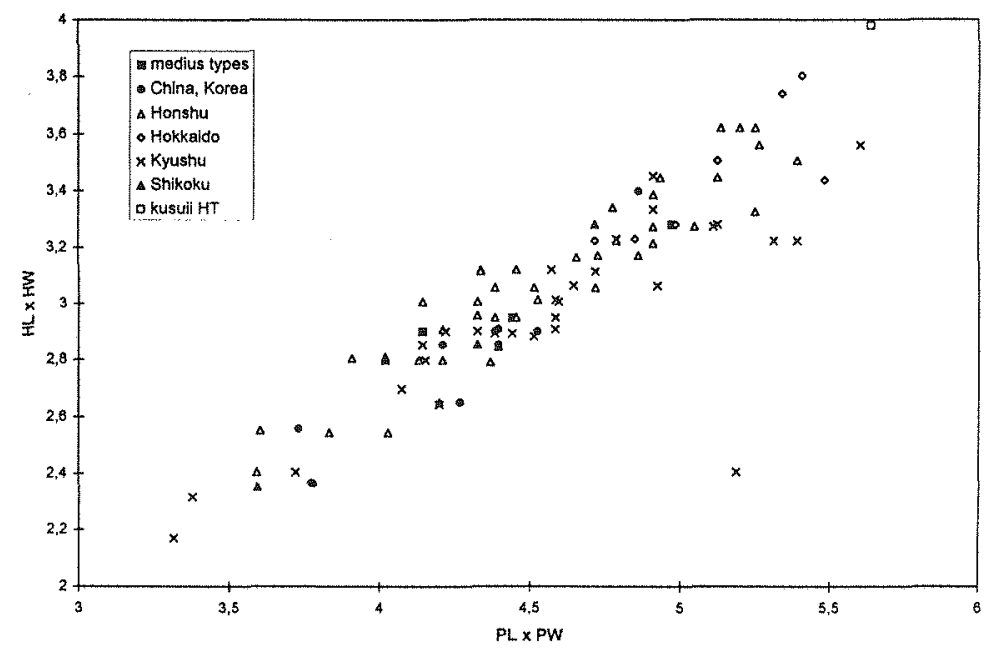

Fig. 2: O. medius SHARP: intraspecific variation of head and pronotum size. 


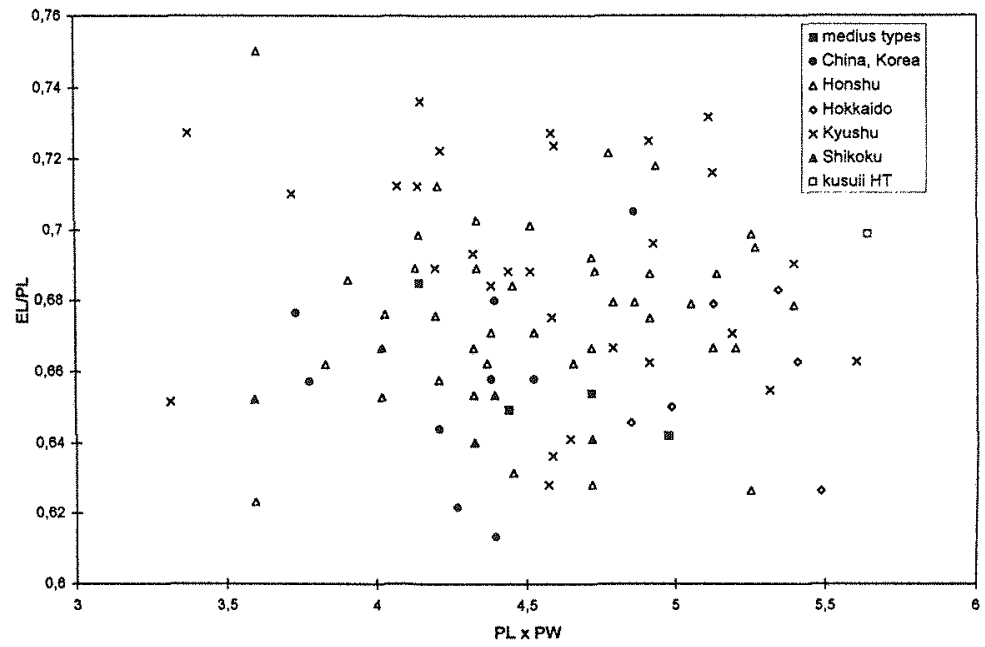

Fig. 3: $O$. medius SHARP: intraspecific variation of relative elytral length in relation to pronotum size.

Pronounced intraspecific variation (see Figs 2,3 ) is what can be expected in a widespread species like $O$. medius, whose area of distribution today is largely fragmented by the Pacific Ocean (see also remarks in section 4.4.1 and 4.8). In addition, constant differences could be observed neither in the shape of the internal structures of the median lobe, the most reliable and significant sexual character in Othius taxonomy, nor in the secondary sexual characters of both sexes. Therefore, and in the absence of convincing biogeographical evidence, the differences indicated in the original descriptions are here considered insufficient to support the hypothesis that $O$. medius kusui and $O$. medius yakushimanus should represent distinct subspecies. Consequently, both names are regarded as junior synonyms of $O$. medius SHARP.

Distribution and bionomics: $O$. medius is one of the most widespread species of the Eastern Palaearctic region. It is apparently common in Japan from Hokkaidō in the north to Kyūshü in the south and is also known from Tsushima island in the Korea Strait and from various smaller islands (ITO, 1993; WATANABE, 1995, 1996; material examined). The species is here for the first time recorded from South Korea (Cheju-do island) and from northern and eastem China (Gansu, Zhejiang). Altitudes were only rarely indicated both on the labels of the examined specimens and in the literature; those available range between $45 \mathrm{~m}$ and $400 \mathrm{~m}$. Adults of $O$. medius have been collected from April through November; one $\sigma^{x}$ taken in May was teneral.

\subsection{Othius bordonii sp. $\mathrm{n}$. \\ Figs 4 a - $f$}

\section{Othius chinensis BERNHAUER i. 1.}

\section{Types}

Holotype o": Kouy-Tchéou, Rég. de Pin-Fa, Père Cavalerie 1909 (MZS). Paratypes: $20^{*} 0^{7}$, same data as holotype (cBor, cAss); 1 \% , same data as holotype, but 'Othius chinensis Brh. Typ'/ Museum Paris don. Paulian/ chinensis Brnh. Typus Othius/ Chicago NHMus. M. Bernhauer Collection (FMNH). 


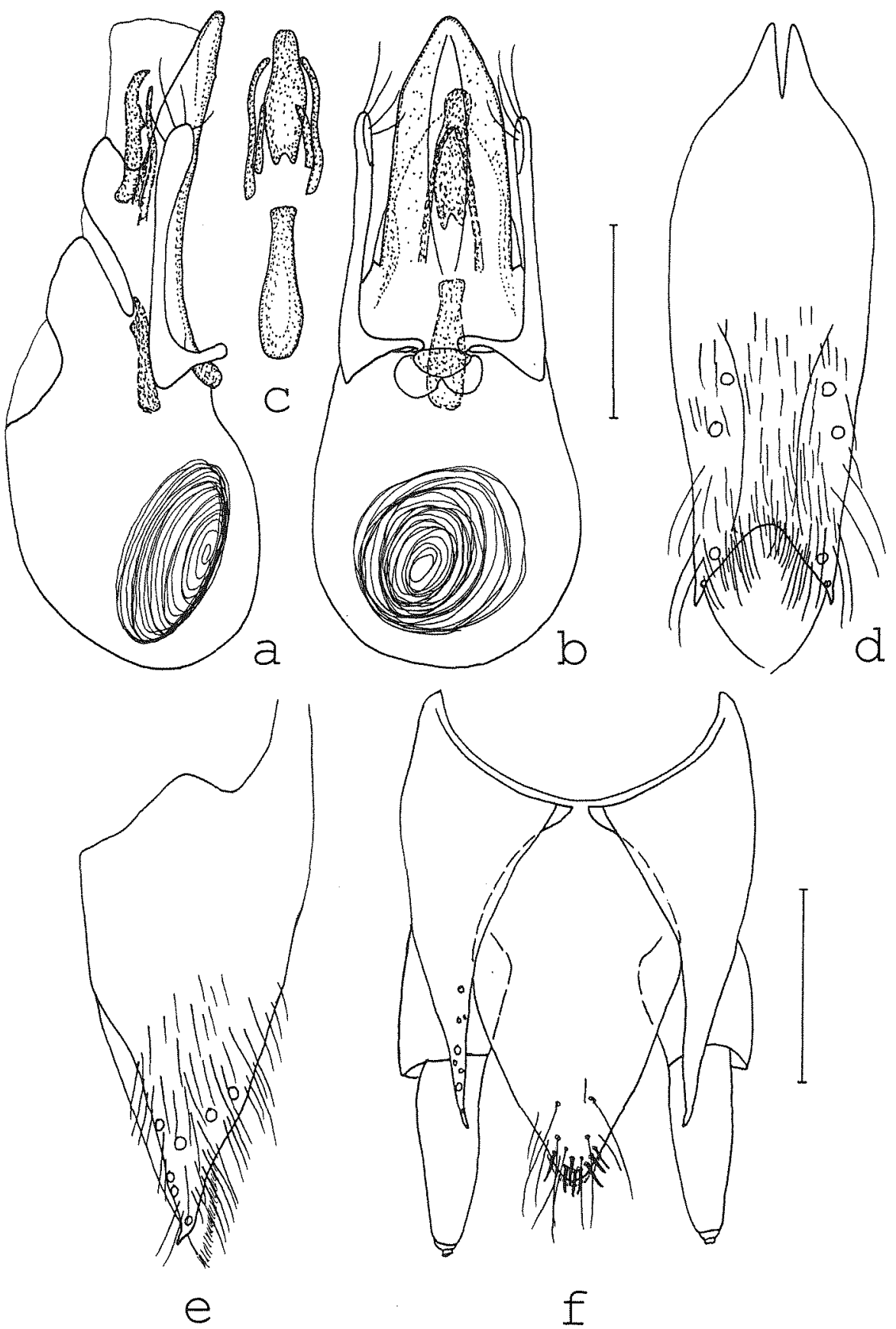

Figs 4 a - f: $O$. bordonii sp. $n$.: aedeagus in lateral and in ventral view $(\mathbf{a}, \mathbf{b})$; internal structures of further $\sigma^{\prime \prime}$ in ventral view (c); $\sigma^{\prime \prime}$ stemum $\mathrm{DX}(\mathbf{d}) ; \sigma^{\prime \prime}$ lateral tergal sclerite IX and tergum X in lateral view (e); outline of $q$ terminalia (i); long setae partly or completely omitted in d, e, f. Scales: $0.5 \mathrm{~mm}$. 


\section{Diagnosis}

Measurements and ratios (range; $\mathbf{n}=4$ ): HL: $1.56-1.68 ; \mathrm{HW}: 1.49-1.62$; PW: 1.77 - 1.89; PL: 2.01 - 2.20; EL: 1.34 - 1.49; TiL: 1.34 - 1.43; TaL: 1.04 - 1.19; TL: 9.8 - 12.0; HL/ HW: 1.04 1.06; HW/PW: 0.83 - 0.86; PL/PW: 1.12 - 1.16; EL/PL: 0.67 - 0.71; TiL/TaL: 1.20 - 1.29.

Closely related to and apparently the sister species of $O$. medius, from which it is distinguished as follows:

Colour darker than average $O$. medius, elytra blackish with only the narrow margins sometimes slightly lighter; legs and antennae dark brown to blackish, sometimes partly (knees, exterior face of protibia) lighter.

Head relatively shorter and wider than in $O$. medius (see ratios); posteriorly subparallel or weakly widened; eyes relatively larger, in lateral view $0.56-0.60 \mathrm{x}$ the length of postenae; microsculpture more distinct, predominantly composed transverse meshes of variable length with interspersed isodiatric meshes; lateral punctation slightly denser and coarser, posterior pair of frontal punctures present; antennae with antennomeres IV subquadrate to weakly oblong, V subquadrate, and VI $\mathrm{X}$ weakly transverse.

Pronotum of similar shape, microsculpture and punctation as in $O$. medius.

Elytra of similar relative length as in $O$. medius; punctation distinctly coarser, sparser and not rugose near suture; surface more shiny, but also with weakly opaque hue; scutellum with distinctly isodiametric microsculpture and several relatively large, but shallow punctures; (always?) macropterous.

Abdomen with punctures slightly less dense, but clearly larger, particularly on tergum VII, than in $O$. medius; palisade fringe at hind margin of tergum VII present.

$\sigma^{\prime \prime}$ : protarsomeres I - IV less strongly dilated and with less pronounced sexual dimorphism; sternum $\mathrm{V}$ and VI similar to $O$. medius, each centrally with \pm circular flattened and distinctly microsculptured area, with tomentose yellowish pubescence; sternum VII posteriorly with shallow, posteriorly widened median impression and weakly concave hind margin; hind margin of sternum VIII \pm truncate; lateral tergal sclerites of segment IX shorter, not reaching hind margin of tergum $\mathrm{X}$, apically only with short spine-like process (Fig. 4e); sternum IX similar to O. medius (Fig. 4d); aedeagus of similar morphology as in $O$. medius, but ventral process basally not constricted and internal structures, especially the median structures, of different shape; flagellum apparently only with 30 - 40 coils (Figs 4 a - c).

: terminalia similar to $O$. medius, but lateral tergal sclerites IX relatively shorter and less acute, not reaching hind margin of tergum $X$, the latter posteriorly more distinctly pointed (Fig. $1 f$ ).

Derivatio nominis: The species is dedicated to my dear colleague and specialist of Xantholininae Arnaldo Bordoni, Firenze, whose material contained the $\sigma^{7}$ type specimens.

Comparative notes and phylogenetics: For distinction from the similar and closely related $O$. medius see diagnosis. A sister species relationship with $O$. medius is supported by the following hypothesized synapomorphies: the apically \pm broadly rounded (ventral view!) median apical structure in the internal sac, and the spine-like processes of the lateral tergal sclerites IX and of the hind angles of the $\sigma^{7}$ sternum IX. These spine-like processes represent a synapomorphy also present in some brachypterous species from Taiwan, which are apparently the adelphotaxon of the monophylum O. medius + O. bordonii (see section 5).

Distribution and bionomics: I have been unable to identify the type locality with certainty. According to BORDONI (pers. comm.), the locality indicated on the labels probably refers to TingFan, S Guiyang, in southern Guizhou, China. No further details regarding the circumstances of collection are available. 


\subsection{Othius rosti BERNHAUER, 1907}

Figs 5 a $-f, 6$

Othius rosti BERNHAUER, 1907: 385

Othius ussuriensis COIFFAIT, 1974: 200f, syn. n.

\section{Types examined}

Othius rosti BERNHAUER: Lectotype $\sigma^{\star}$, here designated and labelled accordingly: N/ Jesso, Nemoro, Japan, Rost/ Othius Rosti Brnh. Cotypus/ Chicago NHMus, M. Bernhauer Coll. (FMNH). Paralectotype 0": same labels as lectotype, but 'Othius Rosti Brnh. Typus' (FMNH).

Othius ussuriensis CoIfFAIT: Paratype o": [locality in Cyrillic, according to original description: Shkotovo, Peishoula], 25.8.71/ Paratype/ Othius ussuriensis H. Coiffait det. 1973/ Museum Paris, 1985, Coll. H. Coiffait (MNHNP).

\section{Additional material examined}

Russian Federation: $20^{\circ} 0^{\circ}$, Kuril'skiye Ostrova, Iturup, 23. \& 24. VIII.1975, leg. Kusnetsov (DEI, cAss); $10^{\circ}$ [slightly teneral], Sakhalin, Korsakov distr., Ismenshyroye lake, 21.-22. VII.1993, leg. Pütz \& Wrase (cAss); $40^{\circ} \sigma^{*}, 5 \% 9\left[10^{7}\right.$ teneral; 19 with mature egg in ovaries], Sakhalin, Aniva distr., Vysokoye vill., valley of Lyutoga river, 22.-23.VII.1993, leg. Putz \& Wrase (cSch, cAss); 30 $0^{*}$, 19, Sakhalin, Aniva distr., 5 km W Petropavlovskiy, tributary of Lyotoga river, 20.-21.VII.1993, leg. Pütz \& Wrase (cAss); $20^{\circ} 0^{\pi}$, Sakhalin, pr. Yuzhno-Sakhalinsk, Mt. Chekhova, 6.VIII.1990, leg. Kasantsev (NHMB); 10", 'Amursk Gebiet, Fluss Urujeka[?]' (NHMW); 1 , Ussuri Peninsula, Marine Biology Station "Rjasanowka", 19.-22.VII.1991, leg. Schröder \& Kriska (cSch).

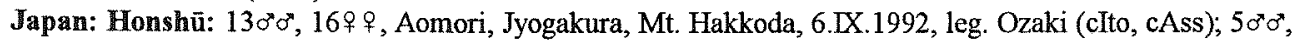
49 ㅇ, same locality, 17.VIII.1992 (cIto); 1 , same locality, 19.VIII.1992 (cIto); $40^{\circ} 0^{\circ}$, 1 \%, same locality, 13.IX.1992 (cIto); 1 ㅇ, same locality, 13.IX.1984 (cIto); 10", Aomori, Shimokita Pen., Osore-Zan, 2.VIII.1987, leg. Nomura (NHMC); 299 , Aomori, Towada, Tsuta spa, 6. VIII.1987, leg. Nomura (NHMC); $10^{*}$, Aomori, Tsuta spa, 8. VIII.1964, leg. Y. Shibata (ShY); 30"0", 2\% $\%$, Iwate, Iwaizumi, Hitsutori, 790m, 11.VIII.1991, leg. Smetana (cSme, cAss); 1 if [teneral], Nikko National Park, Lake Chuzenjiko, 1280m, 14. VII.1980, leg. Smetana (cSme); 1 \%, Iwate, Hayasaka Kogen, 28.IX.1969, leg. Kamei (cIto); 10", Prov. Hyogo, Onsen, VIII.1905, leg. Sauter [rufipennis Sharp det. Bernhauer] (FMNH); 10*, Yamanashi, Gozaishi, 27.VII.1967, leg. Y. Shibata (cShY); 10", 19, Yamanashi, Maruno-Cho, 19.IX.1990, leg. Hosoda (clto); 19, same data, 12.VI.1993 (cIto); 10,3 39 [2\% 9 teneral], same data, 16.V.1997 (cIto, cAss); 1, Yamanashi, Gozaishi, 5.IX.1989, leg. Hosoda (cIto); 19, same data, 25.VI.1991 (cIto), 10", same locality, 14. VIII.1996, leg. Ito (cAss); 19, Yamanashi, Daibosatsu, 7.VII. 1988, leg. Ito (cAss); 1 \%, Yamanashi, Daibosatsu, 12. VIII.1978, leg. Tao (NHMC); 20"0", Yamanashi, Kiyosato, 23.VWI.1969, leg. Y. Shibata (cShY); $10^{\circ}$, Yamanashi, Daibosatsu, Kami Hikawa-Rindo, 19.-20. VIII.1982, leg. Y. Shibata (cShY); 10\%, Yamanashi, Daibosatsu, Domurogawa, 16.-17.X.1982, leg. Y. Shibata (cShY); 3qq. Yamanashi, Makioka, Yanagidaira, 28.VIII. 1986, leg. Y. Shibata (cShY); 10", Yamanashi, Sudama, Kinzandaira, 25.VIII.1986, leg. Y. Shibata (cShY); 10", Tokyo Met., Itsukaichi ['Okutama, Yozawa'], 11.VI.1958, leg. Y. Shibata (cShY); 1 ㅇ [macropterous?], Tokyo, Machida, Zushi, 28.V.1976, leg. Y. Shibata (cAss); 10", Shizuoka, Matsuno, 14.IX.1974 (NHMC); 1ㅇ, Fukushima Pr., Urabandai, Goshikinuma, 18.VIII.1996, leg. Naomi (NHMC); 10", Nagano, Inago-Yu, 29.VII.1966, leg. Ito (cIto); 19, same locality, 27.VII.1960, leg. Konishi (cIto); $2 \%$, Nagano, Inagoyu, 24.VIII. 1969, leg. Y. Shibata (cShY); 19, Nagano, Minamisaku, Kawakami. o., 15. VII.1978 (NHMC); 1 , Nagano, Hakuba, 23.IX.1977, leg. Ogasamara (NHMC); 19, Nagano, Kamikochi, 'N-Alpen', 13.IX.1934, leg. Swenson (NHMW); 19, Nagano, Mt. Myubasa, 5.VIII.1983 (cShY); 10", Kanazawa, Uchikama, 20.X. 1964, leg. Hayashi (clto); 10", Kanazawa, Mt. Noda, 24.X.1962, leg. Hayashi (cIto); 19, Kanagawa, Yadorigi, Tanzawa, 14.IV.1986, leg. Tao (NHMC); 1 [ [teneral], Kanagawa, Tanzawa, Monomi pass, 28. V.1978, leg. Tao (NHMC); $20^{\circ} 0^{*}, 19$, Kanagawa, Hadano City ['Tanzawa, Bodai'], 8.VI.1969, leg. Y. Shibata (cShY); 19 , Kanagawa, Yokohama C., Tsurumi, 16.V.1987, leg. Tao (NHMC); 19, Kanagawa, Yokohama C., 1.X.1983, leg. Tao (NHMC); 10', same data, 21.IX.1986 (cAss); 29 , Mt. Ohyama, Kanagawa, 4.VI.1994, leg. Ito (DED); 10*, Gifu, $8 \mathrm{~km}$ SE Osaka, 750m, 1.VIII.1980, leg. Löbl (cAss); $20^{\circ} 0^{*}$, 19 , Kanagawa, Sagamihara, 5.7.V.1959, leg. Takenaka (cShY); 19 , Kanagawa, Mt. Ooyama, 6.XI.1960, leg. Y. Shibata (ShY); 10", Akita, 
Ogahantou, Tsubaki, 29.VII.1987, leg. Nomura (NHMC); $1 \sigma^{\circ}$, Kantou, Mt. Tsubaki, 24.VII.1980, leg. Tao (cAss); $20^{\circ} \sigma^{\circ}, 1$ 우 [1우 teneral], Tochigi, Nikko Yumoto, 23.VII.1985, leg. Nomura (NHMC); 4우, Tochigi, Okukinu, 21.VII.1987, leg. Nomura (NHMC); 19, Tochigi, Nikkozawa-Kinunuma, Kuriyama-mura, 3.IX.1991, leg. Naomi (NHMC); $1 \sigma^{*}$, Gunma, Numata, 31.VIII 1966, leg. Takei (cIto); $10^{\star *}$, Gunma Ken, 4 km SW Tsumagoi, 1050m, 18.VII. 1980, leg. Löbl (MHNG); 10", Gunma, Mt. Hotaka, 2.IX.1983, leg. Sawai (cIto); 19 , Gunma, Marunuma, 23.IX.1969, leg. Y. Shibata (CShY); $20^{\circ} 0^{\circ}$, Gunma, Marunuma, Oku Nikko, 13. VIII.1980, leg. Y. Shibata (cShY); 10", Gunma, Katashina, Kohzawa, 15.VIII.1980, leg. Y. Shibata (cAss).

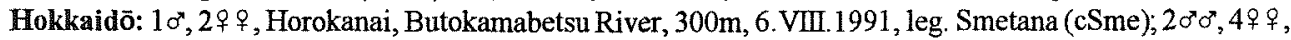
Kaihatsu-cho-minami, 15m, 25.VII.1991, leg. Smetana (cSme, cAss); $40^{\circ} 0^{\prime \prime}, 6 \%$ [1 $1 \%$ teneral; 2 dissected $q$ \% both with one mature egg in ovaries], Shiretoko Pen., Shari, Idashubetsu Crk., 310m, 1.VIII.1991, leg. Smetana (cSme, cAss); 19, Shiretoko, Mt. Rausu, 27.IX.1993, leg. Yasuda (cShY); 20"0, Shirotoko, Iwanbetsu, 16. VIII.1962, leg. Tsukaguchi (cShY); 10, Sapporo, Mt. Moiwayama, 13.VIII.1963, leg. Okumura (cShY); 19, Mt. Moiwayama, 23.VIII.1977, leg. Terada (cShY); 10", Kamikawa-cho, Sounkyo, 2.IX.1983, leg. Yasuda (cShY); 1ㅇ, Rikubetsu, 25.VII.1992, leg. Womira (cIto); 299, Shivetoko, 27.VI.1992, leg. Nomura (cIto); 19, Sawaras, Oshima, 28.IX.1980, leg. Kusui (cIto); 19, Sounkyo, 10.VII.1992, leg. Ueda (clto); $20^{\circ} 0^{\circ}, 2 q \%$, Sounkyo, 26.VII. 1962, leg. Y. Shibata (cShY); $50^{\circ} 0^{\circ}, 2$ 2 $q$, Sounkyo, 2.16. VIII.1962, leg. Y. Shibata (cShY); 10, Sounkyo, 4.VIII.1962, leg. Tsukaguchi (cShY); 1\%, Ishikari, 6.VII.1962, leg. Y. Shibata (cShY); 10", M. Kubetsu [?], 25.VII.1992, leg. Nomura (cIto); 19, Otaru City, Nagabashi, 1.IX.1984,

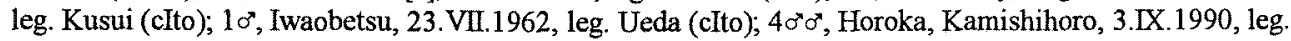
Haga (NHMC, cAss); 1 , Mt. Yotei, Hangetsu Lake, 31.VII.1994, leg. Zakii (NHMC); 10*, Akan lakeside, 3.VII.1986, leg. Nomura (NHMC); 10", Mt. Shirikoma-dake, Horonobe-cho, 400m, 14. VIII.1990, leg. Salto (NHMC); 10", Shivetoka Pass, Rausu-cho, 3.VIII.1989, leg. Haga (NHMC); 50"0, 59., Rishiri Island, Himenuma, 26.VII. 1963, leg. Y. Shibata (ShY, cAss); 107, Rishiri Island, Oshidomari, 23.VII.1963, leg. Y. Shibata (ShY).

\section{Diagnosis}

Measurements (range, arithmetic mean; $\mathrm{n}=176$ ): HL: $1.28-1.68,1.52$; HW: $1.13-1.49,1.33$; PW: 1.34 - 1.74, 1.55; PL: 1.65 - 2.17, 1.91; EL: 0.98 - 1.31, 1.16; TiL: 1.04 - 1.46, 1.26; TaL: $0.79-1.16,0.98 ;$ TL: $8.2-11.8,9.9$.

Colour variable; usual coloration: head, pronotum and most of abdomen dark brown to blackish; elytra, hind margins of abdominal segments VII and VIII, antennae, legs and mouthparts except for the apices of the mandibles lighter, yellowish to reddish brown; elytra often darkened near scutellum.

Head of variable shape, but usually slender, $1.09-1.22 \mathrm{x}$ (mean: 1.14 ) longer than wide and narrower than pronotum (HW/PW: $0.79-0.92$; mean: 0.86 ); eyes of similar relative size as in $O$. medius, ca. 1/3 - 1/4 the length of temples; postgenae mostly slightly widened, sometimes \pm parallel or even slightly narrowed in dorsal view; microsculpture of dorsal surface highly variable, usually predominantly composed of transverse meshes of variable length, often mixed with isodiametric meshes or transverse striae; sometimes predominantly composed of isodiametric meshes, rarely of transverse striae (particularly in posterior region of head); punctation similar to $O$. medius; frontal furrows variable, distinct - occasionally reaching front margin - to indistinct; antennae of similar shape as in $O$. medius, but antennomere $\mathrm{V}$ usually not oblong.

Pronotum of variable shape, $1.16-1.32 x$ (mean: 1.23 ) longer than wide; maximal width in anterior half, but usually at some distance behind anterior angles; in median line posteriorly with scratch-like impression; dorsal surface with microsculpture similar to head, also very variable, in posterior half often more transverse than in anterior half; discal punctures as in $O$. medius.

Elytra relatively short, but length subject to some variation (see measurements and Fig. 6); EL/PL: $0.53-0.69$, mean: 0.61 ; punctation generally less dense than in $O$. medius, but highly variable, often rugose near suture in anterior half and near scutellum; \pm irregular short striae may be present near anterior margin and near scutellum; surface without distinct microsculpture, \pm shining. 

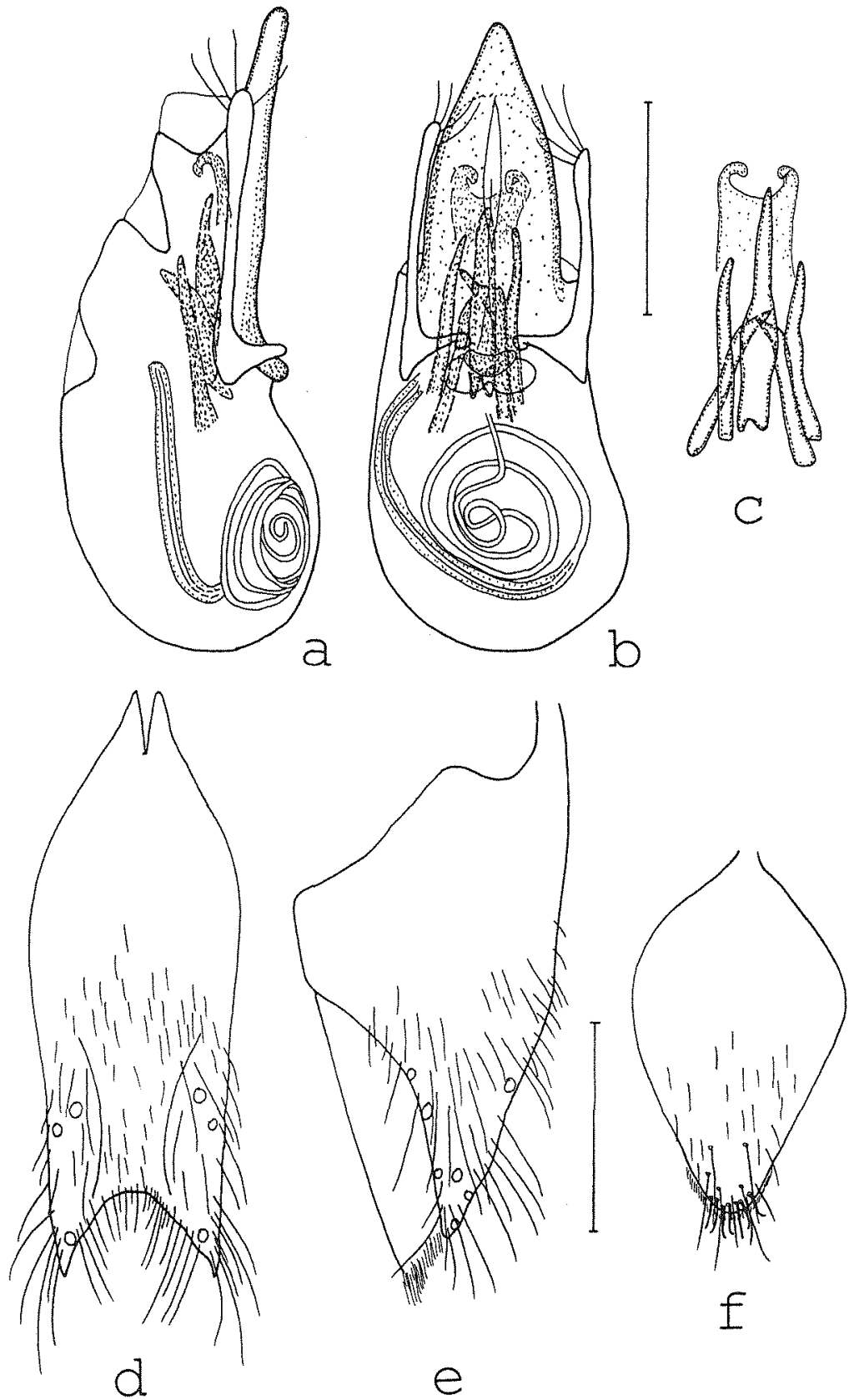

Figs 5 a - f: $O$. rosti BERnhaUer (c - e: LT; a - b: PLT): aedeagus in lateral and in ventral view (a, b); internal structures in ventral view (c); $\sigma^{\prime}$ sternum IX (d); $\sigma^{*}$ lateral tergal sclerite IX and tergum X in lateral view (e); of tergum X (f); long setae partly or completely omitted in d, e, f. Scales: $0.5 \mathrm{~mm}$. 
Scutellum with microsculpture composed of short transverse and/or isodiametric meshes, punctures small or indistinct; hind wing development apparently dimorphic, usually brachypterous; proportions of legs similar to O. medius; TiL/TaL: $1.09-1.40$, mean: 1.28.

Abdomen with microsculpture similar to $O$. medius, but isodiametric microsculpture near anterior margins of terga usually weaker; surface often weakly iridescent; punctation on average less dense and finer than in $O$. medius; palisade fringe at hind margin of tergum VII present.

o: protarsomeres I - IV strongly dilated; sternum V and VI each antero-medially with small (smaller than in $O$. medius) \pm oval flattened area, with tomentose long pubescence; sternum VII with shallow median impression increasing in depth and width posteriorly and with weakly concave hind margin; hind margin of sternum VII centrally flattened to weakly impressed, its shape variable, concave to \pm truncate; lateral tergal sclerites of segment IX apically acute, but shorter than in $O$. medius, not reaching hind margin of tergum $\mathrm{X}$, apically without spine-like process (Fig. 5e); shape of hind margin of sternum IX somewhat variable, but deeply concave, hind angles with spine-like processes (Fig. 5d); ventral process of aedeagus with pair of folds, which are weaker than in $O$. medius, and with basal carina; internal sac with 5 long sclerotized structures (basal median structure absent) and with apical membranous structure of characteristic shape; flagellum short, with 5-7 coils, wide and distally darkened (Figs 5 a - c).

$\%$ : protarsomeres I - IV dilated; extent of dilatation somewhat variable, but always less than in $0^{*}$, sexual dimorphism pronounced; lateral tergal sclerites of segment IX apically without spine-like processes; tergum $X$ with narrow basis, posteriorly with ca. 3 - 10 rather long, apically curved modified setae; inner margin of styli with with fringe of numerous long, rather stout setae (Fig. $5 \mathrm{f}$ ).

Comments: BERNHAUER (1907) based his original description on three specimens from "Nemoro und Sapporo auf Jesso" without specifying a holotype. Therefore, and because of the possibility that the undiscovered third syntype may refer to a different species, a lectotype designation was deemed necessary. As the syntype BERNHAUER had labelled "Typus" has a somewhat deformed pronotum, the second syntype in his collection was selected as lectotype.

In the original description of $O$. ussuriensis, CoIfFAIT (1974) compared the species only with $O$. chrysurus REITTER, but did not refer to any of the species described from Japan. A request for a loan of the holotype in the Khnzorian collection in Yerevan has remained unanswered. The paratype from the Coiffait collection, however, is without doubt conspecific with $O$. rost $i$ BERNHAUER, so that $O$. ussuriensis is here treated as a junior synonym of that species.

Comparative notes: From all its congeners, $O$. rost i is distinguished by the characteristic internal structures of the aedeagus. From the often similar $O$. medius, it is in addition separated by on average smaller size, by the different secondary sexual characters on the $\sigma^{*}$ sterna $V$ and VI, and especially by the absence of spine-like processes on the lateral tergal sclerites IX. In $O$. latus, the body and especially the head are larger and broader, the colour is on the whole darker, and the $\sigma^{*}$ sterna $\mathrm{V}$ and VI are unmodified.

Distribution and bionomics: $O$. rost $i$ is a widespread species, but less so than $O$. medius and with a somewhat more northern distribution, which ranges from Primorskiy Kray and adjacent regions, Sakhalin, and the southwestern Kuril Islands in the north to Honshü in the south (WATANABE, 1994, 1995, 1996; material examined). It is apparently absent from the southern islands of the Japanese archipelago. Specimens from the south of the range of distribution tend to be larger than those from the north (Fig. 6). The labels of the material examined indicate lower to intermediate altitudes $(300-1280 \mathrm{~m})$. The species has been collected from April through November; several specimens taken in May ( 3 ex.), July ( 4 ex.) and August ( 1 ex.) were teneral. The ovaries of three dissected $\uparrow \subsetneq$ collected in July and August each contained a mature egg. 


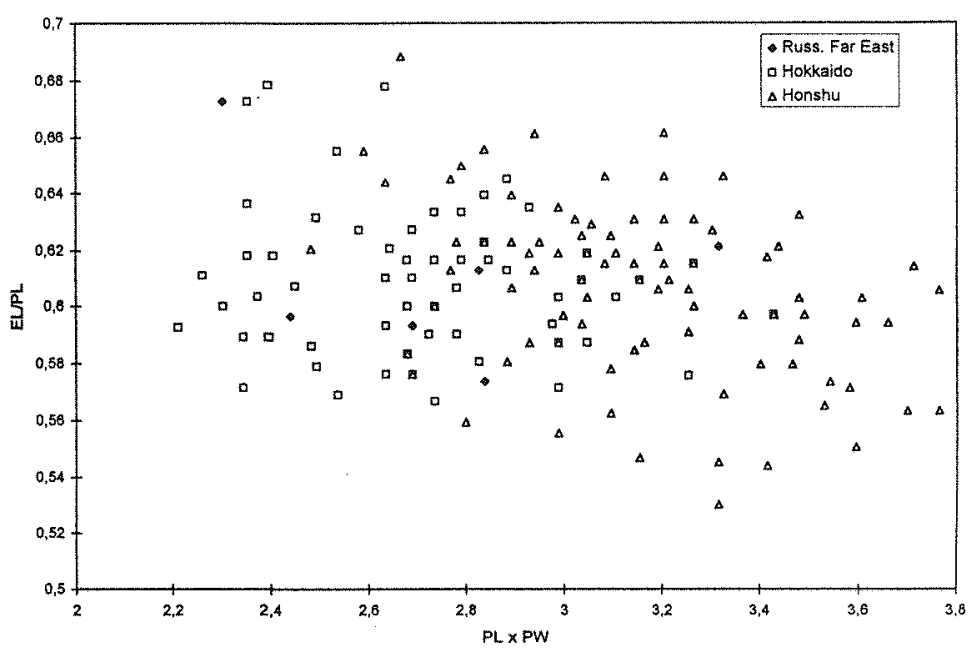

Fig. 6: O. rosti BERNHAUER: intraspecific variation of relative elytral length in relation to pronotum size.

\subsubsection{Othius latus latus SHARP, 1874}

Figs 7 a - f, h-1, $n-p, r, t, 8,9$

Othius latus SHARP, 1874: $51 \mathrm{f}$.

Othius latus SHARP: ITO (1993)

Othius stötzneri BERNHAUER, 1931: 1f., syn. n.

Othius latus ozakii ITO, 1993: 143f., syn. n.

Othius chongqingensis ZHENG, 1995: 343, syn. n.

\section{Types examined}

O. latus SHARP: Lectotype : : Type [red curator label]/ Japan. Lewis/ Japan/ Sharp Coll. 1905-313/ Othius latus type D.S./ Lectotypus Othius latus Sharp, V. Gusarov des. 1993/ Othius latus Sharp, V. I. Gusarov det. 1993 (BMNH). Paralectotypes: 19: Japan, G. Lewis. 1910-320/ 240/ Othius latus mihi D.S./ Paralectotypus Othius latus Sharp, V. Gusarov des. 1993/ Othius latus Sharp, V. I. Gusarov det. 1993 (BMNH); 1 o [dissected prior to present study; aedeagus missing]: China/ O. latus Shp., cfd. c type/ Othius latus Sharp, V. I. Gusarov det. 1993 (BMNH).

O. latus ozakii ITo: Holotype ơ: Jyogakura, Mt. Hakkoda, Aomori, 6.IX.1992, T. Ozaki/ Holotype Othius latus ozakii T. Ito ssp. nov. (cShT). Paratypes: $10^{\prime \prime}$, same data as holotype/ Paratype Othius latus ozakii T. Ito ssp. nov. (cSol); 10", same locality as holotype, 13.IX.1984/ Paratype Othius latus ozakii T. Ito ssp. nov. (cAss).

O. stoetzneri BERNHAUER: Lectotype $\$$, here designated and labelled accordingly: Szetschwan, Omisien, Exp. Stötzner/ Stötzneri Brnh. Typus/ Othius stötzneri Brh. n. sp./ Staatl. Museum für Tierkunde Dresden (SMTD). Paralectotype: 1 sex?, severely damaged (abdomen missing): Szetschwan, Kwanhsien, Exp. Stötzner, 1923/4/ Othius stötzneri Brh. n. sp./ Stötzneri Bernh. Typus/ Chicago NHMus, M. Bernhauer Collection (FMNH).

O. chongqingensis ZHENG: Paratype o : 1985.V.16 [locality and further data in Chinese, according to original description: Sichuan, Mt. Jin-yun, Chongqing City, 800-919m, leg. Hu Shu-hui et al.] (cBor). 


\section{Additional material examined}

Russian Federation: $10^{*}, 2 \% q[1 \%$ teneral], Sakhalin, Korsakov distr., Ismenshyroye lake, 21.-22.VII.1993, leg. Putz \& Wrase (cAss).

Japan: Hokkaidō: $20^{\circ} 0^{\circ}, 1 \%$, Ishikari, 6. VIII.1962, leg. Y. Shibata (cShY, cAss); 1 \%, Nanaye, Lake Ohnuma, 26. VIII.1980, leg. Matsumoto (cShY); 10, Rubeshibe, Itonmuka R., marsh, 770m, 29. VII.1991, leg. Smetana (cAss); 1 [ [with mature egg in ovaries], Horokanai, Butokamabetsu River, 300m, 3. VIII. 1991, leg. Smetana (cSme); 1, Sapporo c., Misumai, 20.VII.1985, leg. Haga (NHMC). Honshü: 10", Jyogakura, Mt. Hakkoda, Aomori, 13.IX.1984, leg. Ozaki (cSol); 19, Aomori Pref., Aomori City, Tashihiro, 30. VIII.1992, leg. Ozaki, 'Paratype Othius latus ozakii T. Ito ssp. nov.' (cAss); $20^{\circ} 0^{\circ}$, Aomori, Twada, 4.VII.1987, leg. Nomura (NHMC, cAss); 10", Aomori, Yachi Spa, 6.VIII.1964, leg. Y. Shibata (cShY); 10", Iwate Pref., Shizukuishi cho, Amihari, 12.-13.VIII.1982, leg. Saito (cShY); 19, Iwate, Shizukuishi, Amihari spa, 17.IX.1981, leg. Saito (cShY); 1 , Fukushima Pref., Goshikinuma, Urabandai, 18.VIII.1996, leg. Naomi (NHMC); $20^{\circ} 0^{\star}, 1$, Fukushima, Goshikinuma, 4.VIII.1969, leg. Y. Shibata (cShY, cAss).

China: 19, Sichuan, Dazu, X.1986, leg. Rougemont (cRou); 1ㅇ, SW-Hunan, SW Huitong, Guangping, $300 \mathrm{~m}, 2 . X I .1993$, leg. Schillhammer (cAss); 1q, Zhejiang (MNHUB); 20 $0^{\circ}, 3 q \%$ Shanghai (MNHUB, NHMW, cAss); 1 \%, 'China' (BMNH).
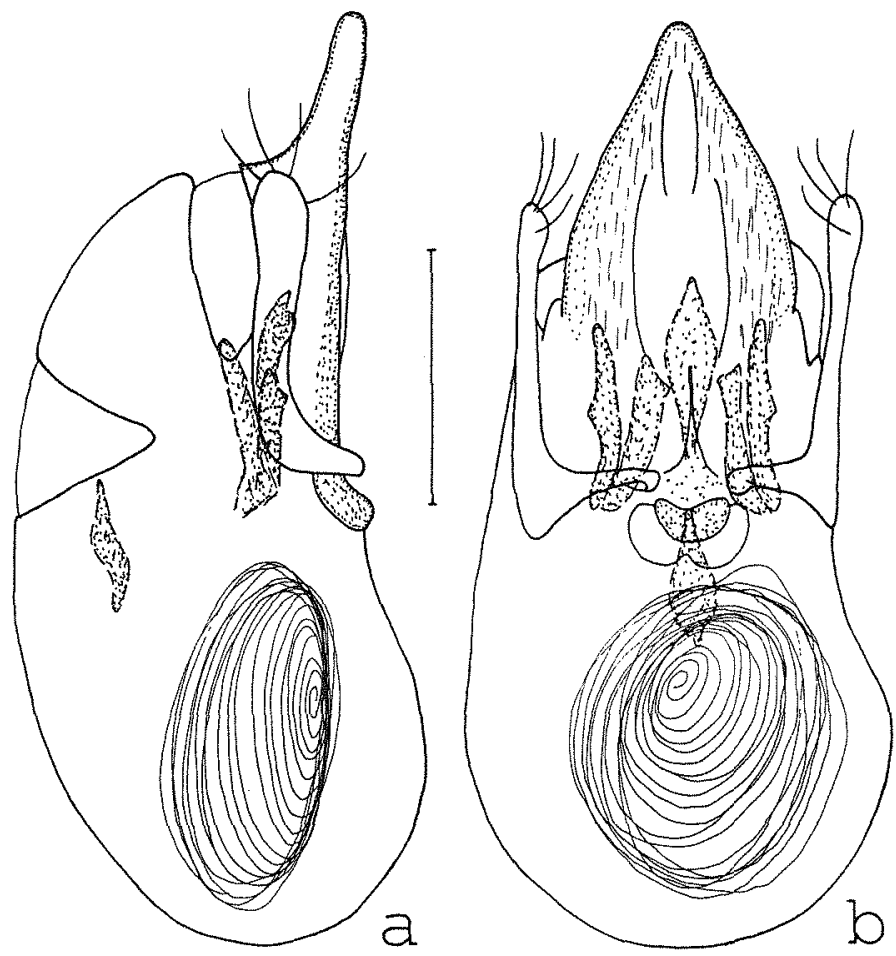

Figs $7 \mathfrak{a}-t:$ : $O$. latus SHARP: aedeagus in lateral and in ventral view $(\mathbf{a}, \mathbf{b})$; internal structures in ventral view of $O$. latus latus from northern Honshü (c), western China (d), Hokkaidō (e), Sakhalin (f), and of $O$. latus gansuensis (g); o" sternum IX of $O$. latus latus from Hokkaido (h); hind margins of $\sigma^{\prime \prime}$ sternum IX of $O$. latus latus from northern Honshū $(\mathbf{i}, \mathbf{j})$, Sakhalin $(\mathbf{k})$, western China (l), and of $O$. latus gansuensis $(\mathbf{m})$; o lateral tergal sclerite IX and tergum X of $O$. latus latus from Hokkaido (n); apex of or lateral tergal sclerite IX and tergum X of $O$. latus latus from Sakhalin (o), western China (p), and of $O$. latus gansuensis (q); hind margin of $\sigma^{*}$ sternum VIII of $O$. latus latus from Hokkaidō (r) and of $O$. latus gansuensis (s); $q$ terminalia of $O$. latus latus PLT (t); long setae partly or completely omitted in $\mathrm{h}-\mathrm{t}$. Scales: $0.5 \mathrm{~mm}$. 


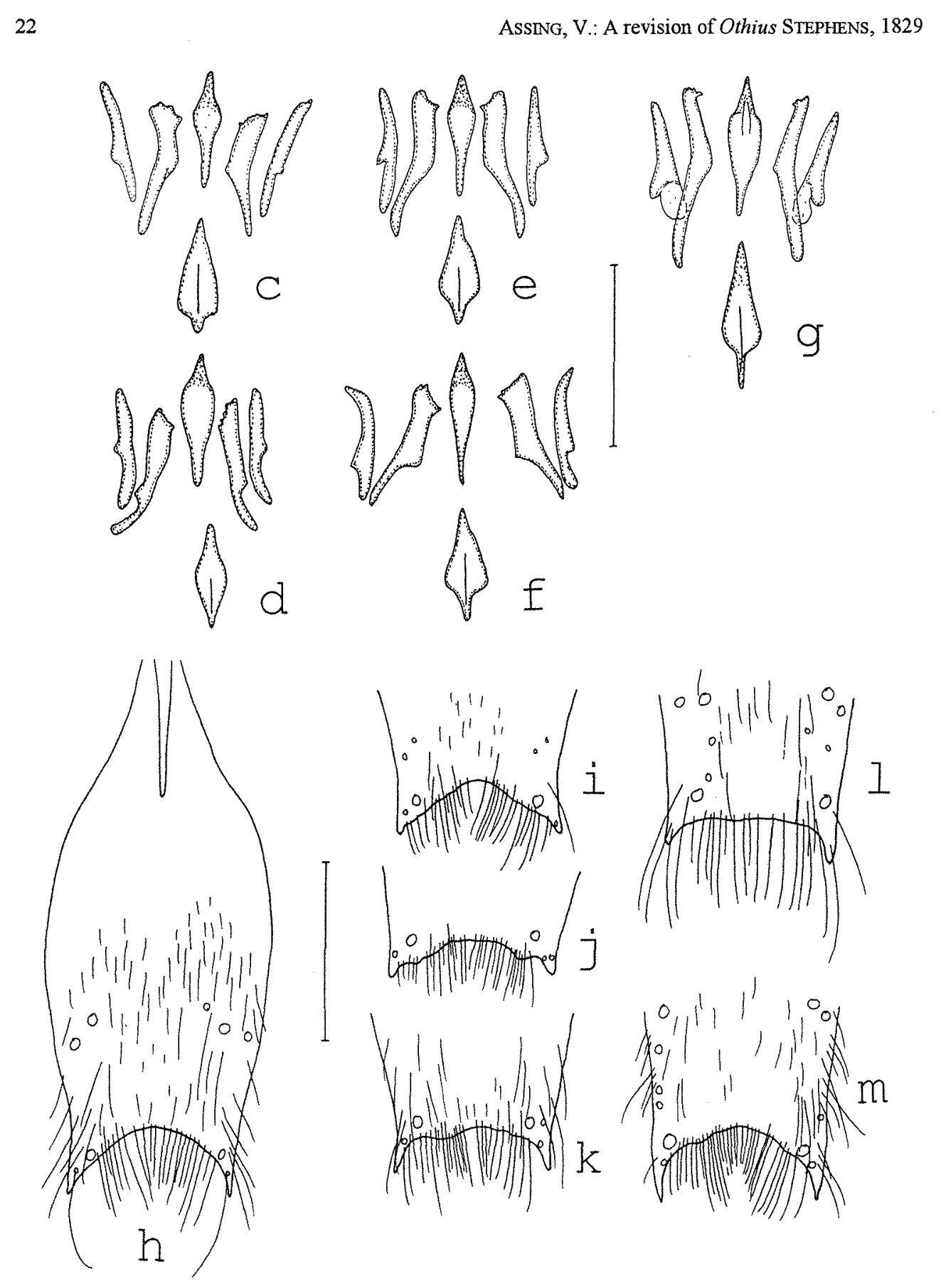



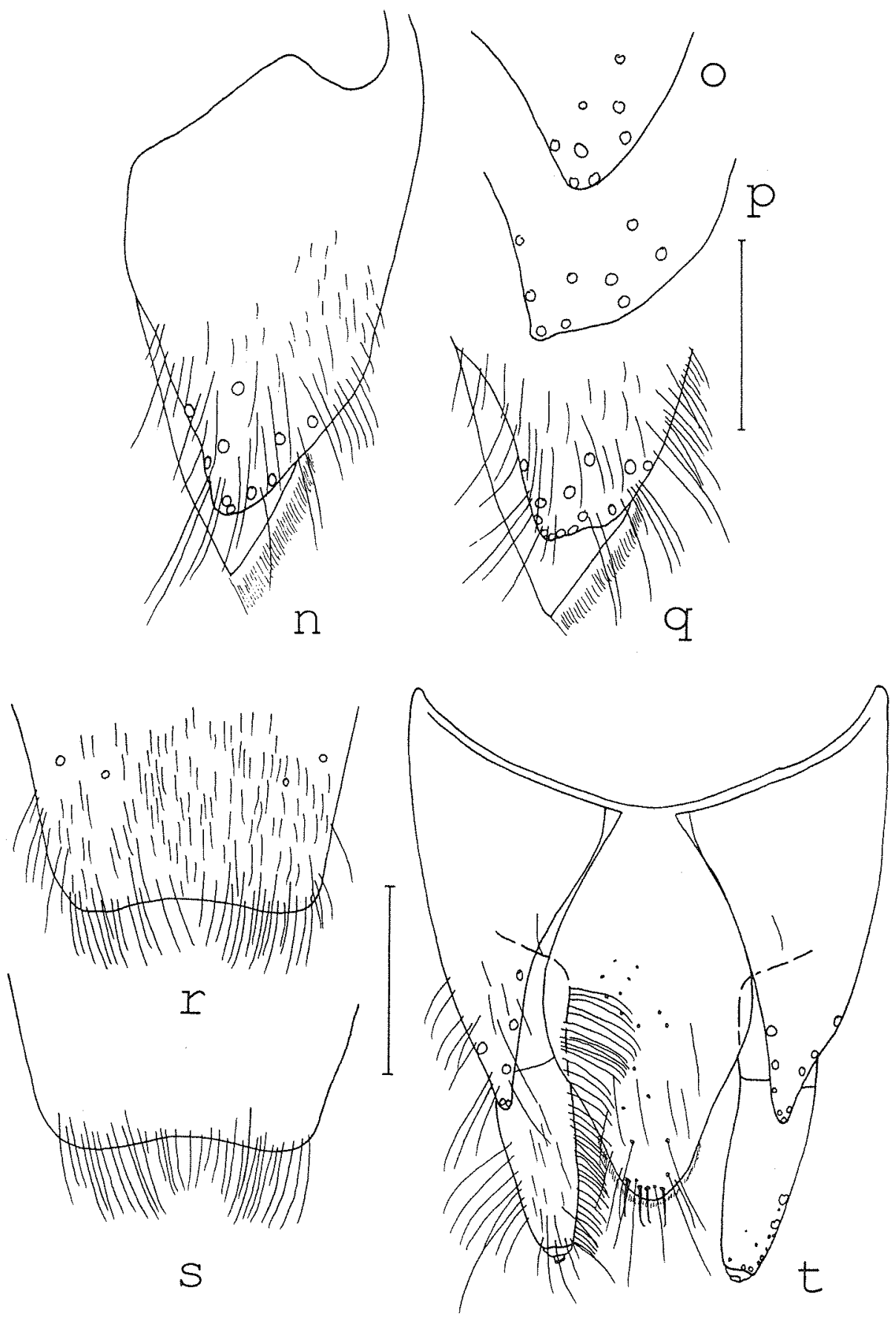


\section{Diagnosis}

Measurements (range, arithmetic mean; $\mathrm{n}=39$ ): HL: $1.71-2.21,2.01$; HW: $1.59-2.10,1.84$; PW: 1.68 - 2.26, 1.97; PL: 1.98 - 2.59, 2.28; EL: 1.28 - 1.98, 1.57; TiL: 1.37 - 1.83, 1.62; TaL: 1.07 $1.40,1.24$; TL: $9.8-15.6,12.5$.

Externally similar to, as large as or larger than $O$. medius; colour similar to $O$. medius, but elytra usually dark brown to black and base of antennae darkened; legs \pm dark brown to blackish.

Head of variable shape, but relatively broader than in $O$. medius, $1.02-1.15 \mathrm{x}$ (mean: 1.09) longer than wide; HW/PW: 0.89 - 1.00 (mean: 0.94); in dorsal view distinctly widened posteriorly; microsculpture of dorsal surface similar to $O$. medius, also highly variable, but on average slightly more distinct; punctation in lateral area of dorsal surface denser than in $O$. medius; frontal punctures and furrows similar to $O$. medius.

Pronotum more distinctly dilated anteriorly than in $O$. medius, maximal width a short distance behind anterior angles, PL/PW: 1.10 - 1.24, mean: 1.16; posterior scratch-like impression in median line often very weak; microsculpture similar to $O$. medius, also usually more transverse in posterior than in anterior half; arrangement of discal punctures as in $O$. medius.

Elytra relatively short, but length subject to considerable variation, on average longer in material from China and southern Japan than in specimens from Sakhalin and northern Japan (see measurements and Fig. 9); EL/PL: 0.60 - 0.79, mean: 0.69; punctation usually less dense than in $O$. medius; rugose and confluent punctation often present near scutellum; surface without, or at most with very weak microsculpture, \pm shining; scutellum with distinct microsculpture composed of isodiametric and/or short transverse meshes, with or without several punctures; (always?) macropterous; tarsi relatively shorter than in 0 . medius; TiL/TaL: $1.21-1.46$, mean: 1.30 .

Abdomen with microsculpture similar to $O$. medius; also with more distinct and \pm isodiametric microsculpture near anterior tergal margins; weak iridiscent shine mostly confined to tergum VII and VIII; punctures of variable density, often similar to O. medius, but mostly somewhat wide and shallow, and \pm distinctly microsculptured; palisade fringe at hind margin of tergum VII present. $\sigma^{*}$ : sexual dimorphism of protarsi as in O. medius; sternum IV and V unmodified; sternum VI weakly flattened posteriorly; sternum VII with broad but shallow median impression increasing in depth and width posteriorly and with weakly concave hind margin, the impression with dense and long, almost tomentose pubescence; hind margin of sternum VIII moderately concave and laterally with long dark setae (Fig. 7r); lateral tergal sclerites of segment IX much broader and shorter than in O. medius, not reaching hind margin of tergum X, apically without spine-like process (Figs 7 $\mathrm{n}-\mathrm{p}$ ); sternum IX shorter and wider than in $O$. medius, anteriorly deeply bifid, central area in posterior half with sparse, short and indistinct pubescence, hind margin deeply (but less so than in $O$. medius) and broadly concave, depth and shape of concavity highly variable, hind angles variably acute (Figs $7 \mathrm{~h}-1$ ); ventral process of aedeagus with pair of weak folds and short basal carina; internal structures characteristic, their shapes somewhat variable; flagellum long and thin, with ca. 20-30 coils, distally not darkened (Figs 7a - f).

o: lateral tergal sclerites of segment IX apically without processes; hind margin of tergum X with a variable number of apically curved, weakly modified setae, which are longer and more slender than in 0 . medius; inner margin of styli with fringe of numerous long setae (Fig. 7t).

Comparative notes: From other Eastern Palaearctic congeners of larger size and with a palisade fringe on the hind margin of tergum VII, $O$. latus latus is best distinguished by the $\sigma^{*}$ primary and secondary sexual characters. In addition, it is separated from $O$. medius by the broader, relatively shorter and posteriorly usually \pm dilated head and by the different morphology of the lateral tergal sclerites IX, and from $O$. taiwanus by the relatively shorter head, the presence of a posterior pair of frontal punctures, the shorter antennae and the more distinct and isodiametric microsculpture of the scutellum. In O. opacipennis CAMERON the microsculpture of the elytra is very distinct and isodiametric. For distinction from $O$. amamianus ITo see diagnosis of that species. 
Comments: Without specifying a holotype, SHARP (1874) based his original description of $O$. latus on two $q$ \% from Japan ("Copper Temple, Nagasaki") and a of from Northern China, which he believed to belong "no doubt to the same species". Consequently, all three specimens were originally syntypes. In stating that he examined the holotype [sic!], probably because of the type label attached to the specimen, and giving a photograph of the labels, ITO (1993) designated a lectotype.

BERNHAUER (1931) based his original description of $O$. stoetzneri on at least two syntypes kept in his own collection and in the "Sammlung des Dresdener Staatsmuseums". Since the possibility cannot be completely ruled out that further unexamined syntypes exist, which are not conspecific with the examined syntypes, the undamaged + syntype in the collection of the SMTD is here designated as lectotype. The description of O. stoetzneri (BERNHAUER, 1931), in which the author compares $O$. stoetzneri with $O$. latus emphasizing the different shape of the head and the different punctation, is apparently a result of BERNHAUER's erroneous interpretation of $O$. latus. All the specimens in the Bernhauer collection identified by him as "O. latus" were in fact $O$. medius.

ITO (1993) indicates eye size, the width of the antennae, the microsculpture of the interstices on the elytra, the less shiny and darker appearance, and the more slender and smaller body as characters distinguishing $O$. latus ozakii from $O$. latus latus.

In his original description of $O$. chongqingensis, ZHENG (1995) compares the species with $O$. latus and $O$. stoetzneri, stating that the new species differs from the former in head width, from the latter in size, and from both in elytral length and elytral punctation. (The reference to $O$. ruficornis CAMERON can be neglected, since this Himalayan species is neither very similar nor closely related to $O$. latus.) The rough sketch of the aedeagus is in good agreement with that of $O$. latus.

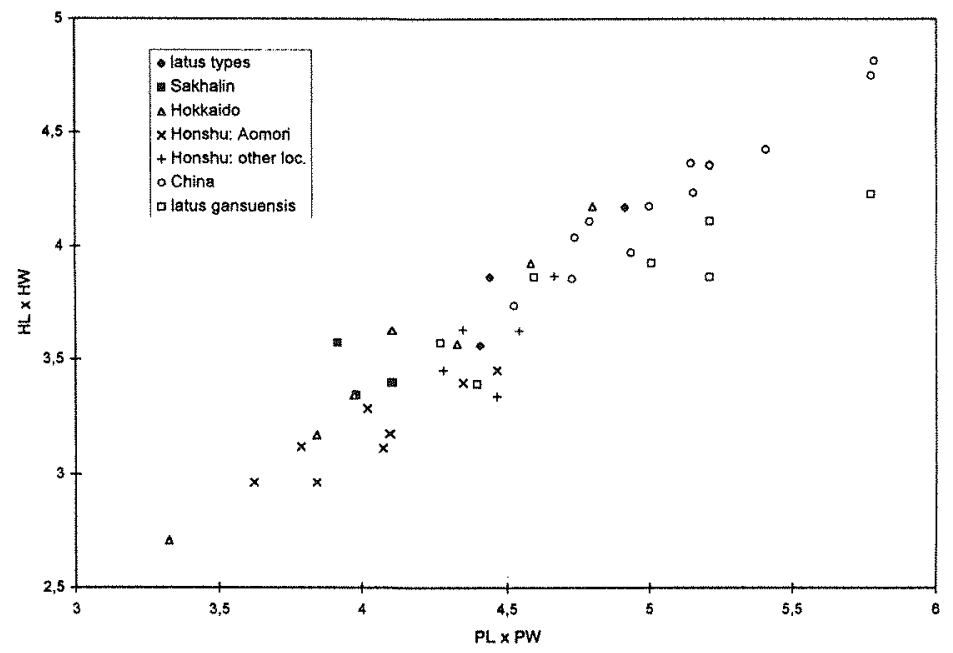

Fig. 8: O. latus latus SHARP and O. latus gansuensis sp. n.: intraspecific variation of head and pronotum size.

An examination of the types of the taxa treated here and of additional material from further localities revealed considerable intraspecific variation in $O$. latus, both within and between populations (Figs 8,9), but yielded constant differences neither in external morphology nor in the primary and secondary sexual characters, including the internal structures of the aedeagus. Specimens from China and southern Japan (types of $O$. stoetzneri, $O$. chongqingensis, $O$. latus and additional material) tend to be larger and have longer elytra than those from the northeastern part of the range of distribution (Sakhalin, Hokkaidō, northern Honshū) (Figs 8, 9). Wing length poly- 
and dimorphism is not uncommon in the genus (AssING 1997a, 1998b), and the length of the elytra is apparently extremely variable in $O$. latus (see measurements and Fig. 9). Considerable intraspecific variation was also observed in elytral punctation, head width, pronotal shape, microsculpture and colour. In addition, there is some - probably allometric - variation in the size of the median lobe, which is usually larger in the Chinese material than in specimens from the northeast of the area of distribution. The shape (length, width, outline) of the internal structures may somewhat differ especially between (and apparently also within) populations, but the general pattern is very similar (Figs $7 \mathrm{c}-\mathrm{f}$ ). Constant differences in the secondary sexual characters were not observed.

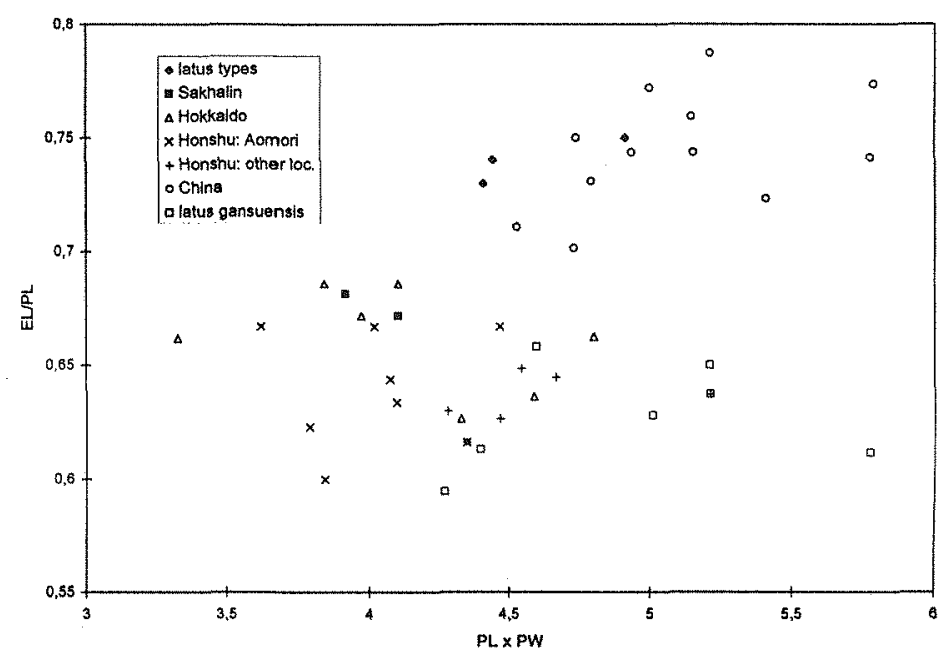

Fig. 9: O. latus latus SHARP and O. latus gansuensis $\mathrm{sp}$. n.: intraspecific variation of relative elytral length in relation to pronotum size.

Pronounced intraspecific variation, especially between populations, is what should be expected with a species like $O$. latus. Both the characteristics of the area of distribution, which is vast and at the same time fragmented by barriers (water and stretches of land without suitable habitats), and the probably low dispersal power of the species are bound to impede gene flow. Judging from the length of the elytra most, if not all the specimens examined from the northwest of the range of distribution (Sakhalin, northern Honshū, Hokkaidō) were incapable of flight. In the absence of convincing morphological and biogeographical evidence in favour of the hypothesis that the different population samples should represent distinct species or subspecies, they are here regarded as subpopulations of one polytypical species. This view is also supported by the fact that $O$. medius, $O$. rost $i$ and $O$. punctatus have a very similarly large and fragmented area of distribution and are as variable as $O$. latus, or nearly so. Consequently, $O$. stoetzneri BERNHAUER, $O$. latus ozakii ITO, and $O$. chongqingensis ZHENG are here considered synonyms of $O$. latus SHARP. Only the material from Gansu proved to be so constantly different in external and the o primary and secondary characters, and apparently also ecologically that it is hypothesized to represent a distinct subspecies, which is described bellow.

The identity of the species referred to by ZHENG (1995), who (apparently without studying the types) reports $O$. latus, $O$. stoetzneri and $O$. chongqingensis for China, is very doubtful, since his key is based on such variable characters as the relative widths and lengths of the head, the pronotum and the elytra, respectively. 
Distribution and bionomics: The area of distribution of $O$. latus latus ranges from Sakhalin in the northeast to eastern central China in the southwest and includes the Japanese archipelago (Hokkaidō, Honshū, Kyüshū). Apparently it occurs at lower altitudes; the altitudes specified on the labels of the examined specimens range from 300 to $900 \mathrm{~m}$. Adult specimens were collected in May and from July through November. One $q$ taken in July (Sakhalin) was teneral; the ovaries of a $q$ collected in August (Hokkaidō) contained a mature egg.

\subsubsection{Othius latus gansuensis ssp. $\mathrm{n}$.}

Figs $7 \mathrm{~g}, \mathrm{~m}, \mathrm{q}, \mathrm{s}, 8,9$

\section{Types}

Holotype o: China, Gansu, $28 \mathrm{~km}$ S Lanzhou, 2200m, 8.VII.94, [C2], A. Smetana (cSme).

Paratypes: 10", 2 우, China, Gansu, Dalijia Shan, 46 km W Linxia, 2980m, 10.VII.1994, [C5], A. Smetana (cSme, cAss); 19, China, Gansu, Dalijia Shan, $62 \mathrm{~km}$ W Linxia, $3600 \mathrm{~m}, 10$. VII. 1994, [C4], A. Smetana (cSme); 1 \%, China, SW Gansu, road Linxia/Hanjiaji-Xining km 43, 2600m, 11.VII.1994, K. W. Anton (cSme); $10^{*}$, China: Gansu, Maijishan, VIII.1986, Rougemont (cRou).

\section{Diagnosis}

Measurements and ratios (range; $n=7$ ): HL: $1.95-2.17$; HW: $1.74-1.95$; PW: $1.89-2.23$; PL: 2.26 - 2.59; EL: 1.34 - 1.59; TiL: 1.43 - 1.71; TaL: 1.22 - 1.40; TL: 11.3 - 15.3; HL/HW: 1.06 1.12; HW/PW: 0.88 - 0.97; PL/PW: 1.13 - 1.19; EL/PL: 0.59 - 0.66; TiL/TaL: 1.14 - 1.29.

Size and shape similar to $O$. latus latus, but distinguished as follows:

Coloration different, elytra reddish, distinctly contrasting with the blackish head, pronotum and abdomen.

Pronotum more strongly convex, less distinctly widened anteriorly, maximal width nearer to middle than to anterior angles; legs unicoloured reddish (in $O$. latus latus mostly darker).

$\sigma^{*}$ : sternum VIII with more numerous and darker long setae than in $O$. latus (Fig. 7s); lateral tergal sclerites of segment IX apically \pm truncate (Fig. 7q); sternum IX as in Fig. 7m; median lobe of aedeagus of similar outline as in $O$. latus latus, but sclerotized internal structures, though of similar arrangement, longer; long lateral structures more slender and apically distinctly less dilated than in $O$. latus latus (Figs $7 \mathrm{~g}$ ).

$:$ : terminalia as in $O$. latus latus.

Comparative notes: see below $O$. latus latus.

Distribution and bionomics: The subspecies is known only from several localities in Gansu, China, where it was collected in July and August. Apparently, it inhabits higher altitude habitats than O. latus latus; the altitudes specified on the labels range from 2200 to $3600 \mathrm{~m}$.

\subsection{Othius amamianus ITO, 1993 \\ Figs 10 a - g}

Othius amamianus ITO, 1993: 144ff.

\section{Types examined}

Holotype ơ: Shimmura, Amami Is., 5.IV.1966/ T. Ito/ Holotype Othius amamianus T. ITO sp. nov. (cShT). Paratypes: 1\%, Nishinakama, Amami Is., 6.IV.1969/ Y. Maeda/ Paratype Othius amamianus T. ITO sp. nov. (cAss); 19, Hatsuno, Amami Is., 30.III.1966, H. Nomura/ Paratype Othius amamianus T. ITO sp. nov. (cSol).

\section{Additional material examined}

2\% \%, Amami Is., Kagoshima P., 18.IV.1974, leg. Makihara (NHMC); 19, same locality, 27.III.1978, leg. Naomi (cAss). 


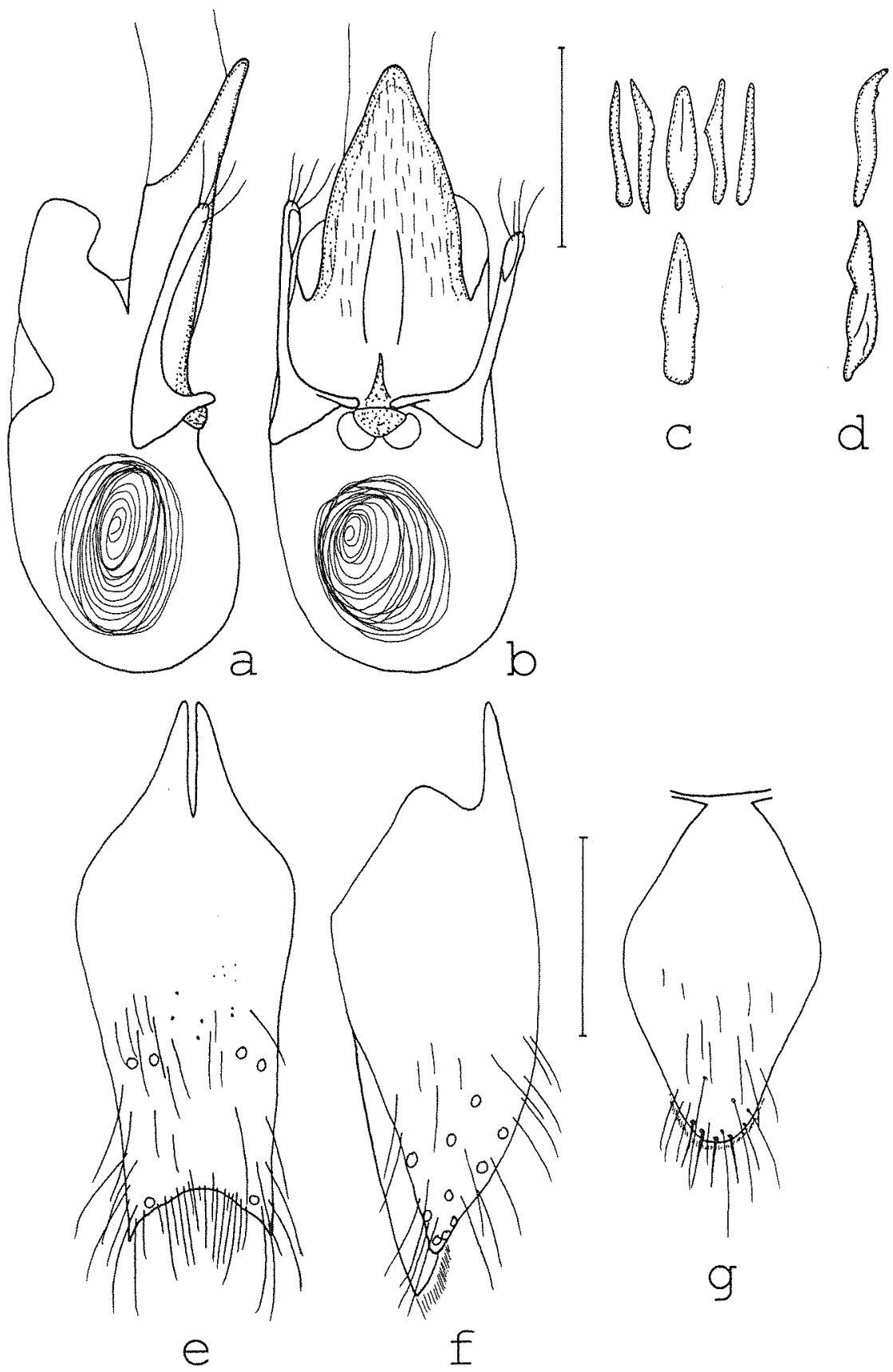

Figs 10 a - g: O. amamianus ITo (a - f: HT; $\mathrm{g}$ : PT): aedeagus in lateral and in ventral view, internal sac extruded $(\mathbf{a}, \mathbf{b})$; internal structures in ventral view (c); apical and basal median structure in lateral view (d); $\sigma^{*}$ sternum IX (e); $\sigma^{*}$ lateral tergal sclerite IX and tergum X in lateral view (f); $q$ tergum X (g); long setae partly or completely omitted in e, f. Scales: $0.5 \mathrm{~mm}$. 


\section{Diagnosis}

Measurements and ratios (range; $\mathrm{n}=6$ ): $\mathrm{HL}: 1.68-1.86$; HW: $1.56-1.77$; PW: 1.65 - 1.83; PL: 1.98 - 2.14; EL: 1.53 - 1.71; TiL: 1.40 - 1.59; TaL: 1.07 - 1.22; TL: 9.8 - 12.1; HL/HW: 1.04 1.08; HW/PW: 0.94 - 0.97; PL/PW: 1.16 - 1.20; EL/PL: 0.74 - 0.80; TiL/TaL: 1.24 - 1.32.

Externally highly similar to $O$. latus latus and also rather variable, but separated from that species by the following characters:

Colour of legs more distinctly reddish (in mature $O$. latus latus usually reddish brown to brown); body on average smaller; head on average relatively shorter (see measurements), and eyes on average somewhat larger; elytra longer than in average $O$. latus.

$0^{*}$ : protarsomeres I - IV strongly dilated; sternum VI unmodified; posterior margin of sternum VII weakly concave, with shallow median impression and less dense pubescence than in $O$. latus; sternum VIII with convex hind margin; lateral tergal sclerites of segment IX longer, more slender and apically more acute (Fig. 10f); sternum IX more slender than in $O$. latus and with different pubescence (Fig. 10e); aedeagus smaller and more slender, ventral process longer, and basally more constricted; sclerotized internal structures of characteristic shape; internal sac with numerous (ca. 25) thin coils (Figs $10 \mathrm{a}-\mathrm{d}$ ).

\%: protarsomeres almost as wide as in $\sigma^{\prime} \sigma^{\circ}$, sexual dimorphism weak; hind margin of sternum VIII weakly convex and with numerous setae of variable lengths; tergum $\mathrm{X}$ posteriorly with few, moderately stout, apically uncurved and thus weakly modified setae (Fig. 10g); inner margin of styli with fringe of numerous long setae.

Comments: ITO (1993) indicates the more pronounced microsculpture of head and pronotum as a further character distinguishing this species from $O$. latus, but I have been unable to appreciate this.

Distribution and bionomics: $O$. amamianus is apparently endemic to the Amami Islands (SW Kyūshü, Japan), where it was collected in spring.

\subsection{Othius rufipennis SHARP, 1874}

Figs $11 \mathrm{a}-\mathrm{h}$

Othius rufipennis SHARP, 1874: 49f

\section{Types examined}

Lectotype $\sigma^{x}$ [aedeagus dissected prior to present study], here designated: Type [red curator label]/ Japan. Lewis/ Japan/ Sharp Coll. 1905-313/ Othius rufipennis type D.S./ Lectotypus Othius rufipennis Sharp, V. Gusarov des. 1993/ Othius nufipennis Sharp, V. I. Gusarov det. 1993 (BMNH).

Paralectotype $\sigma^{*}$ [aedeagus dissected prior to present study]: same labels as lectotype, but no type label, 'Exchange ex Collection British Mus. (N.H.)' (FMNH). It can be inferred from the original description that SHARP (1874) had several syntypes, among them at least one female, before him. Since not all the syntypes could be located and examined, a lectotype designation was deemed necessary to ensure that the present interpretation of the species is preserved.

\section{Additional material examined}

$10 *$, China, Sichuan, Emei Shan, X.1986, leg. de Rougemont (cRou).

\section{Diagnosis}

Measurements and ratios (range; $\mathrm{n}=3$ ): HL: $1.49-1.56$; HW: $1.22-1.28$; PW: 1.46 - 1.59; PL: 1.86 - 2.04; EL: 1.43 - 1.49; TiL: 1.37 - 1.40; TaL: 1.25 - 1.28; TL: 11.4 - 12.3; HL/HW: 1.21 1.23; HW/PW: 0.80 - 0.83; PL/PW: 1.24 - 1.29; EL/PL: 0.73 - 0.79; TiL/TaL: 1.07 - 1.14. 

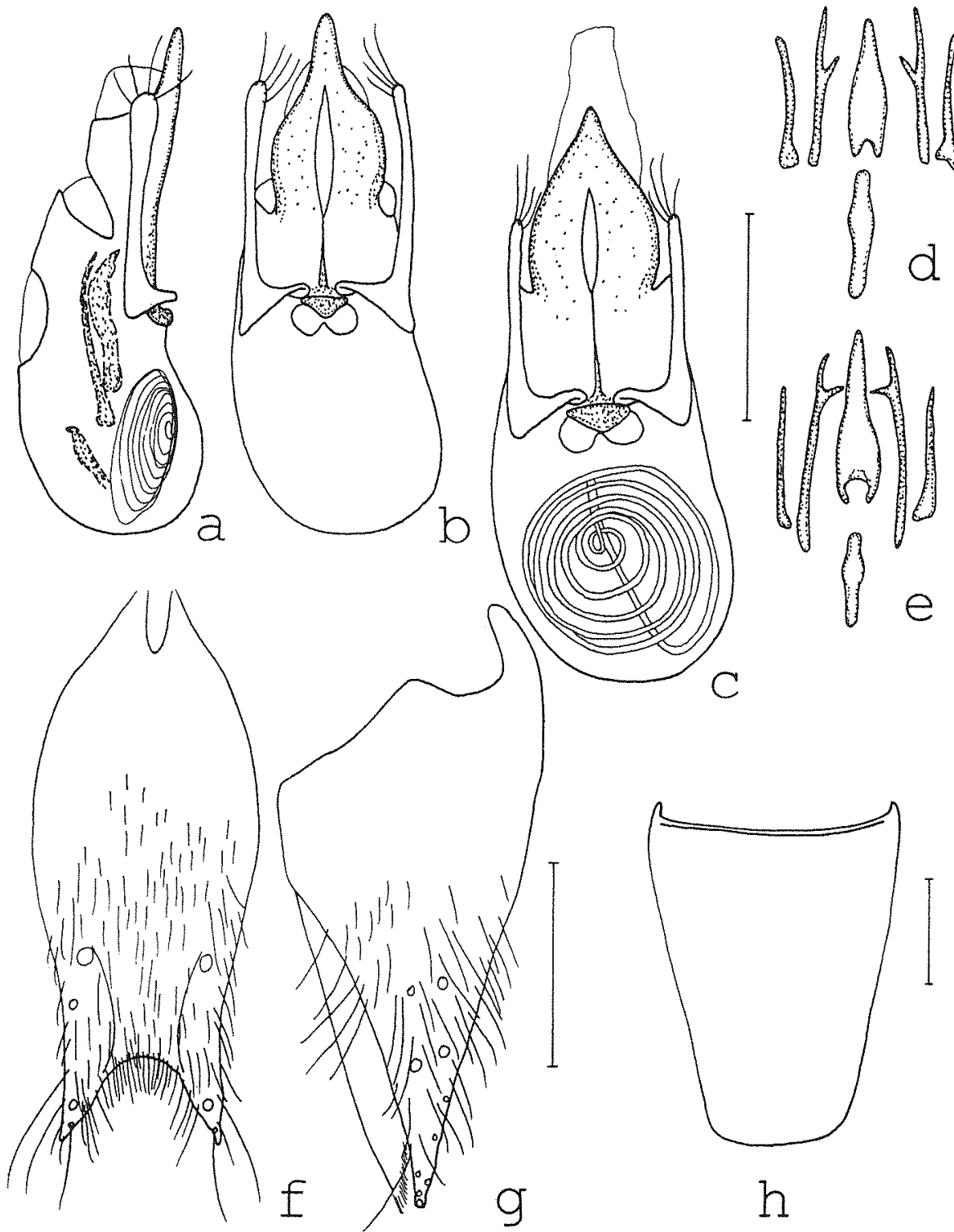

Figs 11 a - h: O. rufipennis SHARP (a - f: HT; $\mathrm{g}$ : PT): aedeagus in lateral view (a); aedeagus without internal structures in ventral view (b); aedeagus of $\sigma^{\circ}$ from Emai Shan in ventral view, sclerotized internal structures omitted (c); internal structures in ventral view of PLT (d) and of $\sigma^{*}$ from Emai Shan (e); $\sigma^{*}$ sternum IX (I); $\sigma^{\pi}$ lateral tergal sclerite IX and tergum X in lateral view (g); outline of $\sigma^{\prime \prime}$ sternum VIII (h); long setae partly or completely omitted in $\mathrm{f}-\mathrm{h}$. Scales: $0.5 \mathrm{~mm}$.

Colour of head, pronotum and abdomen dark brown to blackish; mandibles, femora and tibiae reddish to dark brown; antennae, except for the sometimes darkened basal antennomeres, ferrugineous; elytra light reddish; tarsi and posterior margin of abdominal segment VIII yellowish. 
Head slender, distinctly oblong (see ratios); eyes large and prominent, ca. half the length of postgenae in dorsal view, in lateral view $0.60-0.67 x$ (in the specimen from China only $0.5 x$ ) the length of postgenae; temples behind eyes \pm parallel or narrowed in dorsal view; transverse microsculpture on dorsal surface fine; punctation rather coarse and dense not only on sides, but also near occiput; absent in central dorsal area; frons with two pairs of large punctures in \pm quadrate arrangement, the anterior punctures deeper, larger, situated in oval grooves and accompanied by further - partly confluent - punctures; frontal furrows rather shallow, not reaching front margin; antennae long and slender, penultimate antennomeres not transverse.

Pronotum comparatively slender (see ratio); maximal width a short distance anterior to middle or nearer to anterior angles; in median line posteriorly with a scratch-like impression; dorsal surface with microsculpture similar to head; position of discal punctures similar to $O$. medius.

Elytra very long (see ratio); punctation well-defined, not very coarse, but very dense, interstices approximately equal to diameter of punctures; rugose punctation only near scutellum; surface without distinct microsculpture, shining; scutellum with distinct microsculpture composed of isodiametric and transverse meshes, and with several punctures; macropterous; legs long and slender.

Abdomen with the area near the anterior margins of the terga mat due to distinct and extensive isodiametric microsculpture; the remaining tergal surfaces at most with very indistinct microsculpture and weakly iridescent; punctation dense and relatively fine, finer and sparser on terga VII - VIII than on anterior terga; palisade fringe at hind margin of tergum VII present.

ot: protarsomeres I - IV moderately dilated; sternum V and VI each centrally with small (much smaller than in $O$. medius) oval area with long, tomentose yellowish pubescence and rasp-like sculpture; sternum VII posteriorly weakly flattened and weakly concave to truncate hind margin; hind margin of sternum VIII truncate or weakly concave (Fig. 11h); lateral tergal sclerites of segment IX long, reaching, or slightly protruding over hind margin of tergum $X$, with one terminal seta, and apically without spine-like process (Fig. 11g); hind margin of sternum IX deeply concave, hind angles acute (Fig. 11f); ventral process of aedeagus apically pointed and with sinuate lateral margins, with long, but weakly sclerotized basal carina and with indistinct apical folds; internal sac with 6 sclerotized structures: a median basal, a median apical, a pair of straight lateral and a pair of bifid lateral structures; flagellum with ca. 10 - 15 coils (Figs $11 \mathrm{a}-\mathrm{e}$ ). \%: unknown.

Comparative notes: From other Eastern Palaearctic congeners with dark body and sometimes or always red elytra $(O$. latus gansuensis, $O$. medius, $O$. rost $i), O$. rufipennis is readily distinguished by the relatively longer elytra (cf. ratio EL/PL), smaller size, relatively larger eyes, and by the different shape and internal structures of the aedeagus.

Comments: The specimen from the Emai Shan differed from the two types in the slightly smaller eyes, the relatively shorter elytra, and in the lighter colour of the basal antennomeres. In addition, the $\sigma^{\prime}$ sternum IX was somewhat less oblong, the aedeagus was slightly larger, the ventral process somewhat broader, and the relative length of the sclerotized structures in the internal sac of the aedeagus differed slightly (Figs 11 a - e). These differences, however, may well be within the range of intraspecific variation, and in general, the arrangement and shapes of the internal structures are quite similar. Slight differences in the shape of the ventral process were also observed in the two type specimens, and the size and shape of the aedeagus is quite variable in $O$. punctatus, too (see section 4.8). Therefore, the specimen from China is here regarded as conspecific with the type material of $O$. rufipennis.

Distribution and bionomics: $O$. rufipennis has become known only from the type locality, "Orakami Marsh", which is in Nagasaki City (Japan: Kyüshü) and from the Emai Shan in Sichuan, China (SHARP, 1874; material examined; see also ZHENG, 1995). Remarkably, further records are unknown, although the external morphology of the species (length of wings, eye size etc.) suggests that it is capable of flight. 


\subsection{Othius atavus sp. $\mathrm{m}$.}

Figs 12 a - e

Type

Holotype ơ: China, Yunnan prov., Gaoligongshan mts., $90 \mathrm{~km}$ W of Baoshan, 26.-28. V.1995, lgt.

S. Becvar (NHMW).

\section{Diagnosis}

Measurements and ratios (HT): HL: 1.74; HW: 1.43; PW: 1.62; PL: 2.01; EL: 1.59; TiL: 1.59; TaL: 1.25 ; TL: 11.1; HL/HW: 1.21 ; HW/PW: 0.89; PL/PW: 1.25; EL/PL: 0.79; TiL/TaL: 1.27. In general appearance (size, colour, proportions) somewhat reminding of $O$. rufipennis. Most of body blackish; elytra dark reddish; external faces of tibiae and tarsi light brown to yellowish.
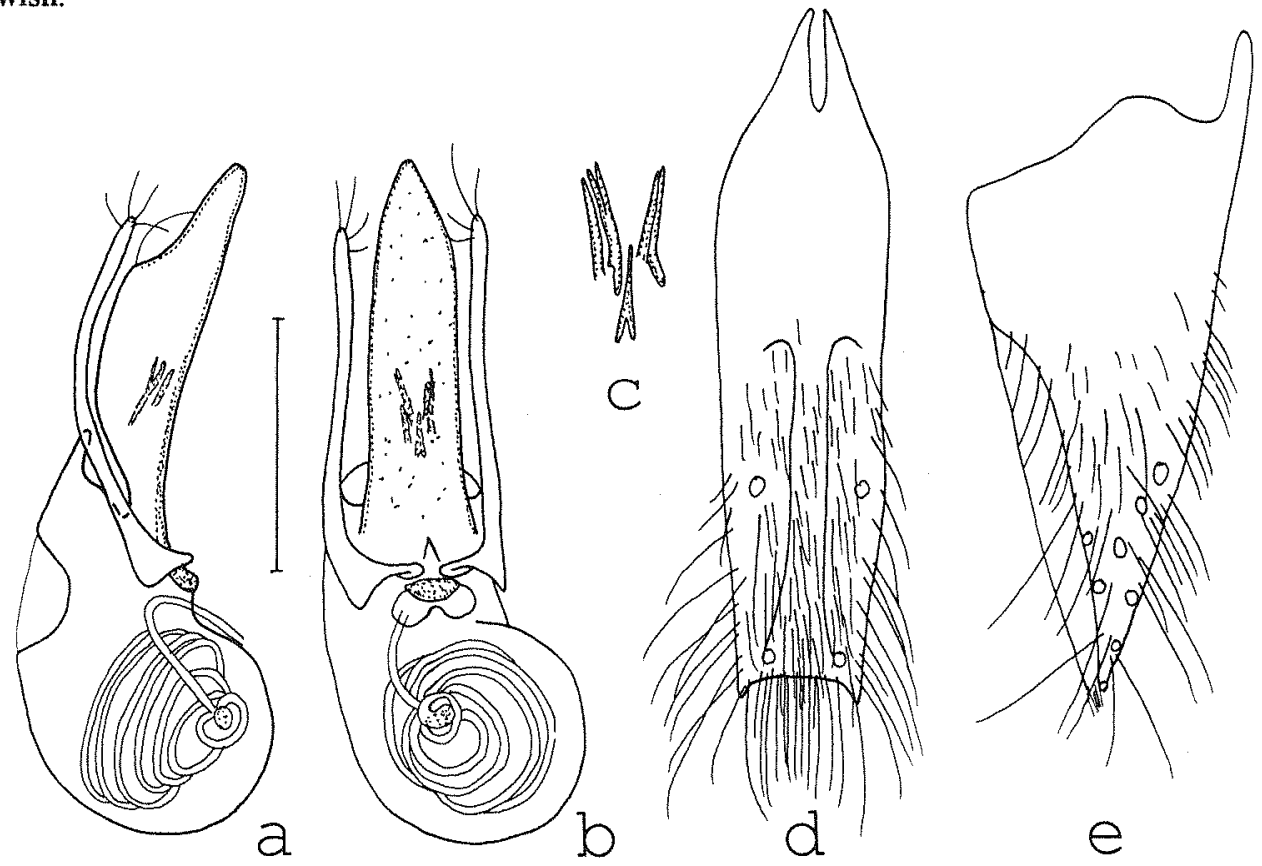

Figs 12 a - e: $O$. atavus sp. $n$.: aedeagus in lateral and in ventral view $(\mathbf{a}, \mathbf{b})$; internal structures in ventral view (c); on sternum IX (d); o lateral tergal sclerite IX and tergum $\mathrm{X}$ in lateral view (e); long setae partly omitted in d, e. Scales: a-b, d-e: $0.5 \mathrm{~mm}$; c: $0.25 \mathrm{~mm}$.

Head distinctly oblong and narrower than pronotum (cf. ratios), posteriorly subparallel; eyes large, ca. $0.5 \times$ the length of postgenae; macropunctation rather coarse and extensive, present on whole posterior half of dorsal surface; posterior pair of frontal punctures absent; frons anteriorly with shallow impression with 10 mostly large punctures; frontal furrows shallow; microsculpture fine and rather shallow, distinctly transverse; antennae long, antennomeres IV weakly oblong, V subquadrate, and VI - X weakly transverse.

Pronotum with maximal width in anterior half, but nearer to middle than to anterior angles, posteriorly weakly tapering; lateral margins in posterior half indistinctly concave in dorsal view; microsculpture and shine similar to head; arrangement and position of dorsal punctures similar to O. rufipennis, posterior puncture very close to hind angles; posterior median scratch-like impression distinct. 
Elytra long (see measurements and ratio); punctures relatively small, but well defined, much sparser than in $O$. rufipennis, interstices mostly distinctly wider than punctures; microsculpture similar to $O$. opacipennis, composed of distinct micropunctation; micropunctures slightly less dense, surface therefore with more shine than in $O$. opacipennis; scutellum mat due to very distinct microreticulation, several punctures present, though barely noticeable because of the microsculpture; hind wings present.

Abdomen with punctation very fine and distinctly less dense than in O. rufipennis; microsculpture near anterior and lateral tergal margins very distinct and isodiametric, on central and posterior surface of terga shallow and transverse; palisade fringe at hind margin of tergum VII present.

$\sigma^{*}$ : protarsomeres I - IV moderately dilated; sternum V and VI centrally with subcircular area with minute punctation and very sparse pubescence; sternum VII truncate, not flattened posteriorly; sternum VIII very oblong, with dark pubescence and posteriorly distinctly convex (shape similar to 9 sternum VIII in other species); sternum IX very long and slender, with mostly dark pubescence, posteriorly weakly concave and with numerous long dark setae (Fig. 12d); lateral tergal sclerites of segment IX similar to O. rufipennis, very long and apically acute, with one terminal seta, and just reaching hind margin of tergum X (Fig. 12e); aedeagus of remarkable morphology (shape similar to that in Atrecus and Parothius): ventral process extremely long and slender, basal carina short and indistinct; parameres very long, apically weakly dilated; internal sac with 5 very weakly sclerotized structures: an almost unsclerotized median apical, and two pairs of \pm fused lateral structures; flagellum rather wide and with ca. 10 - 15 coils (Figs 12 a - c).

o: unknown.

Derivatio nominis: The name (lat.: ancestor) alludes to the morphology of the aedeagus, which somewhat resembles that in Atrecus and Parothius and may therefore represent either an ancestral or an atavistic character.

Comparative notes and phylogenetics: From all its Palaearctic congeners $O$. atovus is distinguished by the remarkable morphology of the aedeagus. From those Eastern Palaearctic species with a palisade fringe at the hind margin of tergum VII, it is in addition separated by the following character combination: head without posterior pair of frontal punctures, elytra dark reddish and with distinct and dense micropunctation.

The external and the male secondary sexual characters (slender head, microsculpture and punctation of head and pronotum, and the shape and chaetotaxy of the lateral tergal sclerites IX) suggest a closer relationship with $O$. rufipennis. The flagellum is also rather short and wide, but otherwise the morphology of the aedeagus is completely different.

Distribution: The species is only known from the type locality in Yunnan, China. Its external morphology suggests that it is more widely distributed.

\subsection{Othius punctatus BERNHAUER, 1922}

Figs 13 a-1, 14, 15, Map 1 (p. 85)

Othius puncticeps BERNHAUER, 1916: 26 (nom. praeocc.)

Othius punctatus BERNHAUER, 1922: 124, nom. n.

Othiellus arisanus SHIBATA, 1973: 126ff., syn. n.

Othius arisanus (SHIBATA): SHIBATA (1986); ITO (1989).

\section{Types examined}

O. punctatus BERNHAUER: Holotype o" (aedeagus examined): Kiautschou, China/ puncticeps Brh., Typus unic, Bang-Haas/ Chicago NHMus., M. Bernhauer Collection (FMNH). 
O. arisanus (SHIBATA): Holotype $\sigma^{\prime}$ : (Alishan) Chiai - Hsien, Formosa, Aug. 7th, 1970, Coll. Y. Shibata/ [Holotype] Othiellus arisanus, $0^{*}$, Y. Shibata, 1973 (TUA). Paratypes: $10^{\circ}, 2 \% \%$, same data as holotype (cShY, cAss); $20^{\pi} \sigma^{\star}, 2{ }^{\circ}+$, same data as holotype, but Aug. 8th (cShY, cAss).

\section{Additional material examined}

China: Zhejiang: $30^{7} 0^{7}, 1$ if [slightly teneral], Tienmushan, 29.IV.1993, leg. de Rougemont (cRou, cAss). Hunan: 19 , NW-Hunan, Wulingyuan, N Dayong, Zangiajie, 450m, 30.X.1993, leg. Schillhammer (NHMW). Shaanxi: 19, Nanwutai, 17.DX.1995, leg. de Rougemont (cRou); 10*, Qin Ling Shan, 108.49E, $33.55 \mathrm{~N}$, River Valley, $40 \mathrm{~km}$ S Xian, Autoroute $\mathrm{km} 50$, river bank, 1200m, 31.VIII.1995, leg. Pütz (cAss); 277. Qin Ling Shan, 108.49E, 34.00N, River Valley, $30 \mathrm{~km}$ SSW Xian, Autoroute km 33, river bank, $600 \mathrm{~m}$, 31.VIII.1995, leg. Pütz, Wrase (cSch). Sichuan: 10, 1 \% , Emei Shan, 7.X.1985, leg. de Rougemont (cRou, cAss). Gansu: 10", Maijishan, VIII.1986, leg. de Rougemont (cRou).

Taiwan: $40^{\circ} \sigma^{\circ}, 1$ i [teneral], Chiai Hsien, Alishan, Sister Ponds, 2180m, 26.IV.1990, leg. Smetana (cSme,

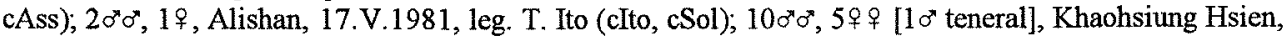

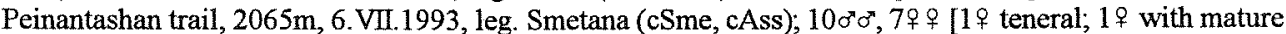
eggs in ovaries], Khaohsiung Hsien, 2 km E Tien Chih, Hwy. 20, 2400m, 22.VII.1993, leg. Smetana (cSme, cAss); $20^{\circ} 0^{\circ}$, Khaohsiung Hsien, Kuanshan trail at Kaunshanchi River, 2400m, 20. VII.1993, leg. Smetana (cSme); $1 \sigma^{\circ}, 29$ ㅇ [1 9 teneral], Khaohsiung Hsien, $4 \mathrm{~km} \mathrm{E} \mathrm{Yakou,} \mathrm{2600m,} \mathrm{23.} \mathrm{VII.1993,} \mathrm{leg.} \mathrm{Smetana} \mathrm{(cSme,}$ cAss); 10", 2q $q$, Nantou Hsien, Piluchi, 2300m, 3.VIII.1983, leg. Y. Shibata (cShY); $10^{\circ}, 4 q \%$, Hualien Hsien, Filu, 2400m, 10. VIII.1977, leg. Y. Shibata (cShY, cAss).

\section{Diagnosis}

Measurements and ratios (range, arithmetic mean; $\mathrm{n}=73$ ): $\mathrm{HL}: 1.07-1.43,1.25 ; \mathrm{HW}: 0.88-1.17$, 1.04; PW: 1.04 - 1.40, 1.23; PL: 1.28 - 1.77, 1.53; EL: 0.88 - 1.31, 1.08; TiL: 0.98 - 1.31, 1.14; TaL: 0.73 - 1.01, 0.87; TL: 6.4 - 11.5, 8.5; HL/HW: 1.13 - 1.26, 1.20; HW/PW: 0.80 - 0.89, 0.85; PL/PW: 1.16 - 1.34, 1.25; EL/PL: 0.61 - 0.78, 0.71; TiL/TaL: 1.21 - 1.44, 1.31.

In facies, punctation and microsculpture similar to $O$. rufipennis.

Colour of body \pm uniformly dark to blackish brown, with the antennae only slightly lighter; hind margin of abdominal segment VIII, mouthparts, and legs yellowish to light brown, with the internal faces of the tibiae and parts of the femora in mature specimens bright reddish or infuscate to various degrees.

Head with shape similar to $O$. rufipennis, distinctly narrower than pronotum; temples behind eyes usually \pm parallel, occasionally weakly widened or narrowed in dorsal view; microsculpture shallow, predominantly composed of transverse striae; macropunctation variable, on average denser in material from the Chinese mainland than in specimens from Taiwan; eyes slightly smaller than in $O$. rufipennis, but size highly variable, $0.40-0.58 \mathrm{x}$ the length of postgenae in lateral view; posterior pair of frontal punctures present, sometimes accompanied by additional punctures; frontal furrows in most specimens weakly impressed, sometimes \pm absent; antennae slender, penultimate antennomeres \pm subquadrate, not distinctly transverse.

Pronotum with shape similar to O. rufipennis, maximal width in anterior half, often nearer to middle than to anterior angles; lateral margins in posterior half usually straight to weakly convex; microsculpture weak and composed of transverse striae; position of discal punctures similar to $O$. rufipennis, but posterior puncture more distant from hind angles (Fig. 131).

Elytra relatively long, but absolute and relative length subject to considerable intraspecific variation (see measurements and Fig. 15); punctation very variable, usually well-defined and interstices on average of similar width as punctures, near scutellum often with confluent punctation; interstices sometimes with traces of shallow microsculpture; macropterous; scutellum with distinct microsculpture usually predominantly composed of isodiametric and/or transverse meshes, and with several punctures; legs, especially tarsi, shorter than in O. rufipennis. 
Abdomen with punctation similar to $O$. rufipennis; microsculpture near anterior margins of terga usually not distinctly different from that of central and posterior tergal areal, only occasionally with traces of microreticulation; palisade fringe at hind margin of tergum VII present.
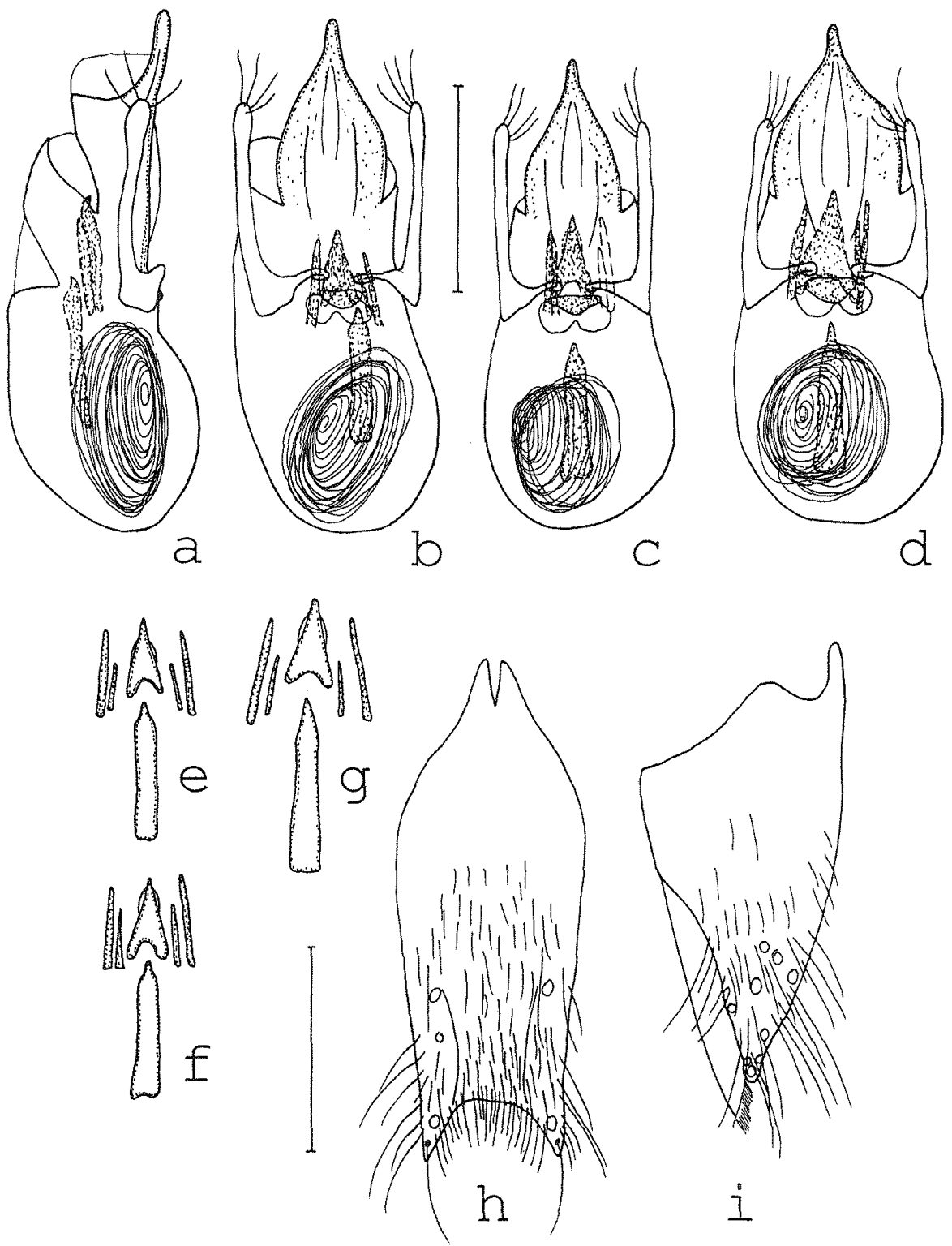

Figs 13 a - i: $O$. punctatus BERNHAUER (h: HT): aedeagus in lateral and in ventral view of $\sigma^{\text {n from }}$ Zhejiang, China (a, b); aedeagi in ventral view of $0^{*} 0^{*}$ from Alishan, Taiwan (c), and from Sichuan, China (d); internal structures of $\sigma^{x} \sigma^{x}$ from Zhejiang (e), Taiwan (f), and Sichuan (g); $\sigma^{x}$ sternum IX (h); o lateral tergal sclerite $\mathrm{IX}$ and tergum $\mathrm{X}$ in lateral view (i). 


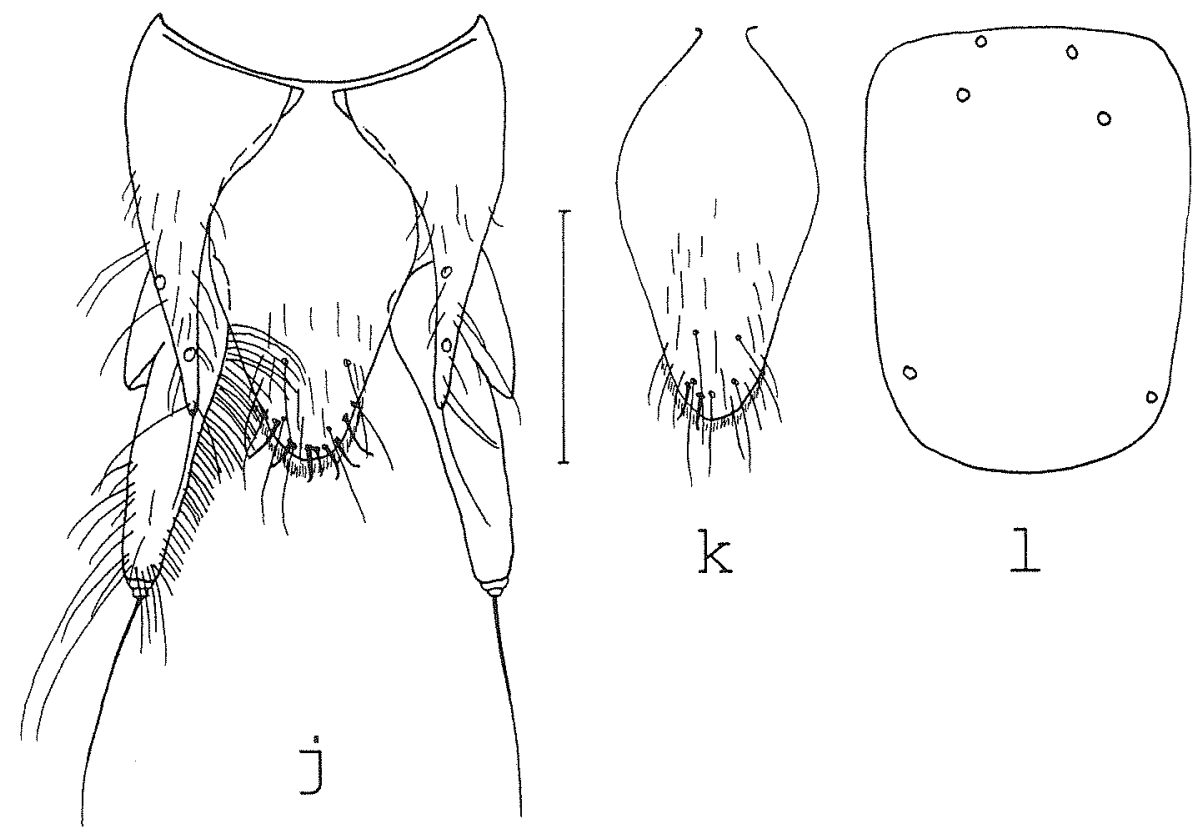

Figs 13 j - 1 : O. punctatus BERNHAUER (h:HT): + terminalia (j); tergum X of $q$ from Taiwan (k); schematic representation of pronotal punctation pattern (1); long setae partly or completely omitted in $\mathrm{i}, \mathrm{j}$. Scales: 0.5 $\mathrm{mm} ; 1$ without scale.

$0^{*}$ : protarsomeres I - IV moderately dilated; sternum V and VI with rather large, usually ellipsoid, sometimes subcircular central callosities of somewhat variable size and shape; callosities usually shallowly impressed, with dark tomentose pubescence, which is directed postero-mediad and which is sometimes denser on sternum V than on sternum VI, rasp-like microsculpture indistinct; sternum VII posteriorly concave and distinctly flattened or shallowly impressed; sternum VIII with dense and rather long black pubescence, posteriorly weakly concave, centrally with shallow, \pm triangular impression, without row of marginal setae; sternum IX with dense and mostly blackish pubescence, posteriorly broadly and moderately to deeply concave (Fig. 13h); lateral tergal sclerites of segment IX with numerous long and one or two terminal setae, apically acute, shorter than in $O$. rufipennis, nearly reaching hind margin of tergum $X$ in lateral view (Fig. 13i); aedeagus with apically dilated parameres; ventral process without basal carina, but with pair of pronounced and long lateral folds and with pair of less distinct apical folds of variable length; internal sac with 6 sclerotized structures: a long median basal, a somewhat triangular apical, a pair of longer straight lateral, and a pair of shorter straight lateral pieces; flagellum thin and with ca. 30 coils (Figs $13 \mathrm{a}-\mathrm{g}$ ).

: protarsomeres I - IV weakly dillated, sexual dimorphism usually pronounced; tergum X with very variable number $(0-7)$ of modified setae (Figs $13 \mathrm{j}-\mathrm{k}$ ); inner margin of styli with fringe of numerous setae, which are short and thin near apices of styli and very long and stout near the bases.

Comparative notes: For distinction from $O$. rufipennis and $O$. maculativentris ZHENG see the diagnosis above and the diagnosis of the latter species, respectively. From the externally also similar $O$. atavus, $O$. punctatus is distinguished especially by the presence of the posterior pair of frontal punctures on the head, by the absence of distinct elytral microsculpture, and by the primary and secondary sexual characters. 


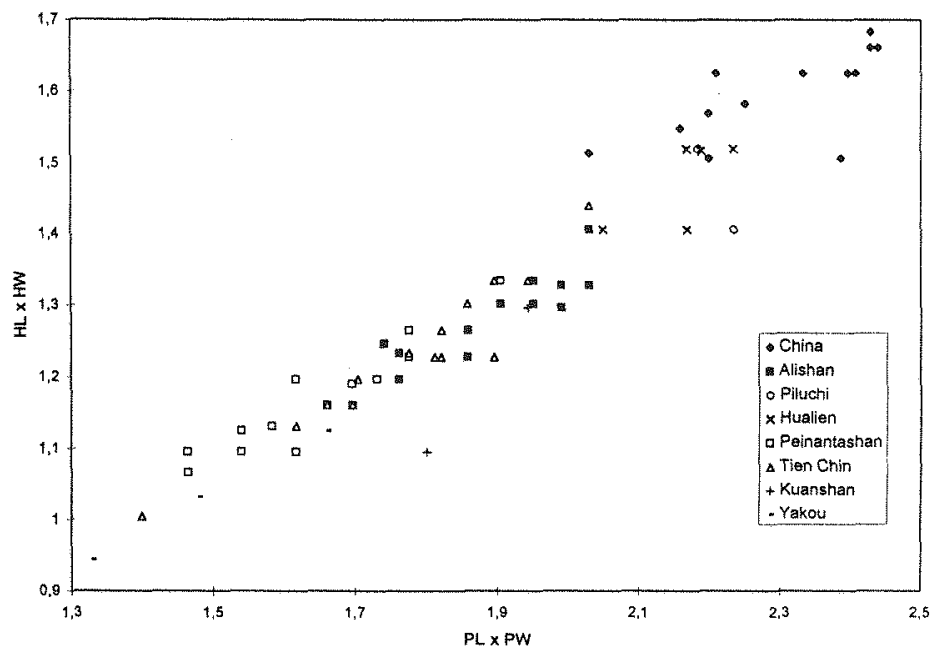

Fig. 14.: O. punctatus BERNHAUER: intraspecific variation of head and pronotum size.

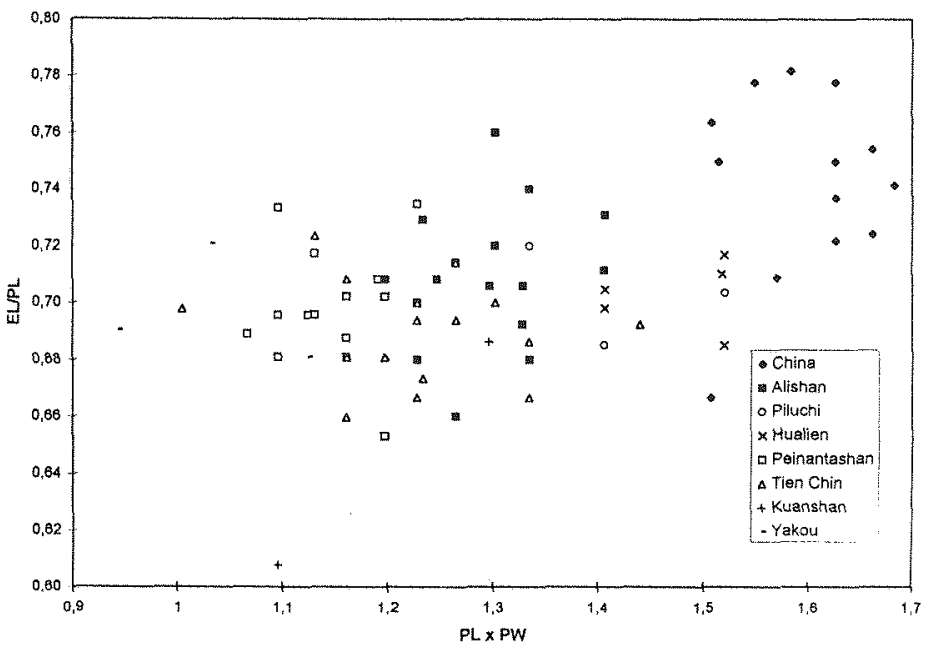

Fig. 15: O. punctatus BERNHAUER; intraspecific variation of relative elytral length in relation to pronotum size.

Comments: In the original description, SHIBATA (1973) compares $O$. arisanus (type locality: Alishan) with $O$. medius and two - phylogenetically distant - species of the Western Palaearctic $O$. subuliformis group ( $O$. myrmecophilus KIESENWETTER, which is now a synonym of $O$. subuliformis STEPHENS, and $O$. korgei COIFFATT); there is, however, no reference to $O$. punctatus. The material from Taiwan examined here was slightly smaller (no overlap in HL; little overlap in HW, PW, TiL, and TaL) and had somewhat shorter elytra than the specimens from the Chinese mainland; in addition, the punctation on the head was on average less dense. Differences in size, elytral length and punctation were also observed between the Taiwanese populations; e. g. the specimens from Alishan were larger than those from Peinantashan and from Yakou (no or only little overlap) (see Figs 14, 15). ITO (1989) observed differences in colour and punctation between the material 
from Alishan and that from Houhuanshan. The specimens from Gansu, Sichuan and Shaanxi also differed from the material of other localities in that the colour of the legs was bright reddish and that the ventral process was slightly wider. Considerable intraspecific variation in external characters, especially in size, is what can be expected in a widely distributed species, particularly in island populations, and is a well-known phenomenon in several widespread Othius species both from the Eastern Palaearctic and from the Western Palaearctic region, e. g. O. medius, O. latus, O. rosti (see above), and O. lapidicola MÄRKEL \& KIESENWETTER (ASSING, 1997a). The shorter elytra in the material from Taiwan (Fig. 15) are hardly surprising; in many island Staphylinidae, particularly in soil-dwelling and more or less $\mathrm{K}$-selected species, the wings are reduced as a result of selection operating against active dispersal by flight. I have been unable to find any further constant differences between the material from the Chinese mainland and that from Taiwan, neither in external morphology nor in the primary and secondary sexual characters. Therefore, $O$. arisanus SHIBATA is here regarded as junior synonym of $O$. punctatus BERNHAUER.

Distribution and bionomics: $O$. punctatus is widespread in China (Sichuan, Gansu, Shaanxi, Shandong, Hunan, Zhejiang) and Taiwan. In Taiwan, $O$. punctatus is apparently the most common and widely distributed Othius species (Map 1, p. 85). In addition to the localities indicated above it was also collected on the Houhuanshan, Nantou (ITO, 1989). The species seems to inhabit a wide range of altitudes; the material examined was collected from as low as $450 \mathrm{~m}$ (China) up to $2600 \mathrm{~m}$ (Taiwan). The type specimens of $O$. arisanus "were collected among the roots of grasses near the margin of a pond" (SHIBATA, 1973); some of the material from Shaanxi, too, was collected near water. Adult specimens have been observed from April through May and from July through October (ITO, 1989; SHIBATA, 1973; and material listed above). Teneral specimens were collected in April and July; the ovaries of a dissected $\&$ collected in July contained a mature egg.

\subsection{Othius maculativentris $\mathbb{Z H E N G}, 1995$}

Figs $16 \mathrm{a}-\mathrm{h}$

\section{Othius maculativentris ZHENG, 1995: $344 \mathrm{f}$.}

\section{Material examined}

China, Sichuan: $20^{\circ} 0^{\circ}, 3{ }^{\circ}+$ [partly teneral], Gongga Shan, Hailuogou, $29^{\circ} 35 \mathrm{~N}, 102^{\circ} 00 \mathrm{E}$, in front of glacier 1, 2800m, deep forest litter between stones, 9. VII.1996, leg. Smetana, Farlač \& Kabátek (cSme, cAss); 1 q [teneral], Gongga Shan, Hailuogou, $29^{\circ} 35 \mathrm{~N}, 102^{\circ} 00 \mathrm{E}$, above camp 3, 3200m, 7.VII.1996, leg. Smetana, Farlač \& Kabátek (cSme); 1 \%, Gongga Shan, route Camp 3 - glacier, Moxi river, 3300m, 22.VII. 1994, leg. Anton (cSme); $250^{\circ} 0^{\circ}, 20$ \% \& [partly teneral], Gongga Shan, Hailougou Glacier Park, $102^{\circ} 04 \mathrm{E}, 29^{\circ} 36 \mathrm{~N}$, river valley ca. $1 \mathrm{~km}$ above Camp 1, 2100m, 27.-31.V.1997, leg. Pütz, Schülke \& Wrase (cSch, cAss).

\section{Diagnosis}

Measurements and ratios (range, arithmetic mean; $\mathrm{n}=52$ ): HL: $1.40-1.62,1.52$; HW: $1.22-1.42$, 1.30; PW: 1.34 - 1.56, 1.45; PL: 1.65 - 1.92, 1.75; EL: 1.10 - 1.37, 1.25; TiL: 1.31 - 1.59, 1.47; TaL: 0.98 - 1.16, 1.06; TL: 8.2 - 12.0, 9.4; HL/HW: 1.11 - 1.22, 1.17; HW/PW: 0.86 - 0.94, 0.90; PL/PW: 1.19 - 1.30, 1.24; EL/PL: 0.62 - 0.77, 0.70; TiL/TaL: 1.28 - 1.47, 1.38 .

In external appearance similar to $O$. punctatus, but on average larger.

Colour of body similar to $O$. punctatus, but legs on average more extensively infuscate and abdominal segment VIII only indistinctly lighter posteriorly (in $O$. punctatus usually distinctly bicoloured).

Head larger and wider than in $O$. punctatus (cf. measurements), posteriorly subparallel or weakly widened; eye size somewhat variable, similar to $O$. punctatus; macropunctation dense, rather coarse, and more extensive than in average $O$. punctatus, often practically the whole posterior half of head densely punctured and only small central dorsal areas of head free of punctures. 

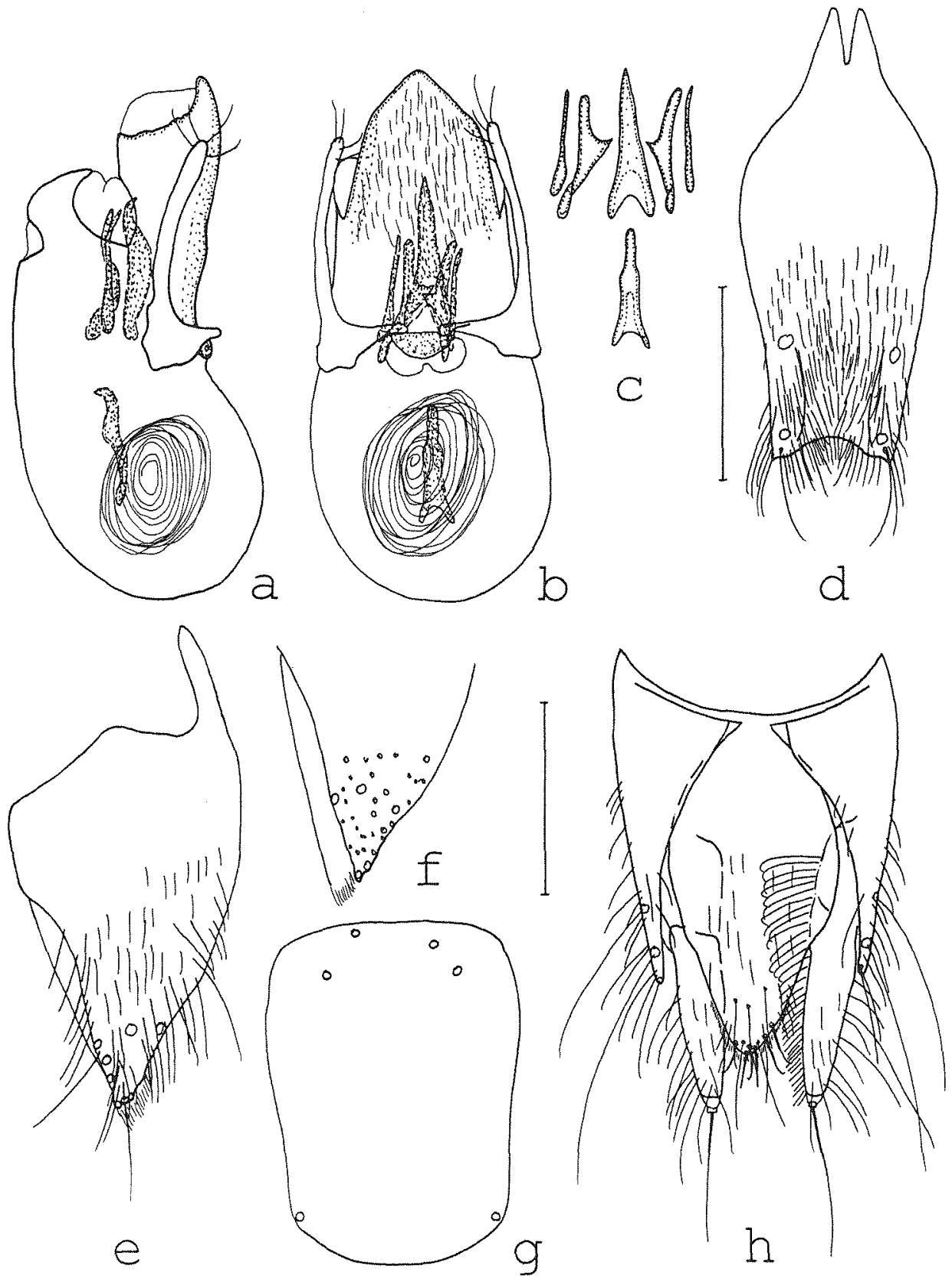

Figs $16 \mathfrak{a}-\mathbf{h}$ : $O$. maculativentris ZHENG: aedeagus in lateral and in ventral view (a, b); internal structures in ventral view (c); $\sigma^{n}$ sternum IX (d); $\sigma^{\circ}$ lateral tergal sclerite IX and tergum X in lateral view (e); apices of $\sigma^{*}$ lateral tergal sclerite IX and tergum $\mathrm{X}$ of further $\sigma^{*}(\mathbf{D})$; $q$ terminalia $(\mathrm{g})$; schematic representation of pronotal punctation pattern (h); long setae partly or completely omitted in $\mathrm{d}-\mathrm{g}$. Scales: $0.5 \mathrm{~mm}$; $\mathrm{h}$ without scale. 
Posterior pair of frontal punctures present, but sometimes difficult to distinguish from surrounding additional punctures; anterior frontal punctures usually accompanied by further punctures; frontal furrows in most specimens distinct; microsculpture relatively shallow, predominantly composed of transverse striae; antennae as in $O$. punctatus.

Pronotum on the whole similar to $O$. punctatus, but lateral margins in posterior half in most specimens weakly concave; microsculpture shallow, usually composed of transverse striae, sometimes with interspersed isodiametric or transverse meshes; pronotal punctation pattern similar to $O$. punctatus, but posterior puncture very close to hind angles (Fig. 16h).

Elytra long, but absolute and relative length subject to some intraspecific variation; punctation similar to $O$. punctatus; interstices usually \pm opaquely shining, sometimes with traces of shallow microsculpture; length of hind wings variable, in the material examined ca. $1.5-2.5 \mathrm{x}$ the length of elytra; scutellum with \pm distinct microsculpture usually predominantly composed of transverse meshes and striae, and with several punctures.

Abdomen with punctation and microsculpture similar to $O$. punctatus; palisade fringe at hind margin of tergum VII present.

$\sigma^{*}$ : dilatation of protarsomeres I - IV variable, usually pronounced, occasionally moderate; sternum $\mathrm{V}$ and VI with small subcircular, weakly elevated central callosities of somewhat variable size and shape, with not very dense dark pubescence and shallow microsculpture; callosity of sternum $\mathrm{V}$ even smaller than that of sternum VI; sternum VII posteriorly weakly concave, only weakly flattened; sternum VIII with dense and rather long black pubescence, its hind margin weakly concave to truncate, centrally \pm flattened, and at most with few short marginal setae (Fig. 16d); sternum IX with dense and mostly blackish pubescence, posteriorly broadly and moderately to deeply concave; lateral tergal sclerites of segment IX similar to $O$. punctatus, but broader in lateral view (Fig. 16e, f); aedeagus completely different from that in $O$. punctatus: ventral process broad and short, apically weakly pointed, without distinct lateral folds, but with median apical carina; basal carina indistinct; dorsal membranous region very small and situated much more distally than in $O$. punctatus and related species; parameres apically weakly dilated and basally with \pm irregular outline; internal sac with 6 sclerotized structures: a long median basal, an approximately equally long median apical, a pair of thin long lateral, and a pair of stouter bifid lateral pieces; flagellum thin and with ca. 15 coils (Figs $16 \mathrm{a}-\mathrm{c}$ ).

$q$ : dilatation of protarsomeres I - IV variable, weak to moderate, in some $q q$ as strongly dilated as in $0^{\prime \prime} \sigma^{x}$ with relatively weakly dilated protarsomeres; sternum VIII posteriorly of variable shape, weakly concave to weakly convex; tergum X more distinctly pointed than in $O$. punctatus, posteriorly with several long, rather thin and apically curved modified setae; inner margin of styli with fringe of numerous setae, which are short and thin near apices of styli and very long and stouter near the bases (Fig. 16g).

Comparative notes: From the externally similar $O$. punctatus, $O$. maculativentris is readily distinguished by the larger and wider head, the darker legs, the different pronotal punctation pattern (posterior pronotal puncture very close to hind angles), the posteriorly usually concave pronotal lateral margins, and especially by the completely different shape and internal structures of the aedeagus.

Comments: Repeated requests for a loan of the types of the species have remained unanswered. Nevertheless, there is little doubt that the material which the above diagnosis is based on in fact refers to $O$. maculativentris. The most conclusive evidence is provided by the drawing of the aedeagus in ZHENG (1995); the internal structures are not illustrated, but the shape of the aedeagus is very characteristic. In addition, the (few) external characters indicated in the original description are in good agreement with the material studied. Finally, O. maculativentris was described from Sichuan (Wolong), 
not far from where the specimens indicated above were collected, and both the external morphology (eye size, length of hind wings, presence of palisade fringe) and the altitude at which the species was taken (see below) suggest that it is probably more widely distributed.

Distribution and bionomics: The species is presently known only from Wolong and Gongga Shan in Sichuan, western China, where it was collected at altitudes between $1920-3300 \mathrm{~m}$ (ZHENG, 1995; material examined). Many of the specimens taken at the end of May and in July (see above) were teneral.

\subsection{Othius lubricus sp. n.}

Figs $17 \mathrm{a}-\mathrm{g}$

\section{Types}

Holotype $o^{*}$ : China, Yunnan, Kunming, Western Hills, $1800 \mathrm{~m}, 25^{\circ} 04 \mathrm{~N}, 102^{\circ} 41 \mathrm{E}, 24$.VII.1996, C68/ collected by A. Smetana, J. Farlač and P. Kabátek (cSme). Paratypes: $30^{\circ} 0^{\circ}, 2$ 2 우, same data as holotype (cSme, cAss); 10, 1ㅇ, China: Yunnan, Kunming, 9.X.1985, Rougemont (cRou, cAss); 10", Yunnan, 2300m, 24.57N 102.38E, Xishan mts., 27/6.1993,1 Vit Kubán leg. (NHMB); $20^{*} 0^{\star}$, 1 if [2 ex. teneral], Yunnan, Xishan Mts., 2300m, 24.57N 102.38E, 19 May 1993, Bolm lgt. (NHMB, cAss).

\section{Diagnosis}

Measurements and ratios (range, arithmetic mean; $n=12$ ): HL: $1.49-1.59,1.55$; HW: 1.37 - 1.53, 1.43; PW: 1.56 - 1.71, 1.63; PL: 1.83 - 2.04, 1.96; EL: 1.31 - 1.39, 1.43; TiL: 1.43 - 1.56, 1.50; TaL: 1.13 - 1.28, 1.20; TL: 8.7 - 11.6, 10.0; HL/HW: 1.04 - 1.13, 1.08; HW/PW: 0.85 - 0.93, 0.88; PL/PW: 1.15 - 1.27, 1.20; EL/PL: 0.67 - 0.76, 0.71; TiL/TaL: 1.14 - 1.34, 1.25 .

In external appearance similar to and apparently the sister species of $O$. apicalis CAMERON; for a detailed diagnosis of that species see ASSING (1998a).

Colour of body black, legs dark brown to blackish, tarsi, palpi and hind margins of abdominal segments VII and VIII light brown to reddish brown.

Head smaller, more slender and with denser macropunctation than in $O$. apicalis; eyes larger, in lateral view $0.58-0.66 \mathrm{x}$ the length of postgenae; outline of head weakly widened posteriorly; microsculpture composed of transverse striae and transverse meshes, but very shallow, surface therefore shining; posterior pair of frontal punctures present and relative large; frontal furrows relatively shallow; antennae slender, penultimate antennomeres weakly transverse.

Pronotum of similar shape and with similar punctation pattern as in $O$. apicalis (cf. Fig. $1 \mathrm{~g}$ in ASsING, 1998a); microsculpture reduced to very indistinct traces visible only at higher magnifications, surface therefore very shiny.

Elytra relatively long (see measurements); microsculpture indistinct; punctation much denser than in $O$. apicalis, diameter of interstices clearly smaller than that of punctures; scutellum with distinct microsculpture composed of transverse meshes and with several punctures.

Abdomen with clearly denser punctation than in $O$. apicalis; microsculpture both near anterior margins of terga and on posterior tergal area very weak and shallow; palisade fringe at hind margin of tergum VII present.

o": protarsomeres I - IV strongly dilated; sternum V and VI without modifications; sternum VII weakly concave posteriorly; sternum VIII with not very dense black pubescence, its hind margin \pm truncate, centrally with small and shallow impression of \pm triangular shape, without marginal setae; sternum IX with relatively sparse, long and mostly blackish pubescence, posteriorly deeply concave (Fig. e); lateral tergal sclerites of segment IX slender almost reaching hind margin of tergum $X$ (Fig. 17f), with one terminal seta. 

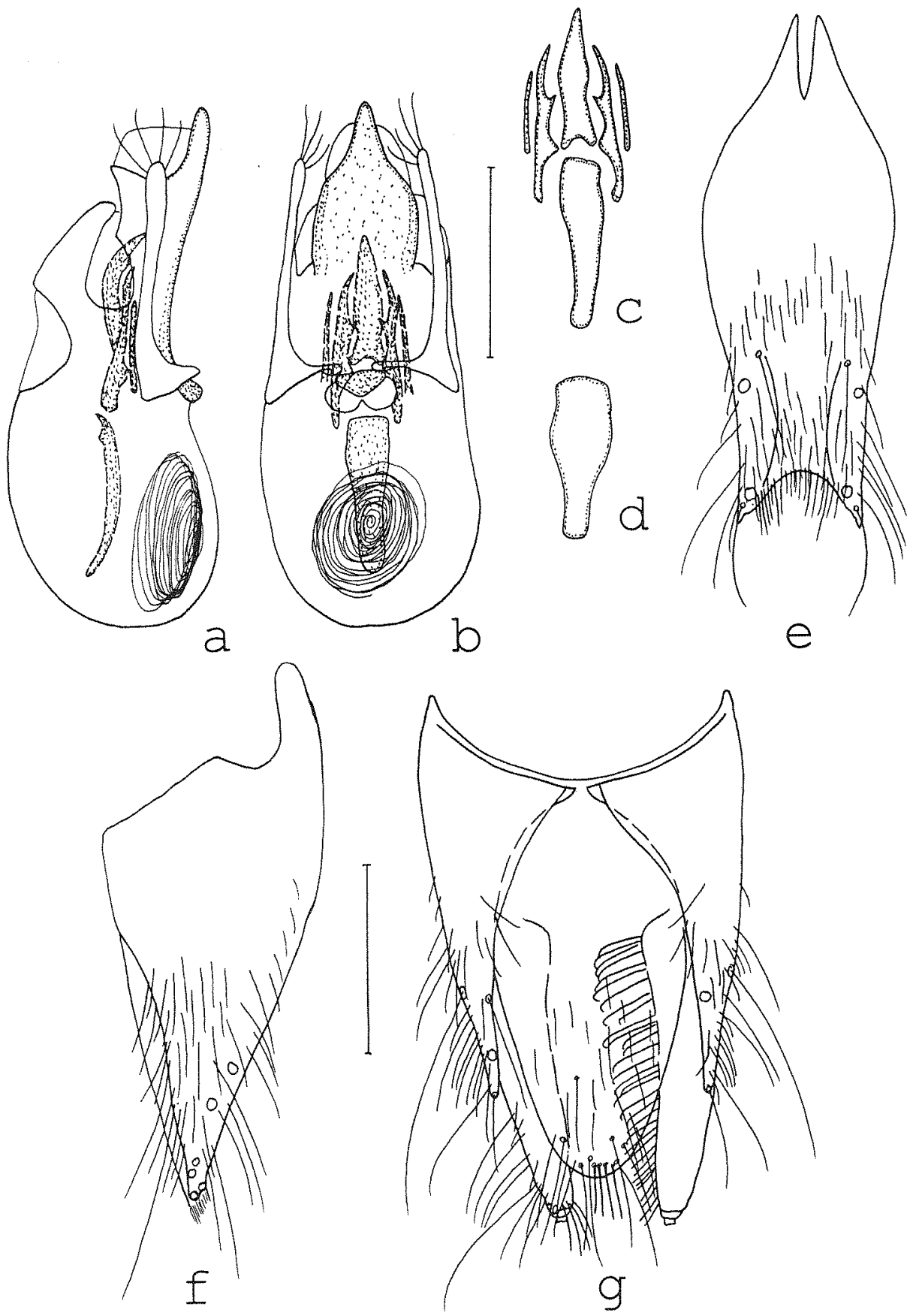

Figs 17 a - g: $O$. lubricus sp. n: aedeagus in lateral and in ventral view (a, b); internal structures of PT in ventral view (c); basal median structure of HT in ventral view (d); $0^{*}$ sternum IX (e); $\sigma^{*}$ lateral tergal sclerite IX and tergum $\mathrm{X}$ in lateral view (f); ? terminalia (g); long setae partly or completely omitted in e - $\mathrm{g}$. Scales: $0.5 \mathrm{~mm}$. 
General morphology of aedeagus similar to that of $O$. apicalis; ventral process without distinct carinae or folds, apically acutely pointed and with sinuate lateral margins in ventral view; parameres apically weakly dilated, relatively shorter than in $O$. apicalis; internal sac with 6 sclerotized structures: a long and distally wide median basal, an almost equally long median apical, a pair of thin long lateral, and a pair of stouter, characteristically shaped lateral pieces; flagellum thin and with ca. 25 coils (Figs $17 \mathrm{a}-\mathrm{d}$ ).

q: protarsomeres I - IV distinctly dilated, only slightly less so than in o", sexual dimorphism therefore not very pronounced; hind margin of sternum VIII weakly convex and with numerous yellowish apical setae; tergum $X$ posteriorly broadly rounded, setae unmodified; inner margin of styli with fringe of numerous long and stout setae (Fig. 17g).

Derivatio nominis: The name (lat:: smooth, slippery) refers to the remarkably shiny surface of the head and especially of the pronotum.

Comparative notes: From the similar $O$. apicalis, $O$. lubricus is readily distinguished by the denser punctation of head, elytra and abdomen, by the presence of a pair of frontal punctures, by the distinctly larger eyes, and by the o primary and secondary sexual characters. $O$. taiwanus ITO, a species with an equally shining pronotum, is much larger, its head is distinctly more massive, the eyes are relatively smaller, the pronotum is more strongly widened anteriorly, the o primary sexual characters (size and shape of aedeagus, internal structures) are completely different, and the $q$ tergum $\mathrm{X}$ is equipped with modified setae posteriorly.

Comments: As can be inferred from the drawings of the aedeagal outlines - the internal structures are either not or inadequately illustrated - and from the external characters referred to, none of the species described by ZHENG (1995), all of them from Sichuan, is conspecific with O. lubricus.

Distribution and bionomics: The species is known only from Yunnan, southwestern China. Both its external morphology (eye size, wing development) and the relatively low altitude (1800 $2300 \mathrm{~m}$ ) of the localities, where the material was collected, suggest a wider distribution. Two specimens taken in May were teneral.

\subsection{Othius badius ZHENG, 1995}

Figs $18 \mathrm{a}-\mathrm{b}$

Othius badius ZHENG, 1995: 341.

\section{Type examined}

Paratype $:$ : 1982. VII.28, II-38 [further data in Chinese letters, according to original description: Sichuan, Mt. Emei, 1752 - 2070m, leg. Lu Ying] (cAss).

\section{Additional material examined \\ 1ㅇ, China, Sichuan, Emei Shan, VI.1992 (cAss).}

\section{Diagnosis}

Measurements and ratios (range, $n=2$ ): HL: $1.74-1.80$; HW: $1.37-1.43$; PW: 1.37 - 1.43; PL: 1.80 1.85; EL: 1.31 - 1.37; TiL: 1.53 - 1.62; TaL: 1.07 - 1.13; TL (abdomen fully extracted): 10.6 - 11.2; HL/HW: 1.25 - 1.27; HW/PW: 1.0; PL/PW: 1.36 - 1.38; EL/PL: $0.69-0.70$; TiL/ TaL: 1.43.

Colour of body \pm uniformly reddish brown to dark brown, the head slightly darker.

Head rather large and distinctly oblong, behind eyes \pm subparallel; eyes relatively small, 0.28 $0.33 x$ the length of postgenae in lateral view; macropunctation relatively dense and extensive, covering the whole posterior half of dorsal surface (nontype specimen) or nearly so; posterior pair of frontal punctures present; frontal furrows shallowly sulcate. 


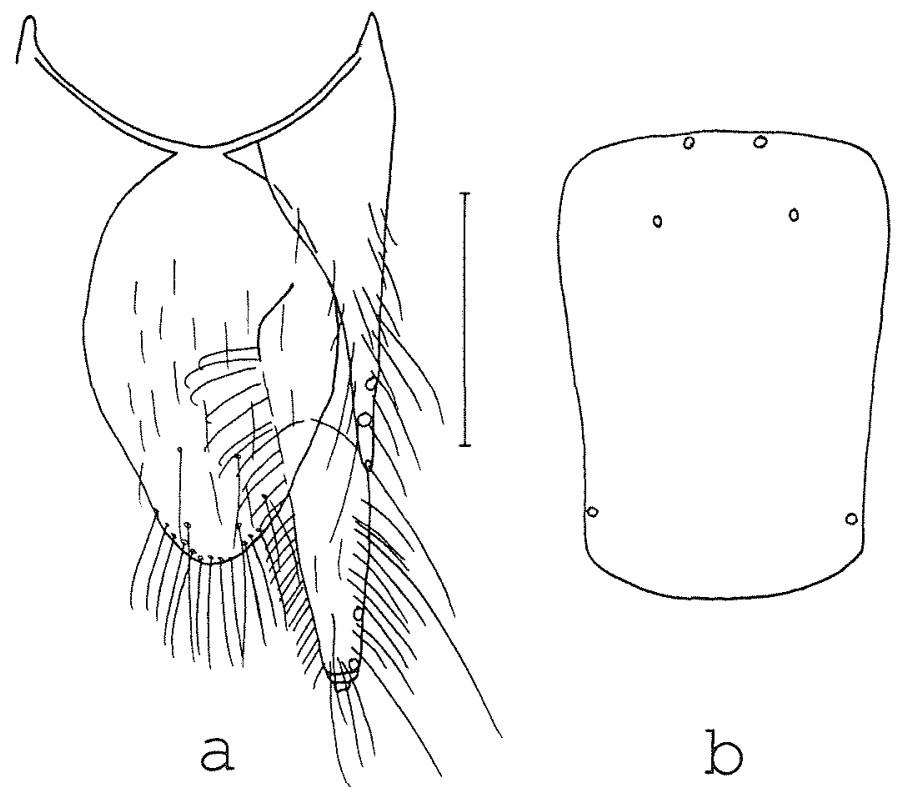

Figs 18 a - b: $O$. badius ZHENG: o terminalia (a); schematic representation of pronotal punctation pattern (b); long setae partly omitted in a. Scale: $0.5 \mathrm{~mm}$; b without scale.

Microsculpture on most of dorsal surface predominantly composed of isodiametric and short transverse meshes, near occiput and laterally also of transverse striae and meshes; antennae long and slender, antennomeres III ca. $3 x$ longer than wide, IV - VII distinctly oblong, and $X \pm$ subquadrate.

Pronotum of very characteristic shape, very slender, as wide as head (see ratios) and dorsally flattened, so that the full length of both lateral margins is visible when viewed from above (in other species of Othius the lateral margins are usually not visible at and near the anterior angles in dorsal view); outline of pronotum only weakly narrowed posteriorly; lateral margins in posterior half weakly sinuate; posterior angles more distinct than is usually the case in Othius, and hind margin only weakly convex; discal puncture near lateral margin, but distinctly distant from hind angles (Fig. 18b); microsculpture fine, predominantly composed of transverse striae and long transverse meshes; posterior median scratch-like impression present.

Elytra relatively long (see measurements); punctation well-defined but not very coarse and moderately dense, interstices on average wider than punctures; microsculpture indistinct; surface with weak opaque shine; scutellum with rather shallow transverse microsculpture and with several punctures; hind wings fully developed.

Abdomen with distinct, but fine punctation; microsculpture extremely shallow, barely visible even at higher magnifications, transverse microsculpture only slightly more distinct near anterior margins of terga; palisade fringe at hind margin of tergum VII present.

o: not available for examination.

$\%$ : protarsomeres I - IV moderately dilated; hind margin of sternum VIII centrally obtusely pointed and with numerous yellowish apical setae; tergum $X$ posteriorly broadly rounded, setae near hind margin long and unmodified; inner margin of styli with fringe of not particularly dense setae, which are rather short and thin posteriorly, and long and stout anteriorly (Fig. 18a).

Comparative notes: $O$. badius is distinguished from other Chinese congeners based on external characters alone: the \pm uniform brown colour, the long antennae, the relatively small eyes in 
combination with the presence of a palisade fringe and fully developed wings, the extensive punctation of the head, and especially the characteristic shape and punctation pattern of the pronotum.

Distribution and bionomics: The species has become known only from the Emai Shan in Sichuan, China, where it was collected at an altitude of approximately $2000 \mathrm{~m}$ in June and July.

\subsection{Othius discrepans sp. n.}

Figs $19 \mathrm{a}-\mathrm{f}$

\section{Type}

Holotype $\sigma^{x}$ : China, Sichuan, Xiling Mt., 1600-2400m, litter, 30.07.-4.08.96, leg. S. Kurbatov (MHNG).

\section{Diagnosis}

Measurements and ratios (HT): HL: 1.19; HW: 0.92; PW: 1.13; PL: 1.53; EL: 0.76; TiL: 0.98; TaL: 0.85; TL: 7.2; HL/HW: 1.30; HW/PW: 0.81; PL/PW: 1.35; EL/PL: 0.50; TiL/ TaL: 1.14.

Head and abdomen dark brown; pronotum, elytra, and antennae reddish brown; legs testaceous. Head distinctly oblong and narrower than the pronotum (cf. ratios); outline of head subparallel; eyes small, in lateral view $0.25 \mathrm{x}$ the length of postgenae; macropunctation present on dorsal surface of most of the posterior half, distinctly sparser than in $O$. badius; posterior pair of frontal punctures present; both anterior frontal punctures in HT accompanied by 2 additional punctures; frontal furrows very shallow; microsculpture of whole dorsal surface distinct and isodiametric; antennae shorter and less slender than in $O$. badius, antennomeres IV \pm subquadrate, and $\mathrm{V}-\mathrm{X}$ weakly transverse.

Pronotum widest in anterior half, maximal width nearer to middle than to anterior angles, posteriorly moderately tapering; microsculpture similar to head, also isodiametric, but shallower; pronotal punctation pattern very characteristic: with five discal punctures on either side; posterior pronotal puncture clearly distant from hind angles and from lateral margins (Fig. 19f); posterior median scratch-like impression distinct and long.

Elytra very short (see measurements and ratio); microsculpture weak, but surface only with little, slightly opaque shine; punctation rather shallow and not very dense, interstices wider than punctures; anterior part of elytra and scutellum with a wide and rather deep transverse impression, which in normal conditions is apparently covered by pronotum, so that only the apex of the scutellum is visible; scutellum therefore in cross-section not flat, but distinctly impressed; scutellum with shallow transverse microsculpture and without punctation, surface with distinctly more shine than that of elytra; hind wings reduced.

Abdomen with moderately dense and fine punctation; microsculpture both near anterior margins of terga and on posterior tergal area transverse and extremely shallow, surface shining; palisade fringe absent.

${ }^{\text {A: }}$ protarsomeres I - IV distinctly dilated; sternum V and VI without distinct callosities, but centrally with small subcircular areas with dense punctation and pubescence; sternum VII weakly concave posteriorly; sternum VII with rather sparse and short dark pubescence, its hind margin convex and without marginal setae; sternum IX with relatively sparse, mostly yellowish pubescence, posteriorly deeply concave (Fig. 19d); lateral tergal sclerites of segment IX apically acute, just reaching hind margin of tergum X (Fig. 19e), with one terminal seta; ventral process with short basal carina, but without lateral folds, apically pointed and with curved lateral margins in ventral view; parameres apically weakly dilated; internal sac with 6 sclerotized structures: a very long median basal, a much shorter median apical, a pair of thin long lateral, and a pair of stouter, weakly curved and basally dilated lateral structures; flagellum thin and with ca. 30 coils (Figs 19 a $-c$ ). 

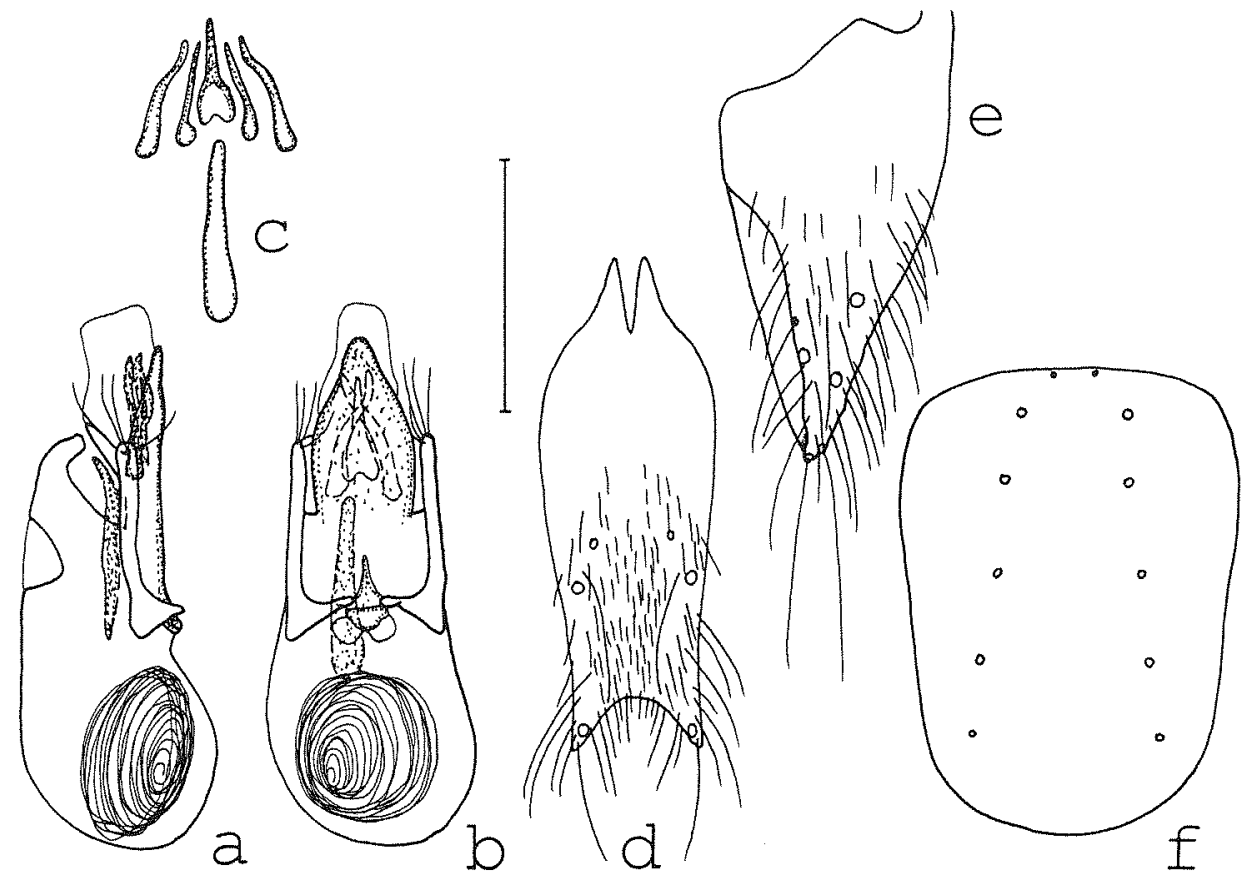

Figs 19 a - f: $O$. discrepans sp. n.: aedeagus in lateral and in ventral view (a, b); internal structures in ventral view (c); $\sigma^{x}$ sternum IX (d); $0^{*}$ lateral tergal sclerite IX and tergum X in lateral view (e); schematic representation of pronotal punctation pattern (f); long setae partly omitted in d, e. Scale: $0.5 \mathrm{~mm}$; f without scale.

१: unknown.

Derivatio nominis: The name (lat: deviating, differing) refers to the remarkable pronotal punctation pattern.

Comparative notes and comments: From all its known congeners, $O$. discrepans is separated by its pronotal punctation pattern. The species is also characterized particularly by the distinctly isodiametric microsculpture of head and pronotum, by the narrow and oblong head, and by the internal structures of the aedeagus. In addition, among the other species without a palisade fringe from the Chinese mainland, it is distinguished by its smaller size and lighter colour.

None of the descriptions in ZHENG (1995) is in agreement with the external characters and the morphology of the aedeagus of this species. Apparently, none of the species referred to in that paper, except for the Taiwanese $O$. parvipennis (SHIBATA), is brachypterous.

Distribution and bionomics: The species is known only from the type locality in Sichuan, where, judging from its external morphology (eye size, reduction of wings and palisade fringe), it is probably more or less endemic. No further data, apart from those indicated on the labels of the holotype, are available.

\subsection{Othius excisus sp. n.}

Figs $20 \mathrm{a}-\mathrm{f}$

Type

Holotype o": China, S Sichuan, S Xichang, Mt. Luoji, 2300-2500m, litter, 16.-24.07.96, Kurbatov (MHNG). 


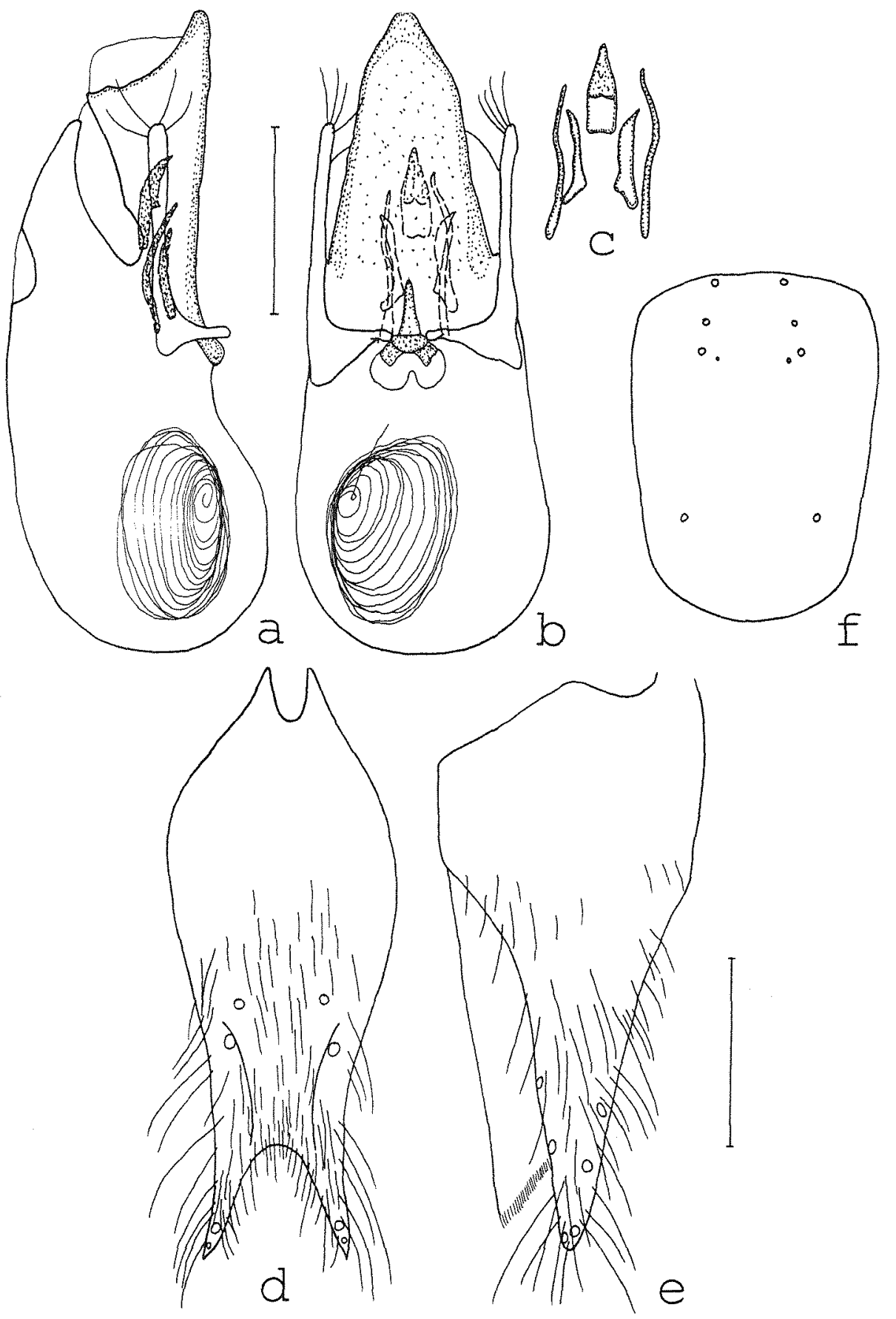

Figs 20 a - f: O. excisus sp. n.: aedeagus in lateral and in ventral view (a, b); internal structures in ventral view (c); $o^{\pi}$ sternum IX (d); $o^{*}$ lateral tergal sclerite IX and tergum $X$ in lateral view (e); schematic representation of pronotal punctation pattern (f); long setae partly omitted in d, e. Scales: $0.5 \mathrm{~mm}$; $f$ without scale. 


\section{Diagnosis}

Measurements and ratios (HT): HL: 1.77; HW: 1.59; PW: 1.89; PL: 2.29; EL: 1.25; TiL: 1.71; TaL: 1.37; TL: 11.2; HL/HW: 1.12; HW/PW: 0.84; PL/PW: 1.21; EL/PL: 0.55; TiL/TaL: 1.24. Head and pronotum blackish; elytra and abdomen, except for the slightly lighter tergal and sternal hind margins, blackish brown; tibiae and femora \pm dark brown; tarsi and antennae reddish brown. Head distinctly oblong and narrower than the pronotum (cf. ratios); lateral margins of head subparallel; eyes of moderate size, in lateral view $0.25 \mathrm{x}$ the length of postgenae; macropunctation in lateral areas of posterior half rather sparse, in central dorsal region absent; posterior pair of frontal punctures present, but small; anterior frontal punctures small and accompanied by $1-2$ additional punctures; frontal furrows shallowly sulcate; microsculpture as in $O$. discrepans on whole dorsal surface distinct and isodiametric; antennae slender, antennomeres IV - X subequal in length and oblong.

Pronotum rather massive (cf. measurements and ratios), wider than head and elytra, widest in anterior half, maximal width nearer to middle than to anterior angles, posteriorly weakly tapering; microsculpture similar to head, also isodiametric; pronotal punctation pattern characteristic: posterior puncture at considerable distance from hind angle and from lateral margin, intermediate puncture accompanied by an additional puncture (Fig. 20f); posterior median scratch-like impression distinct and long.

Elytra short (see measurements and ratio); microsculpture absent, surface with distinct, slightly opaque shine; punctation \pm well-defined and rather dense, interstices approximately as wide as, in some areas smaller than punctures; scutellum only weakly impressed, with shallow transverse microsculpture and with some small punctures; hind wings reduced.

Abdomen with rather dense and fine punctation; microsculpture near anterior tergal margins transverse and very shallow, on posterior tergal area \pm absent, surface therefore with distinct shine; palisade fringe on hind margin of tergum VII absent.

$\sigma^{*}$ : protarsomeres I - IV strongly dilated; sternum $V$ with minute subcircular, indistinctly elevated central area with condensed punctation; sternum VI with small subcircular area with \pm tomentose dark and long pubescence, this area slightly larger than that of sternum V; sternum VII weakly concave and only indistinctly flattened posteriorly; sternum VIII very oblong, with rather dense and long dark pubescence, its hind margin distinctly concave and with short marginal setae; sternum IX with not very dense dark pubescence, posteriorly deeply excised (Fig. 20d); lateral tergal sclerites of segment IX very long and apically acute, projecting beyond hind margin of tergum X (Fig. 20e); ventral process long and slender, with short sclerotized basal carina, but without lateral folds; parameres apically weakly dilated; internal sac with 5 sclerotized structures: a short median apical, a pair of thin long lateral, and a pair of stouter and shorter lateral structures; flagellum moderately thin and with ca. 15 coils (Figs $20 \mathrm{a}-\mathrm{c}$ ).

\%: unknown.

Derivatio nominis: The name (lat.) refers to the deeply excised posterior margin of the of sternum IX.

Comparative notes and phylogenetics: $O$. excisus is apparently closely related to $O$. discrepans, with which it shares the following synapomorphies: the distinctly isodiametric microsculpture of the head and pronotum, the position of the posterior pronotal puncture, the slender head, the reduction of wings and palisade fringe, and the reduction of the $\sigma^{7}$ secondary sexual characters on tergum V and VI. In addition, the external morphology of the aedeagus is similar. It is, however, readily distinguished from that species by the distinctly larger size and darker colour, the larger eyes, the different pronotal punctation pattern, and by the $\sigma^{\prime}$ primary and secondary sexual characters. For distinction from the following brachypterous congeners from the Chinese mainland see below those species. 
Comments: The only completely dark species with the head and the elytra narrower than the pronotum in ZHENG (1995) is the Taiwanese O. parvipennis, so that $O$. excisus is very unlikely to be conspecific with any of the species described in that study.

Distribution and bionomics: The species is known only from the type locality in southern Sichuan. As can be inferred from its external morphology (eye size, reduction of wings and palisade fringe), it is probably more or less endemic. No further data, apart from those indicated on the labels of the holotype, are available.

\subsection{Othius sculptipennis sp. $\mathrm{n}$.}

Figs $21 \mathrm{a}-\mathrm{b}$

\section{Type}

Holotype : : Ch- Sichuan, 24/7.1995, 28.07N 101.05E, $30 \mathrm{~km}$ NW Muli/Bowa, mixed forest, ca. $3500 \mathrm{~m}$, Jaroslav Turna leg. (NHMW).

\section{Diagnosis}

Measurements and ratios (HT): HL: 2.47; HW: 2.10; PW: 2.20; PL: 2.75; EL: 1.56; TiL: 1.92; TaL: 1.46; TL: 15.6; HL/HW: 1.17; HW/PW: 0.96; PL/PW: 1.25; EL/PL: 0.57; TiL/TaL: 1.31. Head, pronotum and abdomen blackish brown; elytra, except for the lighter hind margins, legs and antennae brown to dark brown.

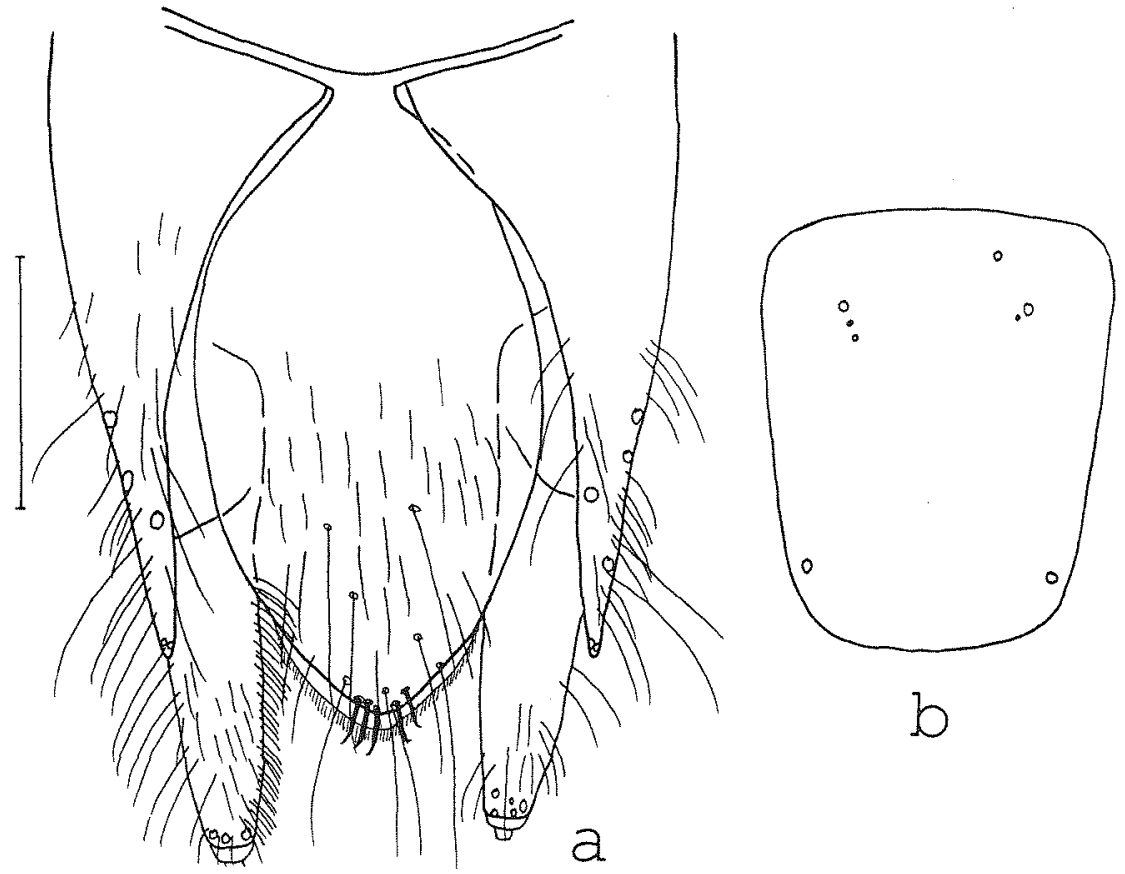

Figs 21 a - b: O. sculptipennis sp. n.: $q$ terminalia (a); schematic representation of pronotal punctation pattern (b); long setae partly omitted in a. Scale: $0.5 \mathrm{~mm}$; b without scale.

Head oblong and slightly narrower than pronotum (cf. ratios), of characteristic oval shape, hind angles obsolete, postgenae in dorsal view evenly curving towards neck; eyes relatively small, in lateral view $0.28 \mathrm{x}$ the length of postgenae; macropunctation extensive, present on all of posterior 
half of dorsal surface, denser and less coarse than in $O$. excisus; posterior pair of frontal punctures absent; anterior frontal punctures accompanied by 2 - 3 additional punctures; frontal furrows dis" tinctly sulcate; whole dorsal surface mat due to fine, but remarkably distinct and isodiametric microsculpture; antennae long, antennomeres IV weakly oblong, V subquadrate, and VI - X weakly transverse.

Pronotum with maximal width near anterior angles, posteriorly distinctly tapering; microsculpture similar to head, also isodiametric, much more distinct than in $O$. excisus, surface therefore mat; posterior puncture relatively close to lateral margin, but at some distance from hind angle; intermediate puncture with $1-2$ small additional punctures; anterior puncture in HT absent on left side (Fig. 21b); posterior median scratch-like impression distinct.

Elytra short (see measurements and ratio); microsculpture very characteristic, mostly composed of fine and dense, \pm distinct rugae of variable length and direction, in which the large, though shallow punctures are barely visible; surface mat; scutellum with microsculpture composed of transverse and isodiametric meshes, and with some small punctures; hind wings reduced.

Abdomen with fine punctation; microsculpture very fine, but distinct, composed of very transverse meshes and transverse striae; near anterior margins of terga slightly more distinct and composed of shorter transverse and isodiametric meshes; surface with reduced shine; palisade fringe at hind margin of tergum VII absent.

$\sigma^{\pi}$ : unknown.

$:$ : posterior margin of sternum VIII concave and with fringe of dense, long and rather stout yellow and with interspersed long black setae; lateral tergal sclerites IX apically very acute; tergum $X$ posteriorly with membranous appendage and with some relatively short modified setae (Fig. 21a).

Derivatio nominis: The name (lat.) refers to the characteristic microsculpture of the elytra.

Comparative notes and phylogenetics: $O$. sculptipennis is readily distinguished from all its known congeners based on external characters alone, especially by the remarkably distinct microreticulation of head and pronotum, the very characteristic microsculpture of the elytra, and the shape of the head. In the Palaearctic region, the only further species of similar size and without a palisade fringe on the hind margin of tergum VII is $O$. strigulosus WOLLASTON from Madeira. $O$. sculptipennis is apparently most closely related to $O$. excisus and $O$. discrepans, with which it shares the isodiametric microsculpture of the head and pronotum and the reduction of wings and palisade fringe, and which also occur in Sichuan. In addition to the characters indicated above, it differs from them in the absence of a posterior pair of frontal punctures on the head and in the different shape and punctation of the pronotum.

Distribution and bionomics: The species is known only from the type locality in Sichuan. Both its external morphology and the altitude at which it was collected $(3500 \mathrm{~m})$ suggest that it may be more or less endemic. The ovaries of the holotype contained a mature egg.

\subsection{Othius opacipennis CAMERON, 1939}

Fig. 22a

Othius opacipennis CAMERON, 1939b: $162 \mathrm{f}$.

Type examined

Paratype $9:$ Paratype/ Yunnanfou/ Othius opacipennis/ Othius opacipennis Cam. Cotype/ M. Cameron Bequest B. M. 1955-147 (BMNH).

Additional material examined

19, China, Yunnan, Dali, 10.II.1993, leg. Rougemont (cRou). 


\section{Diagnosis}

Measurements and ratios (PT, non-type specimen): HL: 1.68, 1.77; HW: 1.53, 1.52; PW: 1.65, 1.74; PL: $2.01,2.14$; EL: 1.49, 1.43; TiL: 1.31, 1.43; TaL: 1.04, 1.13; TL: 10.8, 12.3; HL/HW: 1.10, 1.09; HW/PW: 0.93, 0.93; PL/PW: 1.22, 1.23; EL/PL: 0.74, 0.67; TiL/TaL: 1.27, 127. Colour of body black, appendages dark brown, tarsi brown.

Fig. 22a: O. opacipennis CAMERON: 9 terminalia, long setae partly omitted (a). Scale: $0.5 \mathrm{~mm}$.

Head slightly longer than wide; eyes large, $0.45-0.50 \mathrm{x}$ the length of postgenae in lateral view; temples behind eyes weakly widened in dorsal view; dorsal surface somewhat shiny, but with distinct transversely striate microsculpture; without noticeable micropunctation; punctation in posterolateral area and near occiput rather coarse and distinctly denser than in O. medius; frons with posterior pair of punctures absent, the anterior punctures accompanied by $2-5$ additional punctures; frontal furrows shallow.

Pronotum dilated anterionly, with maximal width ca. halfway between anterior angles and middle; posterior scratch-like impression distinct; dorsal surface with fine and dense microsculpture composed of long transverse meshes; pronotal punctation pattern similar to O. medius, but first puncture separated from anterior margin by at least its diameter.

Elytra rather long EL/PL: 0.67 - 0.75; punctures \pm regularly spaced, not very deep, and moderately dense, the interstices on average wi-

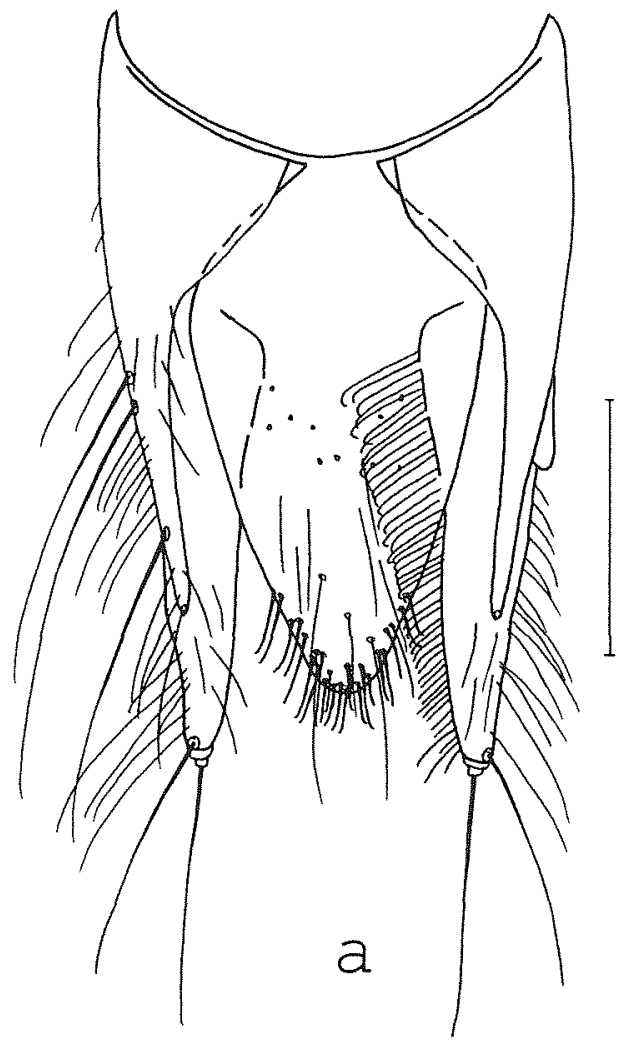
der than the diameter of the punctures; surface mat due to very dense micropunctation, which at lower magnifications may be mistaken for microreticulation; legs relatively long and slender. Abdomen more shining than forebody; punctation rather dense and fine; microsculpture near anterior margins of terga composed of shallow \pm transverse and isodiametric meshes, on remainder of tergal surfaces transverse and very weak; palisade fringe at hind margin of tergum VII present.

o": unknown.

i: tergum $X$ very slender, at and near hind margin with numerous $(20-30)$ apically curved, long modified setae; styli slender, their inner margin with fringe of dense long setae (Fig. 22a).

Comparative notes: Owing to the mat appearance of the elytra, $O$. opacipennis externally somewhat resembles the almost equally large $O$. ruficornis CAMERON, but is readily distinguished from that species by the darker colour, the distinctly larger eyes, the longer elytra and different microsculpture of the elytral surface (in $O$. ruficornis predominantly isodiametric), and by the presence of a palisade fringe at the hind margin of tergum VII. For distinction from the similar $O$. fibulifer and $O$. wrase $i$ see below those species. 
Comments: According to a footnote in the original description, the holotype is deposited in the collection of J. Clermont (CAMERON, 1939b). It was looked for, but not found, in the collections of the MNHNP (BERTI, in litt.).

Distribution and bionomics: $O$. opacipennis is known only from Yunnan, China. Data on the ecological circumstances of its collection are not available.

\subsection{Othius tuberipennis sp. $\mathrm{n}$.}

Figs $23 \mathrm{a}-\mathrm{b}$

\section{Type}

Holotype $q$ [somewhat damaged, hind legs missing]: China, Yunnan prov., Dali, 6.7.1993, lgt. S. Becvar (NHMW).
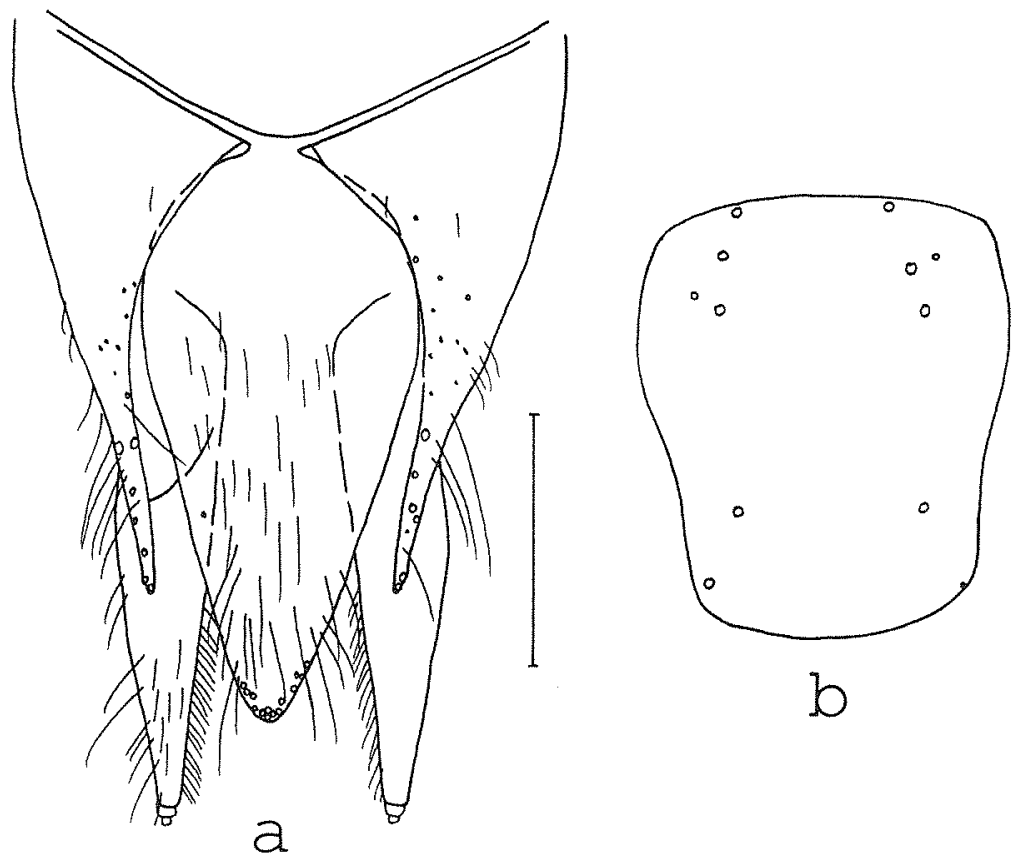

Figs 23 a - b: $O$. tuberipennis sp. n.: क terminalia, long setae partly omitted (a); schematic representation of pronotal punctation pattern (b). Scale: $0.5 \mathrm{~mm}$; b without scale.

\section{Diagnosis}

Measurements and ratios (HT): HL: 1.80; HW: 1.86; PW: 1.95; PL: 2.29; EL: 1.19; TL: 11.5; HL/HW: 0.97; HW/PW: 0.95; PL/PW: 1.17; EL/PL: 0.52.

Head, pronotum and abdomen black; elytra blackish brown; legs, except for the light brown tarsi, dark brown; antennae reddish brown.

Head rather massive, wider than long and only slightly narrower than pronotum (cf. ratios), posteriorly weakly widened; eyes relatively small, in lateral view $0.27 \mathrm{x}$ the length of postgenae; macropunctation rather coarse, but sparse, absent in central dorsal area; posterior pair of frontal punctures present; anterior frontal punctures accompanied by 2 - 5 additional punctures; frontal furrows shallow; whole dorsal surface with subdued shine due to fine, but distinct microsculpture composed of isodiametric and short transverse meshes; antennae long, antennomeres IV - V weakly oblong, V - X \pm subquadrate. 
Pronotum with maximal width in anterior half, but nearer to middle than to anterior angles, posteriorly distinctly tapering; lateral margins in posterior half distinctly concave in dorsal view; microsculpture and shine similar to head; discal punctures somewhat asymmetric in HT (Fig. 23b); posterior median scratch-like impression distinct.

Elytra short (see measurements and ratio); dorsal surface uneven, with large, but shallow protuberances; punctation large, shallow and sparse, interstices distinctly wider than punctures; microsculpture characteristic, mostly composed of wide \pm isodiametric or scale-shaped meshes, which are several times as wide as those of pronotum; scutellum with rather weak \pm transverse microsculpture; hind wings reduced.

Abdomen with fine punctation; microsculpture very shallow, on tergum VII barely noticeable, near anterior tergal margins less clearly transverse and slightly more distinct than on posterior tergal surface; surface \pm shiny; palisade fringe absent.

o: unknown.

q: posterior margin of sternum VIII convex and with fringe of dense, long and rather stout yellow setae; lateral tergal sclerites IX apically extremely acute; tergum $X$ very long and apically almost pointed; all the posterior setae were rubbed off, but judging from the size of the insertions, the hind margin was equipped with numerous modified setae; styli very long and posteriorly distinctly tapering (Fig. 23a).

Derivatio nominis: The name (lat.) refers to the characteristic uneven surface of the elytra.

Comparative notes: From its Palaearctic congeners $O$. tuberipennis is distinguished by the elytral surface (flat protuberances, microsculpture) alone. In addition, it is characterized by its size, the reduced hind wings and palisade fringe on the hind margin of tergum VII, the massive and broad head, the presence of frontal punctures, the shape and punctation of the pronotum, and by the $q$ secondary sexual characters.

Distribution: The species is known only from the type locality in Yunnan. As can be inferred from its external morphology it may have a restricted area of distribution.

\subsection{Othius fibulifer sp. n.}

Figs $24 \mathrm{a}-\mathrm{f}$

\section{Types}

Holotype o [slightly teneral]: China: W Sichuan (9), Daxue Shan, E Theto-La [recte: Tsheto-La] Pass, W Kangding, 3500m, 30.00.42N, 101.51.47E, 25.05.1997, M. Schülke/ Sammlung M. Schülke Berlin (cAss). Paratypes: 1, same data as holotype, leg. Wrase (cSch); 19 [slightly teneral], China: WSichuan (7), Daxue Shan, W Kangding, 2700-2800m, 30.03.13N, 101.57. 11E, 24.05.1997, M. Schülke (cAss); 10", China: W Sichuan, Kangding, 2800m, 30 04N 101 ${ }^{\circ} 58 \mathrm{E}, 21 . \mathrm{VII} .1998$, A. Smetana [C88]/ 1998 China Expedition, J. Farkac, D. Král, J. Schneider \& A. Smetana (cSme); $20^{\text {*0*, }}$ same data, but 2700-2900m [C87] (cSme, cAss); 20" $0^{\circ}$, China (Sichuan), n. Kangding. See Mu-ge-cuo, 3500-3900m, 22. VII.1994, Heinz leg. (cSme); 20"0, China, Sichuan Pass, ca. $30 \mathrm{~km}$ W Kangding, 3600-3700m, 16.6.95, W. Heinz (cSme, cAss); 10\%, China: W Sichuan, 20km N Sabdê, 3200m, $29^{\circ} 35 \mathrm{~N} 102^{\circ} 23 \mathrm{E}, 11 . \mathrm{VII} .1998$, A. Smetana [C77] (cSme); $10^{\prime \prime}$, same data, but 3300m [C82] (cAss).

\section{Diagnosis}

Measurements and ratios (range, arithmetic mean; $\mathrm{n}=12$ ): HL: $1.62-1.95,1.77$; HW: $1.39-1.77$, 1.54; PW: 1.62 - 1.92, 1.78; PL: 2.01 - 2.38, 2.19; EL: 1.19 - 1.46, 1.33; TiL: 1.46 - 1.71, 1.56; TaL: $1.13-1.37,1.24$; TL: $11.1-13.8,12.1$; HL/HW: $1.09-1.20,1.15$; HW/PW: 0.82 - 0.93 , 0.87 ; PL/PW: $1.20-1.28,1.23$; EL/PL: $0.56-0.65,0.61$; TiL/TaL: $1.20-1.33,1.26$. 
Head, pronotum and abdomen black; elytra sometimes slightly lighter; tibiae and femora dark brown to blackish, usually with the external faces somewhat paler; tarsi light brown; antennae dark brown with the basal antennomeres sometimes black.

Head weakly to distinctly oblong, narrower than the pronotum (cf. ratios); lateral margins of head posteriorly subparallel or weakly dilated in dorsal view; eyes in lateral view ca. $0.38-0.40 \mathrm{x}$ the length of postgenae; macropunctation rather dense, in central dorsal region absent or very sparse; posterior pair of frontal punctures usually present, but in most specimens relatively small, only in one of the paratypes absent, sometimes with additional punctures; anterior frontal punctures accompanied by 1 - 4 additional punctures; frontal furrows distinctly sulcate; microsculpture rather shallow, usually predominantly isodiametric, sometimes composed of a mixture of isodiametric and transverse meshes, surface somewhat shining; antennae with antennomeres IV and $\mathrm{V} \pm$ subquadrate and VI - X weakly to moderately transverse.

Pronotum distinctly oblong (cf. ratios), maximal width approximately halfway between anterior angles and middle or nearer to anterior angles, posteriorly weakly tapering; microsculpture predominantly composed of transverse striae and meshes, sometimes partly mixed with interspersed isodiametric meshes; pronotal punctation similar to $O$. opacipennis, posterior puncture slightly more distant from hind angles; posterior median scratch-like impression present.

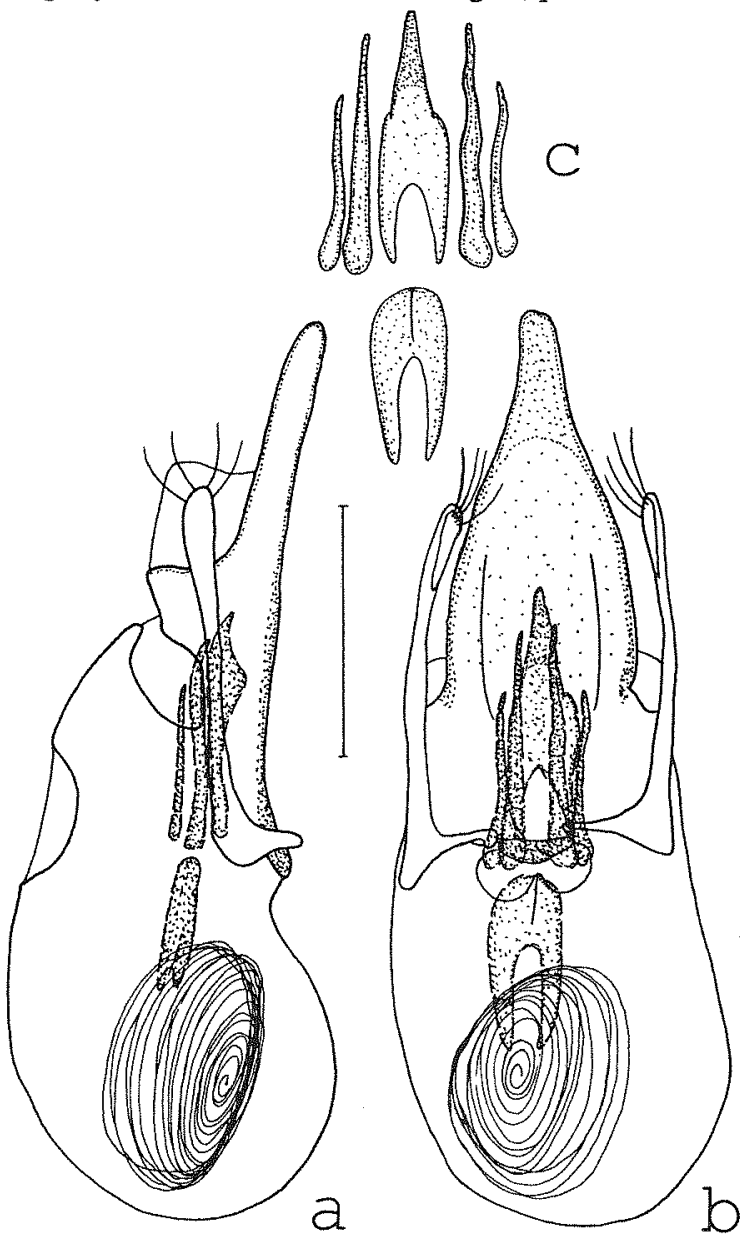

Figs 24 a - f: $O$. fibulifer sp. n.: aedeagus in lateral and in ventral view $(a, b)$.

Elytra moderately short (see measurements and ratio); microsculpture distinct, composed of \pm irregular and partly confluent micropunctation and microrugae, but surface not completely mat; punctation rather dense, distinctly more so than in $O$. opacipennis, and relatively fine, interstices on average as wide as, partly wider than punctures; scutellum \pm flat, with shallow microsculpture composed of isodiametric and short transverse meshes and with some punctures; hind wings of reduced length, slightly longer than elytra.

Abdomen with rather dense and fine punctation; microsculpture very shallow and mostly transverse, near anterior tergal margins slightly more distinct and composed of transverse and isodiametric meshes; palisade fringe at hind margin of tergum VII present, but weakly developed.

o*: protarsomeres I - IV strongly dilated; sternum V and VI without modifications; sternum VII weakly con- 
cave and only indistinctly flattened posteriorly; sternum VIII distinctly oblong, with rather dense and short dark pubescence, with two transverse rows of 4 long setae, its hind margin \pm truncate or weakly concave; sternum IX with mostly short dark pubescence, posteriorly distinctly concave and with broadly rounded hind angles (Fig. 24d); lateral tergal sclerites of segment IX slender, apically moderately acute, just reaching hind margin of tergum X (Fig. 24e); ventral process of aedeagus long and slender, apically pointed, without distinct basal carina, but with weak lateral folds; parameres apically distinctly dilated; internal sac with 6 sclerotized structures: a characteristically shaped median basal, a rather wide and basally weakly sclerotized median apical, a pair of stout long, and a pair of more slender and lateral structures; flagellum thin and with ca. $25-30$ coils (Figs $24 \mathrm{a}-\mathrm{c}$ ).

$\%$ : protarsomeres I - IV moderately dilated, sexual dimorphism distinct; sternum VIII with 2 transverse rows of 4 long setae, posteriorly convex and with fringe of yellow setae; tergum $X$ posteriorly pointed and with weakly modified, not very stout and apically uncurved setae; inner margin of styli with fringe of numerous long and stout yellowish setae (Fig. 24f).
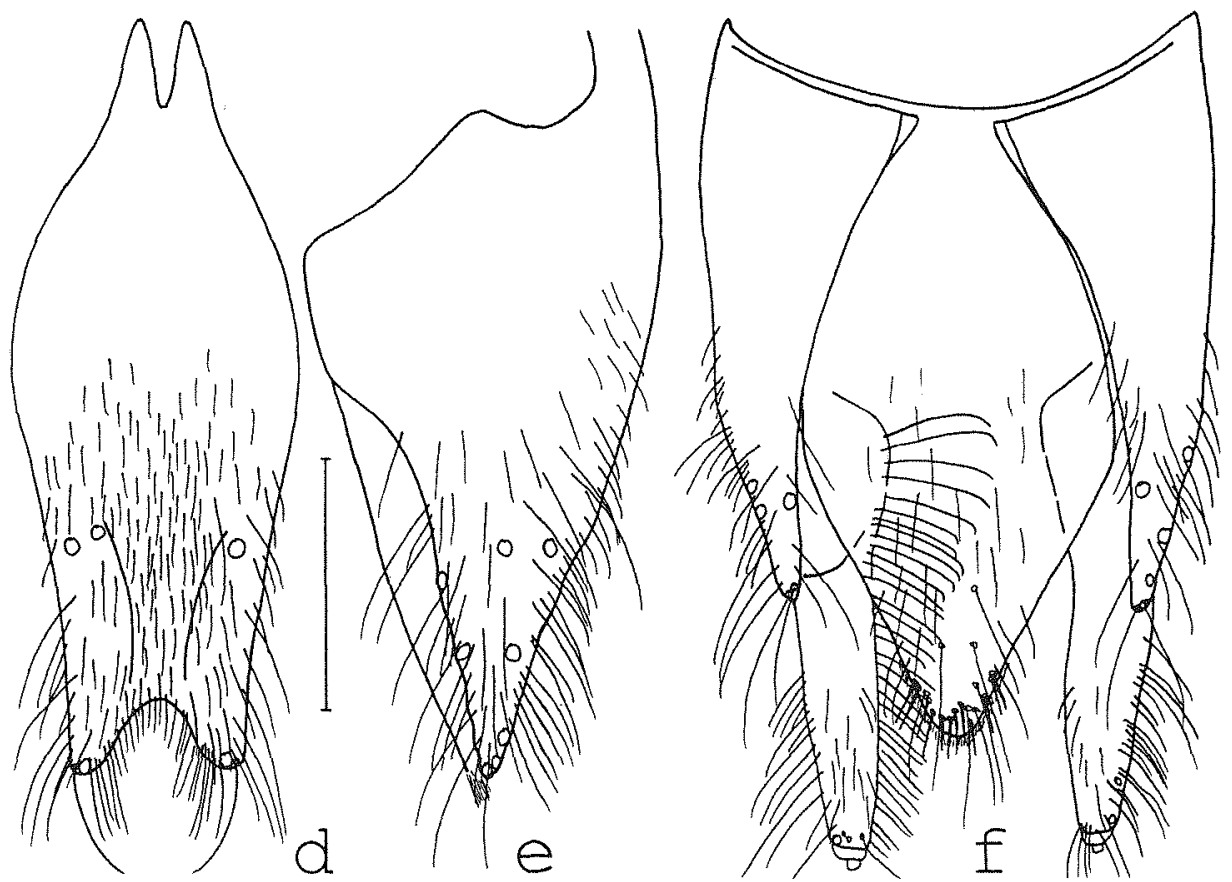

Figs 24 a - f: $O$. fibulifer sp. n.: internal structures in ventral view (c); $\sigma^{*}$ sternum IX (d); $\sigma^{\text {r lateral tergal }}$ sclerite IX and tergum X in lateral view (e); $ᄋ$ terminalia $(f)$; long setae partly or completely omitted in $\mathrm{d}-\mathrm{f}$. Scales: $0.5 \mathrm{~mm}$.

Derivatio nominis: The name (lat.) refers to the shape of the basal median structure in the internal sac, which somewhat resembles a clip.

Comparative notes: From the similar $O$. opacipennis, $O$. fibulifer is distinguished by the predominantly isodiametric microsculpture of the head, the distinctly denser punctation and the much more irregular microsculpture of the elytra, which in $O$. opacipennis is composed of well-defined dense micropunctation. From $O$. tuberipennis it differs in the less massive head, the larger eyes, the different microsculpture especially of the pronotum and the elytra, the longer elytra, the lack 
of elytral protuberances and the presence of a palisade fringe at the hind margin of tergum VII. For distinction from $O$. wrase $i \mathrm{sp}$. $\mathrm{n}$. and remarks on phylogenetics see comparative notes below that species (section 4.18).

Comments: The only species among those described by ZHENG (1995) that seems to be similar in external appearance is $O$. quadratus, but the shape of the ventral process especially in lateral view is different (cf. Fig. 2b in ZHENG, 1995).

Distribution and bionomics: The species is known only from western Sichuan, where it was collected at altitudes of $2700-$ ca. $3900 \mathrm{~m}$ in May and July. Two of the three specimens collected in May were slightly teneral.

\subsection{Othius wrasei sp. n.}

Figs $25 \mathrm{a}-\mathrm{f}$

\section{Types}

Holotype of [slightly teneral]: China: (W Sichuan) (13), Daxue Shan, Hailuogou Glacier Park (Gongga Shan) Camp 1, 2100m, 29.36N/ 102.04E, 27./28./31.V.'97 Wrase (cAss). Paratypes: 2 우 [1와 slightly teneral], same data as holotype ( $\mathrm{CSch}, \mathrm{CSme}) ; 1$ [ [teneral], same data as holotype, leg. Pütz (cAss); 10", China: Sichuan, Gongga Shan, Hailuogou, Lake above Camp 2, 2750 m, $29^{\circ} 35$ N 102’00E, 4.VII.1998, A. Smetana [C74]/1998 China Expedition J. Farkač, D. Král, J. Schneider \& A. Smetana (cAss).
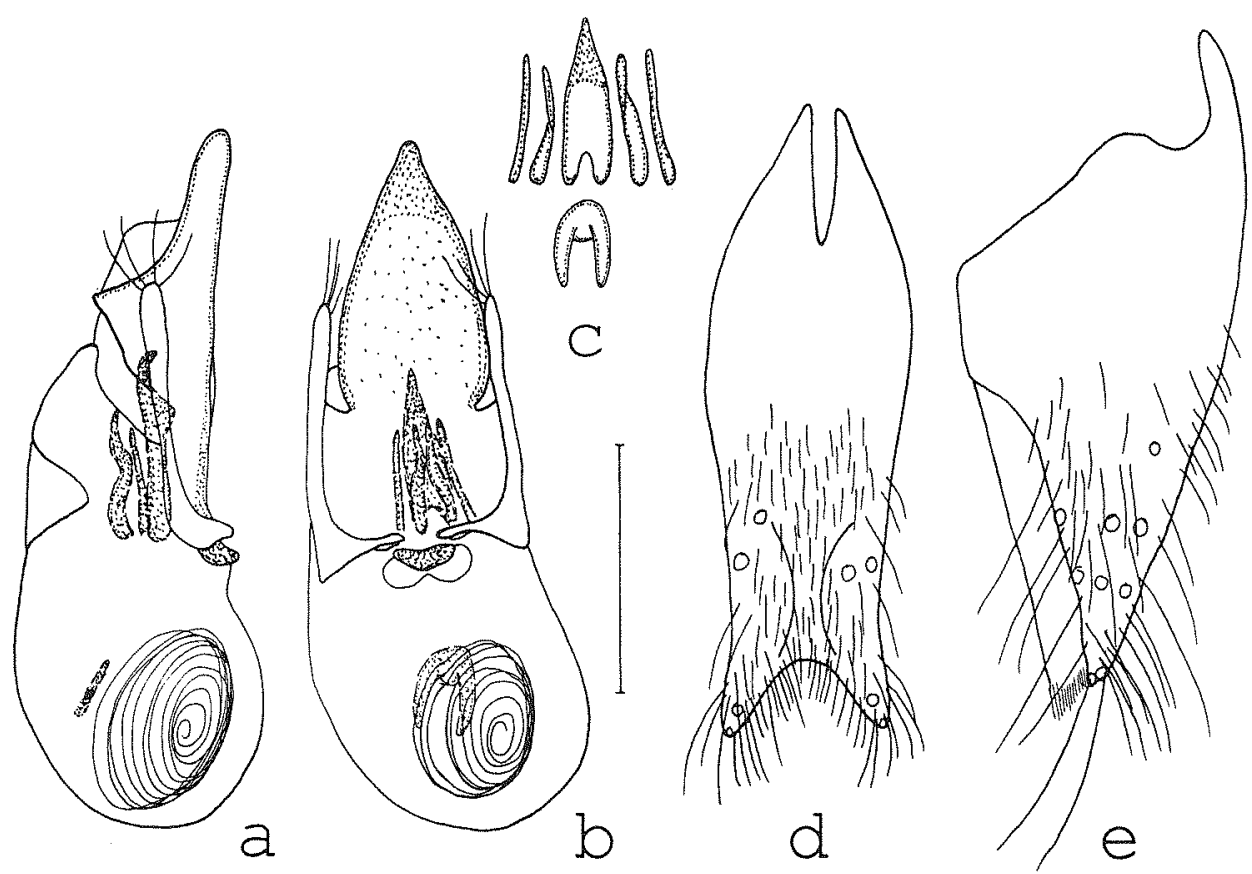

Figs 25 a - e: $O$. wrasei sp. $\mathrm{n} .:$ aedeagus in lateral and in ventral view $(\mathbf{a}, \mathbf{b})$; internal structures in ventral view (c); $\sigma^{\prime \prime}$ sternum IX (d); $\sigma^{\prime \prime}$ lateral tergal sclerite IX and tergum $X$ in lateral view (e); long setae partly or completely omitted in $\mathrm{d}-\mathrm{f}$. Scales: $0.5 \mathrm{~mm}$. 


\section{Diagnosis}

Measurements and ratios (range; $\mathrm{n}=5$ ): HL: $1.49-1.68 ; \mathrm{HW}: 1.34-1.59 ; \mathrm{PW}: 1.40-1.53$; PL: 1.80 - 1.92; EL: 0.92 - 1.13; TiL: 1.25 - 1.40; TaL: 1.01 - 1.07; TL: 9.2 - 10.0; HL/HW: 1.06 1.14; HW/PW: 0.96 - 1.04; PL/PW: 1.24 - 1.30; EL/PL: 0.51 - 0.59; TiL/TaL: 1.23 - 1.35.

Body blackish brown to black; femora, tibiae, and antennae dark brown; tarsi light brown. Head of characteristic shape, weakly oblong, approximately as wide as pronotum (cf. ratios), and posteriorly distinctly dilated (clearly more so than in $O$. latus); eyes moderately small, in lateral view ca. $0.35-0.42 x$ the length of postgenae; macropunctation rather sparse, clearly less dense than in $O$. fibulifer and in $O$. opacipennis, in central dorsal region absent; posterior pair of frontal punctures present, but relatively small; anterior frontal punctures accompanied by $1-3$ additional punctures; frontal furrows distinctly sulcate; microsculpture distinctly isodiametric, meshes more distinct and somewhat larger than in $O$. fibulifer, surface therefore with less shine; antennae as in $O$. fibulifer incrassate distally, antennomeres IV weakly oblong to subquadrate, V subquadrate to weakly transverse, and VI - X moderately transverse.

Pronotum distinctly oblong (cf. ratio), of similar shape as in $O$. fibulifer, but lateral margins in posterior half occasionally weakly concave; microsculpture predominantly composed of transverse meshes and striae; pronotal punctation similar to $O$. fibulifer, but posterior puncture somewhat more distant from hind angles and anterior punctures either closer to anterior margin or absent; additional punctures may be present; posterior median scratch-like impression present.

Elytra short (see measurements and ratio); microsculpture as in $O$. fibulifer, but usually shallower and less distinct; punctation fine, finer and less dense than in $O$. fibulifer, interstices clearly wider than punctures; scutellum with microsculpture composed of transverse meshes of variable length and with some rather small punctures; hind wings reduced.

Abdomen with punctation and microsculpture similar to $O$. fibulifer; palisade fringe at hind margin of tergum VII absent.

o": protarsomeres I - IV moderately dilated; sternum V and VI without modifications; sternum VII weakly concave and only indistinctly flattened posteriorly; sternum VIII as in O. fibulifer; sternum IX with mostly short dark pubescence, of similar shape as in $O$. fibulifer, but posteriorly more broadly and deeply concave, and hind angles less broadly rounded (Fig. 25d); lateral tergal sclerites of segment IX as in $O$. fibulifer (Fig. 25e); aedeagus of similar morphology as in $O$. fibulifer, but smaller, ventral process less slender and less acutely pointed apically, and parameres only moderately dilated; internal sac with 6 sclerotized structures: a very weakly sclerotized, barely visible fibuliform median basal, a rather wide and basally weakly sclerotized median apical, a pair of basally dilated and somewhat twisted lateral, and a pair of straight lateral structures; flagellum with ca. 10 coils (Figs $25 \mathrm{a}-\mathrm{c}$ ).

$:$ protarsomeres I - IV somewhat less dilated than in $0^{\circ}$, sexual dimorphism not pronounced, but noticeable; sternum VIII as in $O$. fibulifer;

Figs 25 f: $O$. wrasei sp. n.: o terminalia (f); long setae partly or completely omitted in $\mathrm{d}-\mathrm{f}$. Scales: $0.5 \mathrm{~mm}$.

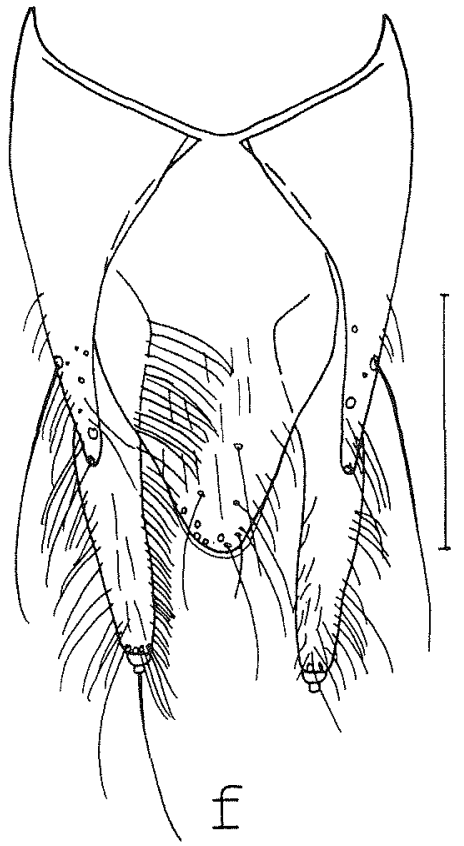


terminalia similar to $O$. fibulifer, tergum $\mathrm{X}$ also of similar shape, but posteriorly apparently with fewer weakly modified - not very stout, apically not bent - setae (such a seta was discovered only in one $q$, most of the setae of the $q$ paratypes were rubbed off) (Fig. 25f).

Derivatio nominis: The species is dedicated to David Wrase, Berlin, who collected most of the types, including the holotype.

Comparative notes and phylogenetics: Externally, $O$. wrasei is distinguished from other Eastern Palaearctic congeners, except $O$. coniceps from Taiwan, by the posteriorly strongly dilated head. Among the known species, it is most closely related to its presumed sister species $O$. fibulifer, with which it not only shares the similar general appearance (proportions, colour, punctation, microsculpture) and a similar external morphology of the aedeagus, but also the following hypothesized synapomorphies: the characteristic microsculpture of the elytra (see diagnosis of $O . f i b u$ lifer), the shape of the hind margin of the $\sigma^{\prime \prime}$ sternum IX, the fibuliform median basal structure in the internal sac of the aedeagus, and the shape and chaetotaxy of the $q$ tergum X. Both species, however, differ in various characters, especially in size, head shape, the microsculpture and punctation of the head, the position of the posterior dorsal puncture of the pronotum, the length of the hind wings, the development of the palisade fringe at the hind margin of tergum VII, and the primary and secondary sexual characters (see diagnosis above).

Distribution and bionomics: The species is known only from the Gongga Shan in western Sichuan, where it was collected at an altitude of $2100 \mathrm{~m}$ and $2750 \mathrm{~m}$ in May and July. Three of the four type specimens taken in May were at least slightly teneral.

\subsection{Othius taiwanus ITo, 1989}

Figs 26 a - f, Map 1 (p. 85)

Othius taiwanus ITO, 1989: $25 \mathrm{ff}$.

\section{Type examined}

Holotype ơ: Mt. Ali, Taiwan, 17.V.1981, T. Ito/ Holotype Othius taiwanus T. Ito sp. nov. (cShT).

\section{Additional material examined}

2웅, Taiwan, Nantou Hsien, Shanlinchi, 1650m, 16.V.1990, leg. Smetana (cSme, cAss); $30^{\pi} 0^{\pi}$, same locality, 19.V.1991, leg. Smetana (cSme, cAss).

Measurements (range, $\mathrm{n}=6$ ): HL: 2.29 - 2.59; HW: 1.92 - 2.23; PW: 1.92 - 2.20; PL: 2.44 - 2.75; EL: 1.80 - 2.07; TiL: 1.95 - 2.17; TaL: 1.46 - 1.68; TL: 13.1 - 15.9.

Colour blackish brown to black, with the tarsi, the bases of first three antennomeres, the hind margins especially of the posterior abdominal segments, and sometimes the elytra lighter.

Head $1.13-1.19 x$ longer than wide, approximately as wide as pronotum (HW/PW: $0.99-1.03$ ); eyes large, $0.40-0.48 \mathrm{x}$ the length of postgenae in lateral view; temples behind eyes \pm parallel or slightly widened; dorsal surface shining, with extremely shallow and fine microsculpture, which is visible only at higher magnifications, micropunctation absent; macropunctation in posterolateral area and near occiput moderately dense and rather coarse; frons with posterior pair of punctures present ( 3 specimens examined), absent ( 1 specimen) or reduced to one puncture ( 2 specimens), the anterior punctures accompanied by 1 - 4 additional punctures; frontal furrows distinctly sulcate; antenna long, with antennomere III ca. $3 x$ longer than wide and ca. $1.5 x$ longer than II, the following antennomeres decreasing in length, but even $X$ noticeably oblong.

Pronotum distinctly dilated anteriorly, with maximal width ca. halfway between middle and anterior angles, lateral margins \pm sinuate, $1.24-1.27 \times$ longer than wide; posterior scratch-like 
impression minute or absent; dorsal surface very shiny, at most with traces of transverse microsculpture; pronotal punctation as in Fig. 26f.

Elytra relatively long, EL/PL: 0.72 - 0.76; punctures rather dense and well-defined, interstices on average subequal in width to punctures, shining and without distinct microsculpture; scutellum with distinct transverse microsculpture and several rather large and well-defined punctures; hind wings apparently fully developed; legs slender, TiL/TaL: $1.24-1.37$.

Abdomen with relatively fine, \pm evenly spaced punctation; microsculpture fine and rather shallow, near anterior margins of terga somewhat more distinct and with transverse meshes; palisade fringe at hind margin of tergum VII present.

Figs 26 a - f: O. taiwanus ITo: aedeagus in lateral and in ventral view $(\mathbf{a}, \mathbf{b})$.

o: protarsomeres I - IV moderately dilated, less so than in $O$. medius and related species; sternum V and VI centrally with subcircular areas with tomentose greyish to yellowish pubescence and rasp-like microsculpture; sternum VII posteriorly weakly concave and slightly flattened; hind margin of sternum VIII weakly concave, centrally flattened, and with long black setae; sternum IX posteriorly deeply concave, hind margin with predominantly dark setae (Fig. c); lateral tergal sclerites of segment IX long and acute, almost reaching hind margin of tergum $X$ in lateral view (Fig. 26d); hind margin of tergum $X$ with long black setae; ventral process of
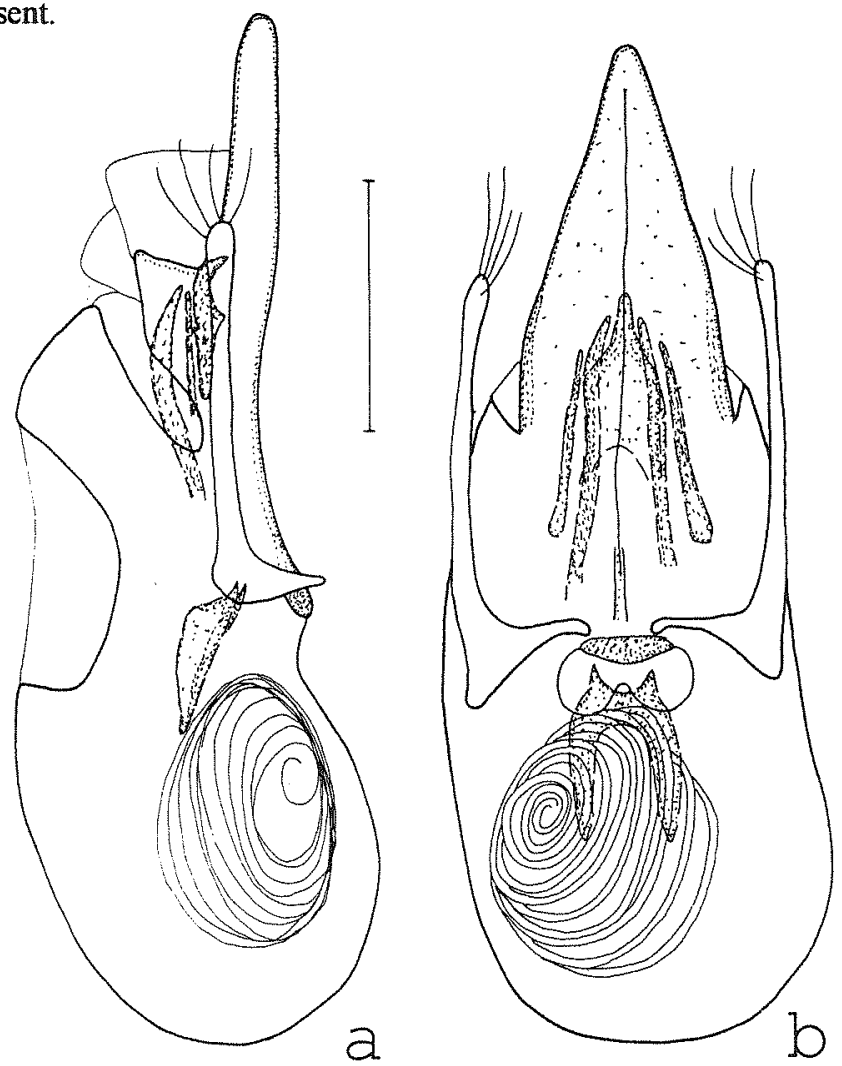
aedeagus sometimes wider than shown in Fig. 26b, with weak, but long median carina; parameres apically hardly dilated; internal sac with 6 characteristic sclerotized structures: a doubly bifid median basal piece, a hook-shaped median apical piece with long proximal processes, a pair of stout and apically curved oblong lateral pieces, and a pair of straight oblong lateral pieces; flagellum relatively wide and with ca. 15 coils (Figs $26 \mathrm{a}-\mathrm{b}$ ).

\%: protarsomeres I - IV slightly less dilated than in $\sigma^{*}$, sexual dimorphism rather indistinct; sternum VIII \pm truncate to weakly convex posteriorly, hind margin with a mixture of black and brownish setae; tergum $X$ near hind margin with few stout, apically weakly curved, modified setae (Fig. 26e); inner face of styli with fringe of numerous long and apically bent setae.

Comparative notes: $O$. taiwanus is distinguished from other Taiwanese species by size alone. Apart from $O$. punctatus, it is the only macropterous species known from the island. For remarks on phylogenetics see section 5 . 


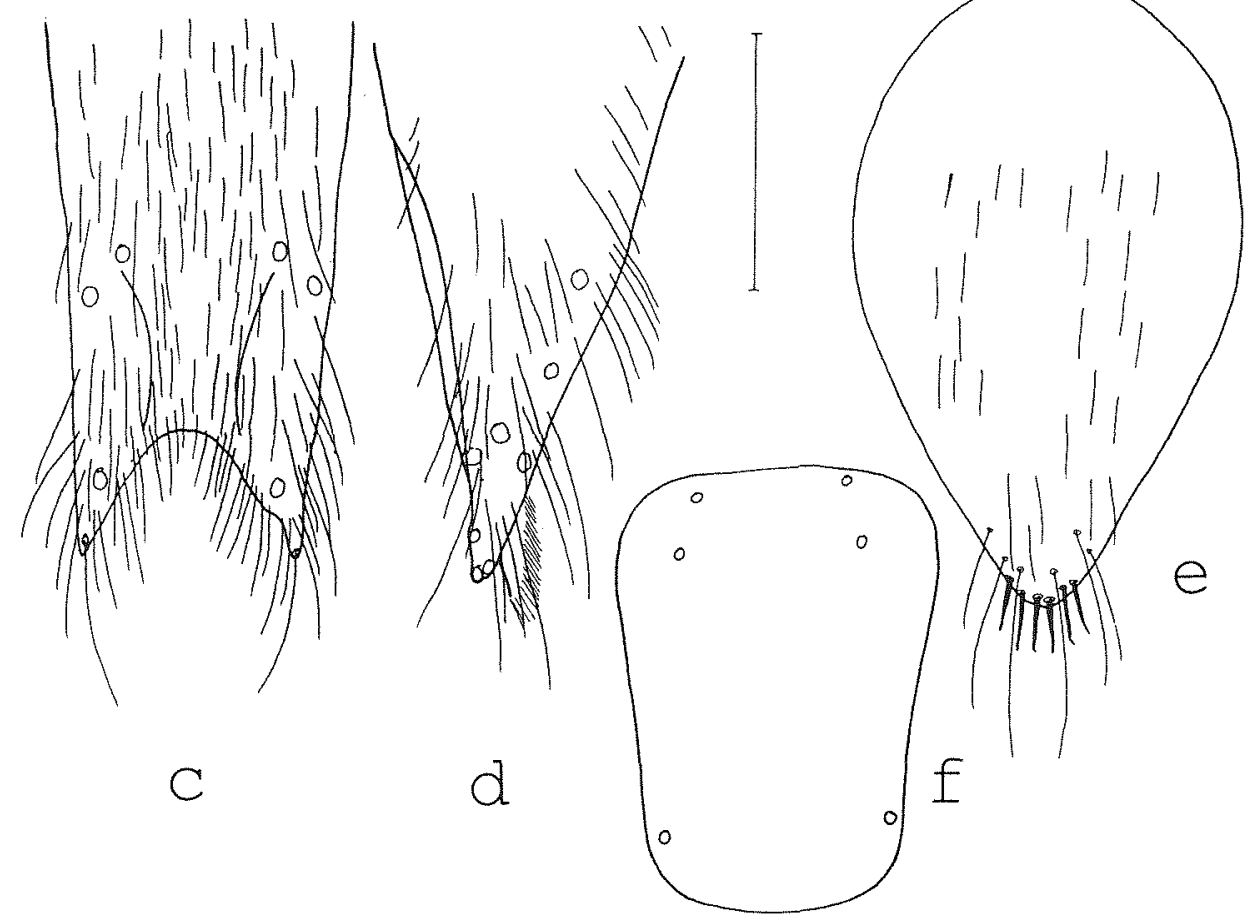

Figs 26 a - f: $O$. taiwanus ITo: posterior part of $o^{\pi}$ sternum IX (c); posterior parts of $o^{\pi}$ lateral tergal sclerite IX and tergum $\mathrm{X}$ in lateral view (d); $;$ tergum $\mathrm{X}(\mathbf{e}) ;$ schematic representation of pronotal punctation pattern (f); long setae partly or completely omitted in $\mathrm{c}-\mathrm{d}$. Scales: $0.5 \mathrm{~mm}$; f without scale.

Distribution and bionomics: The species has become known from two localities in central Taiwan, Alishan (Chiai Hsien, type locality) and Shanlinchi (Nantou Hsien), where it was collected in May (Map 1, p. 85).

\subsection{Othius shibatai ITO, 1989}

Figs 27 a - f, Map 1 (p. 85)

Othius shibatai ITO, 1989: 28f.

\section{Type examined}

Holotype o": Alishan, Taiwan, 3.V.1983, T. Ito/ Holotype Othius shibatai T. Ito sp. nov. (cShT).

\section{Additional material examined}

10", Taiwan, Alishan, 2300m, 26.VII.1982, leg. Y. Shibata (cShY).

Measurements (HT, nontype specimen): HL: 1.37, 1.37; HW: 1.16, 1.16; PW: 1.13, 1.10; PL: 1.51, 1.49; EL: 0.85, 0.85; TiL: 1.07, 1.10; TaL: 0.85, 0.85; TL: 9.2, 8.2.

Colour of body \pm uniformly reddish brown.

Head $1.18 x$ longer than wide, slightly $(1.03-1.06 x)$ wider than pronotum; eyes reduced, with $<20$ ommatidia, $0.15 x$ the length of postgenae in lateral view; temples behind eyes remarkably straight, head posteriorly weakly widened in dorsal view; dorsal surface with subdued shine due to distinct 
isodiametric microsculpture, without noticeable micropunctation; macropunctation in posterolateral area and near occiput moderately dense and coarse; frons with posterior pair of punctures present, the anterior punctures accompanied by 2 - 3 additional punctures; frontal furrows distinctly sulcate; antenna long, with antennomeres II $2 x$ longer than wide, III $2.5 x$ longer than wide, IV distinctly and V weakly oblong, and X weakly transverse.
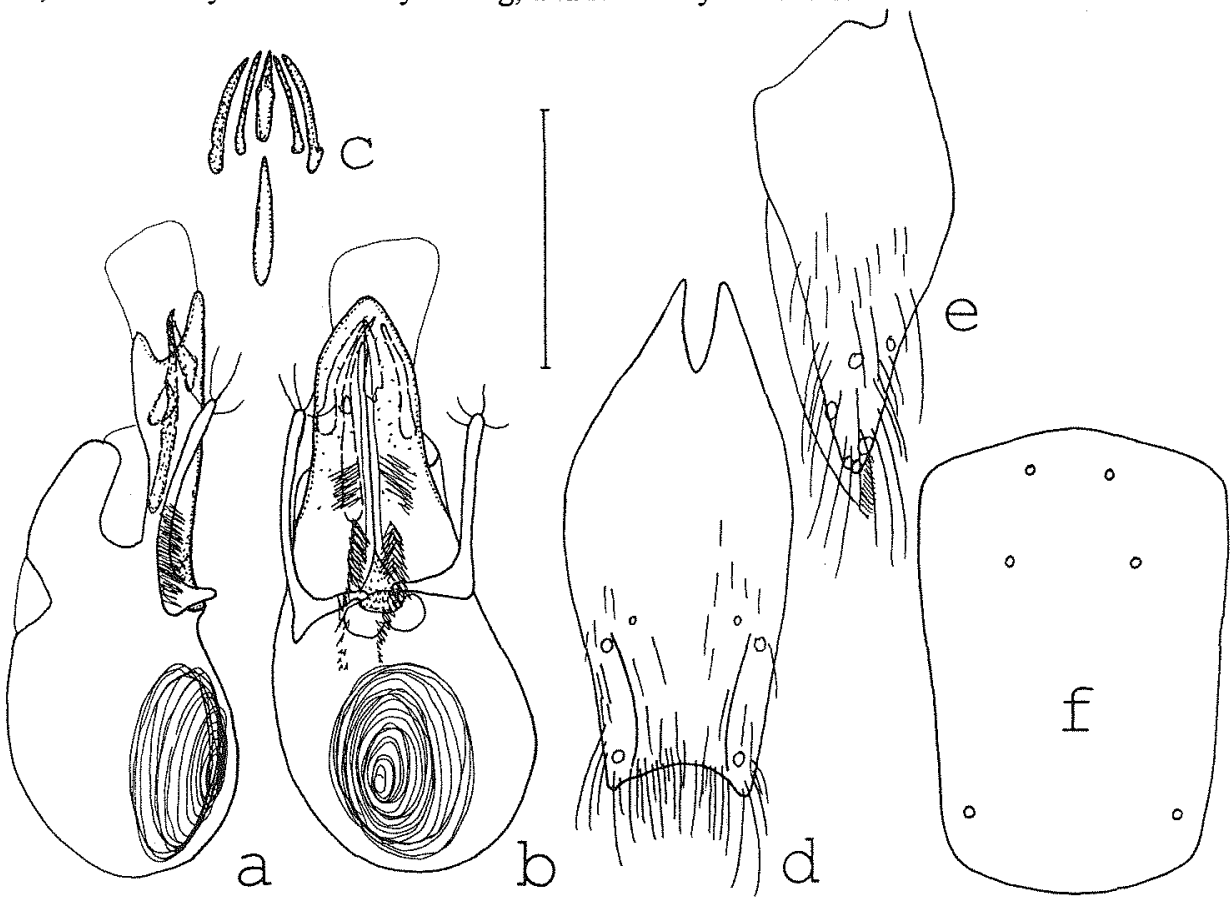

Figs 27 - f: $O$. shibatai Iro (HT): aedeagus in lateral and in ventral view (a, b); internal structures in ventral view (c); $\sigma^{\pi}$ sternum IX (d); $\sigma^{n}$ lateral tergal sclerite IX and tergum X in lateral view (e); schematic representation of pronotal punctation pattern (f); long setae partly or completely omitted in $d-e$. Scale: $0.5 \mathrm{~mm}$; f without scale.

Pronotum dilated anteriorly, with maximal width near anterior angles and remarkably straight lateral margins, $1.34-1.36 \mathrm{x}$ longer than wide; posterior scratch-like impression present; dorsal surface with microsculpture composed of long transverse meshes and transverse striae; pronotal punctation as in Fig. 27f.

Elytra short, EL/PL: 0.57 ; punctures moderately dense, rather large, but shallow; interstices with shallow traces of microsculpture and micropunctation; scutellum with distinct transverse microsculpture, without macropunctation; hind wings reduced; metatibia in the basal third thin, in the apical two thirds distinctly and somewhat abruptly widened; TiL/TaL: $1.25-1.29$.

Abdomen with distinct, \pm evenly spaced punctation; microsculpture near anterior margins of terga composed of distinct isodiametric meshes, on remainder of tergal surfaces transverse and shallow; palisade fringe absent.

$0^{7}$ : protarsomeres I - IV moderately dilated, distinctly less so than in $O$. medius and related species and also somewhat less so than in $O$. punctatus; sternum V and VI centrally with subcircular callosities without conspicuous pubescence; sternum VII posteriorly weakly concave and shallowly impressed; hind margin of sternum VII weakly concave, centrally somewhat impressed, and with 
row of yellowish setae; sternum IX posteriorly broadly and moderately concave, hind margin with long yellowish setae (Fig. 27d); lateral tergal sclerites of segment IX apically rounded, not reaching hind margin of tergum $X$ in lateral view (Fig. 27e); aedeagus with rather short, apically weakly dilated parameres; ventral process with distinct median carina and a pair of long parallel folds; internal sac with 6 sclerotized structures: a long median basal, a shorter, slightly hookshaped median apical, a pair of basally dilated and oblong lateral, and a pair of oblong, weakly sclerotized lateral pieces; internal sac also with two pairs of clusters of dark long spines; flagellum thin and with ca. 25 coils (Figs $27 \mathrm{a}-\mathrm{c}$ ).

q: unknown.

Comparative notes and phylogenetics: Among the Taiwanese Othius species, $O$. shibatai is characterized by the reduced eyes, the light colour, the slender pronotum (which is not wider than the head), the very short elytra, the absence of conspicuous pubescence on the o" sterna V and VI, and the presence of clusters of dark long spines in the internal sac, apomorphic characters which this species only shares with $O$. yushanus, its adelphotaxon, and which characterize both species as a monophyletic group. For distinction from $O$. yushanus see the following diagnosis.

Distribution and bionomics: The species has become known only from the type locality in central Taiwan (Map 1, p. 85), where it was collected under stones at an altitude of $2200-2300 \mathrm{~m}$ (ITO, pers. comm.; additional material examined) in May and July. The light body colour, the reduced eyes, the slender pronotum and the reduced length of the elytra are presumably adaptations to a subterranean habitat.

\subsection{Othius yushanus ITO, 1989}

Figs 28 a - f, Map 1 (p. 85)

Othius yushanus ITO, 1989: 29f.

\section{Types examined}

Holotype $\sigma^{\text {: }}$ Mt. Yushan, Taiwan, 20.V.1981, N. Ito/ Holotype Othius yushanus T. Ito sp. nov. (cShT). Paratypes: $2 \circ ㅇ$ [1우 with mature egg in ovaries], same data as holotype (cIto).

\section{Additional material examined}

19. Taiwan, Nantou Hsien, Mt. Yushan, 20.V.1968, leg. Kikuchi (cShY).

\section{Diagnosis}

Measurements (range, n=4): HL: 1.10 - 1.20; HW: 0.98 - 1.04; PW: 0.98 - 1.02; PL: 1.28 - 1.37; EL: $0.76-0.82$; TiL: $0.82-0.95$; TaL: $0.56-0.70$; TL: $6.4-8.1$.

Externally very similar to $O$. shibatai, but on the whole smaller (see measurements); colour of body \pm uniformly reddish brown.

Head 1.12 - 1.16x longer than wide, about as wide as pronotum (HW/PW: 0.97 - 1.02); eyes small, but larger than in $O$. shibatai, with ca. $25-30$ ommatidia, $0.20-0.24 \mathrm{x}$ the length of postgenae in lateral view; shape of head and punctation similar to $O$. shibatai, but posterior pair of frontal punctures smaller; microsculpture less distinctly isodiametric, partly transverse; antennae clearly shorter than in $O$. shibatai, with antennomeres II ca. $1.5 x$ longer than wide, III $2 x$ longer than wide, IV subquadrate, $\mathrm{V}$ transverse and $\mathrm{X}$ strongly transverse.

Pronotum of similar shape (PL/PW: $1.27-1.36$ ), microsculpture and punctation pattern as in $O$. shibatai, but with weakly concave lateral margins.

Elytra short, EL/PL: $0.56-0.61$; punctation slightly denser than in $O$. shibatai; interstices with shallow, \pm irregular microsculpture and micropunctation particularly near scutellum and near suture; scutellum with distinct transverse and/or isodiametric microsculpture, and with few small punctures; hind wings reduced; metatibia shaped as in $O$. shibatai, but legs on the whole shorter, TiL/TaL: $1.30-1.46$. 

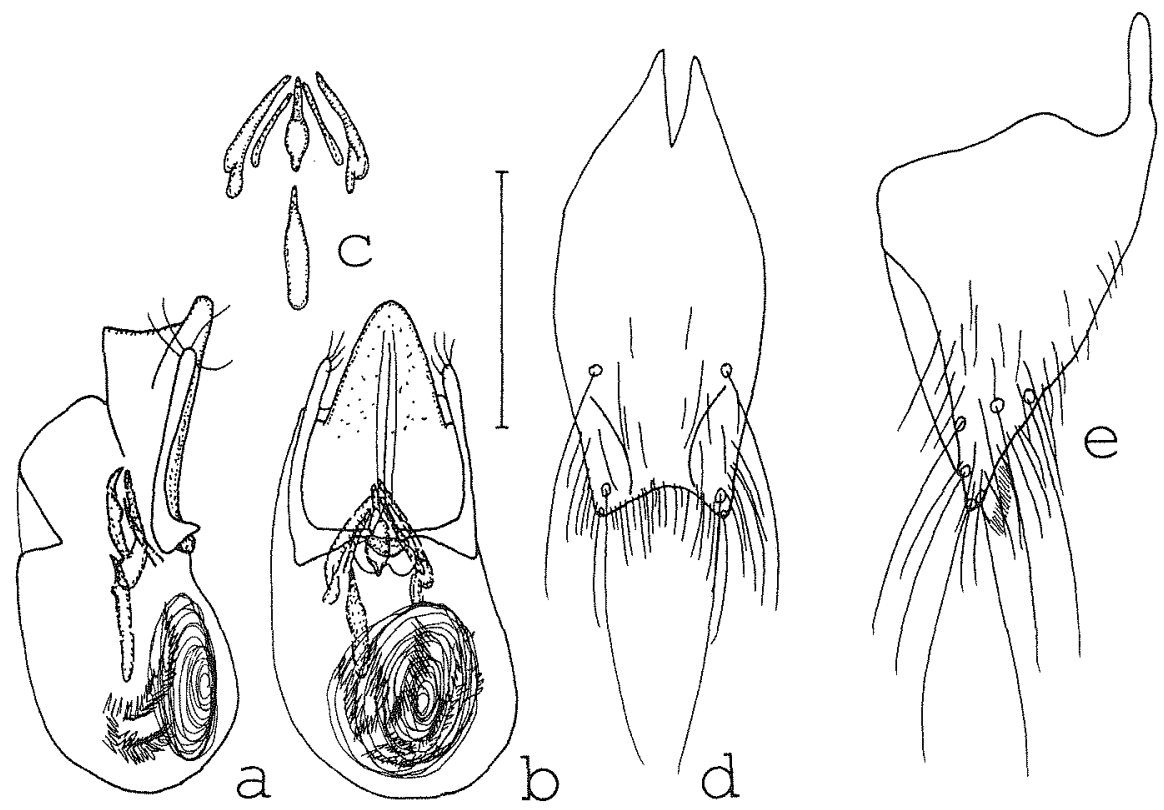

Figs 28 a - f: O. yushanus Iто (a - e: HT): aedeagus in lateral and in ventral view $(\mathbf{a}, \mathbf{b})$; internal structures in ventral view $(\mathbf{c}) ; \sigma^{x}$ sternum IX (d); $o^{x}$ lateral tergal sclerite IX and tergum X in lateral view (e); 9 terminalia (f); long setae partly or completely omitted in $\mathrm{f}$. Scales: $0.5 \mathrm{~mm}$.

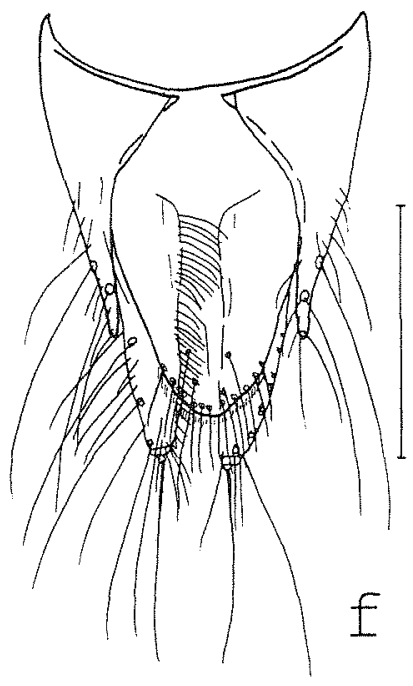

Abdomen with punctation and microsculpture similar to $O$. shibatai, but microsculpture near anterior margins of terga predominantly composed of \pm transverse meshes; palisade fringe at hind margin of tergum VII absent.

o: dilatation of protarsomeres as in $O$. shibatai; callosities of sternum V and VI very weak, reduced to subcircular areas with dense microsculpture and therefore less shine than the surrounding sternal area; sternum VII and VIII as in O. shibatai; sternum IX similar to O. shibatai (Fig. 28d); lateral tergal sclerites of segment IX apically more acute than in $O$. shibatai (Fig. 28e); aedeagus on the whole as in $O$. shibatai, but smaller, apex of ventral process in lateral view 
broader and in ventral view of different shape, and parameres relatively longer; internal sac with differently shaped clusters of long dark spines, apically more acute and basally more dilated median apical piece, and with basally more dilated dark lateral pieces; flagellum as in $O$. shibatai (Figs $28 \mathrm{a}-\mathrm{c}$ ).

\%: protarsomeres I - IV weakly dilated, sexual dimorphism pronounced; sternum V and VI centrally instead of callosities with subcircular areas with denser, not distinctly transverse microsculpture and therefore less shine; hind margin of sternum VIII convex and with marginal row of yellow setae; lateral tergal sclerites IX each with one terminal seta; tergum $X$ with unmodified, long yellow setae posteriorly; inner face of styli with fringe of long, dense and apically weakly curved yellowish setae (Fig. 28f).

Comparative notes: For distinction from the similar and closely related $O$. shibatai see diagnosis. For separation from other Taiwanese congeners and for phylogenetic conclusions see below $O$. shibatai and section 5 .

Distribution and bionomics: Like $O$. shibatai, $O$. yushanus has become known only from the type locality in central Taiwan (Map 1, p. 85), where it was also collected under stones at an altitude of $2500-3000 \mathrm{~m}$ (ITO, pers. comm.) in May. The eggs of a dissected + paratype contained a mature egg. From the external characters (see $O$. shibatai) a subterranean habitat can be inferred.

\subsection{Othius parvipennis (SHIBATA, 1973)}

Figs 29 a - f, Map 1 (p. 85)

Othiellus parvipennis SHIBATA, 1973: 128ff.

Othius parvipennis (SHIBATA): SHIBATA (1986); ITO (1989)

\section{Types examined}

Holotype \%: (Alishan) Chiai - Hsien, Formosa, Aug. 8th, 1970, Coll. Y. Shibata/ [Holotype] Othiellus parvipennis, + , Y. Shibata, 1973 (TUA). Paratype $q$ : same data as holotype, but Aug. 7th (cShY).

\section{Additional material examined \\ 10*, Taiwan, Alishan, 17.V.1981, leg. N. Ito (cIto).}

\section{Diagnosis}

Measurements and ratios (range; $\mathrm{n}=3$ ): HL: 1.59 - 1.68; ; HW: $1.49-1.62$; PW: 1.59 - 1.68; PL: 1.89 - 2.04; EL: 1.13 - 1.19; TiL: 1.43 - 1.46; TaL: 1.10 - 1.22; TL: $10.3-11.0$; HL/HW: 1.04 1.12; HW/PW: 0.89 - 0.98; PL/PW: 1.19 - 1.22; EL/PL: 0.58 - 0.60; TiL/TaL: 1.20 - 1.31.

Colour of body brown, with the elytra, the hind margins of abdominal segments VII and VIII, parts of segments IX and $X$, and the legs yellowish brown.

Head weakly oblong, slightly narrower than pronotum (cf. ratios); eyes ca. $0.33-0.38 x$ the length of postgenae in lateral view; temples behind eyes straight, head posteriorly subparallel or very weakly widened in dorsal view; dorsal surface with subdued shine due to distinct, but fine microsculpture predominantly composed of transverse meshes of variable length, which are on average shorter in the anterior than in the posterior region of head; sparse micropunctation visible only in posterior and lateral area; macropunctation in posterolateral area and near occiput moderately dense and coarse; frons with posterior pair of punctures present, but much smaller than the anterior punctures, which are accompanied by $1-3$ additional punctures; additional punctures may also be present near posterior pair of frontal punctures; frontal furrows distinctly sulcate; antennae moderately long, moderately incrassate apically; antennomeres II ca. $1.5 x$ longer than wide, III 2 $2.3 \mathrm{x}$ longer than wide, IV and V subquadrate, and VII - X transverse. 


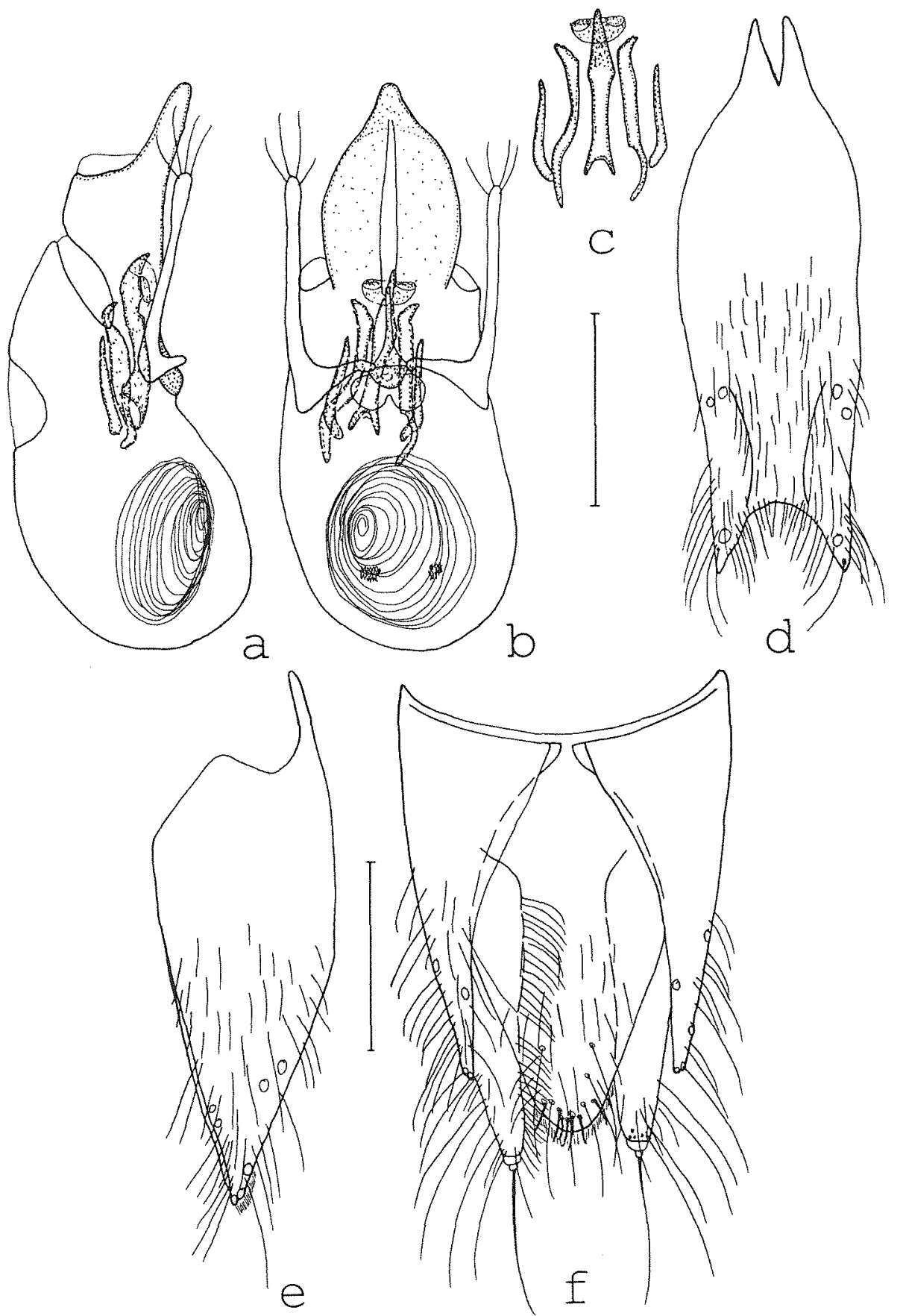

Figs 29 a - f: O. parvipennis (SHBBATA) (f: HT): aedeagus in lateral and in ventral view (a, b); internal structures in ventral view (c); of sternum IX (d); or lateral tergal sclerite $\mathrm{XX}$ and tergum $\mathrm{X}$ in lateral view (e); o terminalia (f); long setae partly or completely omitted in $\mathrm{d}-\mathrm{f}$. Scales: $0.5 \mathrm{~mm}$. 
Pronotum with maximal width in anterior half, but nearer to middle than to anterior angles, on the whole shorter and with more convex surface than in $O$. taiwanus; posterior scratch-like impression present; dorsal surface with microsculpture composed of long transverse meshes and transverse striae; posterior discal puncture clearly distant from hind angles, much more distant from lateral margins than in O. taiwanus (cf. Fig. 301).

Elytra short (cf. ratio); punctures dense, rather large and well-defined; interstices shining, without distinct microsculpture; scutellum shining, microsculpture very shallow and composed of large meshes, with macropunctation; hind wings reduced.

Abdomen with distinct, \pm evenly spaced punctation, which is finer on posterior than on anterior terga; microsculpture very weak, transverse, near anterior margins of terga only slightly more distinct and not reticulate; surface with weakly iridescent shine; palisade fringe at hind margin of tergum VII absent.

$0^{*}$ : protarsomeres I - IV strongly dilated; central subcircular callosities on sternum V and VI large, larger than in $O$. yushanus and approximately of similar relative size as in $O$. medius, especially anteriorly more distinctly delimited from surrounding sternal area than in those two species, and with less dense, blackish pubescence; sternum VII posteriorly weakly concave and centrally weakly flattened; hind margin of sternum VIII \pm truncate, centrally somewhat flattened, without row of marginal setae; sternum IX with mostly blackish pubescence, posteriorly broadly and deeply concave (Fig. 29d); lateral tergal sclerites of segment IX apically acute, just reaching hind margin of tergum X in lateral view (Fig. 29e); aedeagus with apically weakly dilated parameres; ventral process with distinct basal carina and pair of long apical folds; internal sac with 5 sclerotized structures: a long median apical, a pair of long curved lateral, and a pair of long straight, basally somewhat dilated lateral pieces; near apex of median apical structure with membranous structure of characteristic shape; basally with a pair of small membranous structures equipped with \pm sclerotized short spines; flagellum thin and with ca. 20 coils (Figs 29 a - c).

$q$ : sternum VIII posteriorly convex and with fringe of dense and rather long yellow setae; tergum $\mathrm{X}$ with very narrow basis, near hind margin with several long, apically weakly curved modified setae; inner margin of styli with fringe of dense and relatively long setae (Fig. 29f).

Comparative notes: Among its Taiwanese congeners, $O$. parvipennis is readily separated from the macropterous $O$. punctatus BERNHAUER and $O$. taiwanus ITo by the smaller eyes, lighter colour, shorter elytra, the reduced hind wings and by absence of a palisade fringe at the hind margin of abdominal tergum VII, and from the microphthalmous $O$. shibatai ITO and $O$. yushanus ITO by the larger eyes, darker colour, larger size, broader pronotum, and the primary and secondary sexual characters. For distinction from the following new species, their diagnoses and the comparative notes are referred to. There are no close affinities of $O$. parvipennis to the Himalayan $O$. kashmirica CAMERON and the Canarian O. microphtalmus CoIFFAIT as suggested by SHIBATA (1973). These species belong to the - primarily Western Palaearctic - O. laeviusculus species group (AsSING, 1997a, 1998a, b).

Distribution and bionomics: Like the related congeners (see below), O. parvipennis apparently has a very limited area of distribution and is confined to higher altitudes. O. parvipennis has become known only from the type locality in central Taiwan: Alishan, Chiai Hsien (Map 1, p. 85). The two type specimens were collected under a large stone at an altitude of $2200 \mathrm{~m}$ in August (SHIBATA, 1973), the only known non-type specimen was taken in May (see material examined). 
Beitr. Ent. 49 (1999) 1

4.23. Othius smetanai sp. $\mathrm{m}$.

Figs 30 a - f, Map 1 (p. 85)

Type

Holotype $o^{n}$ [teneral]: Taiwan, Pingtung Hsien, Peitawushan, Kuai-Ku Hut, 2325m, 21.V.1991, A. Smetana (T88) (cSme).
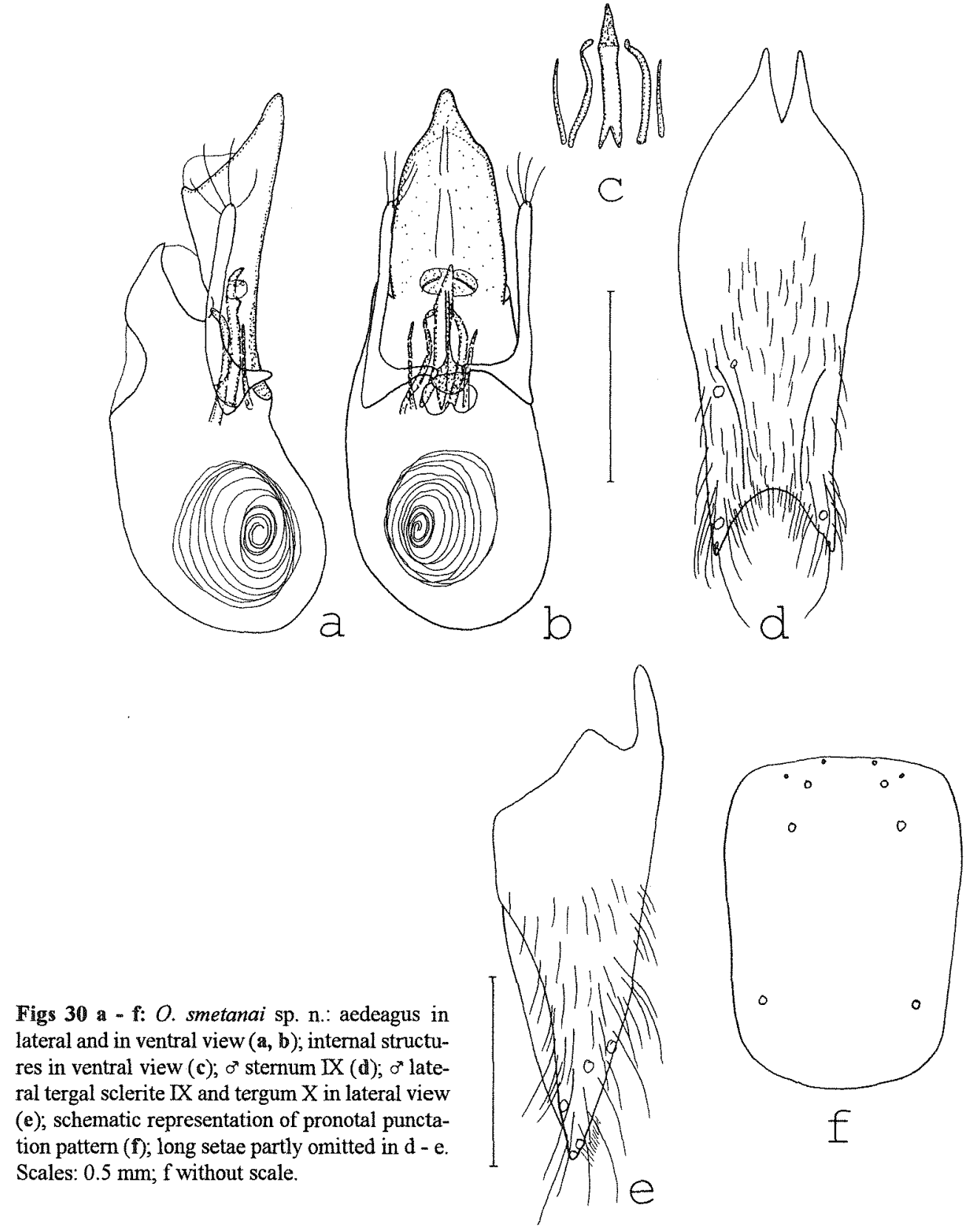


\section{Diagnosis}

Measurements and ratios (HT): HL: 1.53; HW: 1.34; PW: 1.49; PL: 1.86; EL: 1.07; TiL: 1.40; TaL: 1.07 ; TL: 10.8; HL/HW: 1.14; HW/PW: 0.90; PL/PW: $1.25 ;$ EL/PL: 0.57 ; TiL/TaL: 1.31.

Externally highly similar and closely related to $O$. parvipennis, but distinguished from that species as follows:

Colour darker, dark brown to blackish, with the legs and part of the basal two antennomeres light brown or reddish; body on the whole smaller (see measurements).

Head with less distinct, predominantly transverse microsculpture; posterior pair of frontal punctures larger.

Pronotum with discal punctures as in $O$. parvipennis (Fig. 30f).

Abdomen with slightly denser punctation, on the whole less shiny, but more intensely iridescent. $\sigma^{x}$ : protarsomeres I - IV somewhat less dilated than in O. parvipennis; sternum V and VI centrally with subcircular callosities with tomentose brownish pubescence, the callosities distinctly smaller (less than half the area) than in $O$. parvipennis; sternum VII posteriorly weakly concave, not distinctly flattened; hind margin of sternum VIII weakly convex, laterally with fewer dark setae; sternum IX similar to O. parvipennis (Fig. 30d); lateral tergal sclerites IX as in Fig. 30e; aedeagus smaller; ventral process more slender, pair of apical folds shorter and less distinct; internal sac with similar arrangement of sclerotized and membranous structures, but lateral pieces thinner and less dilated basally (probably due to the fact that the only of available was teneral, the pair of dark basal membranous structures were not distinctly visible); flagellum moderately thin (thinner than in $O$. parvipennis) and with only ca. 12 coils (Figs $30 \mathrm{a}-\mathrm{c}$ ).

q: unknown.

Derivatio nominis: This species is dedicated to Aleš Smetana, to whom I am indebted especially for his remarkable material from Taiwan, which contained type material of five Taiwanese species described here for the first time.

Comparative notes and phylogenetics: For separation from the preceding Taiwanese Othius species and for phylogenetic affinities see comments below $O$. parvipennis and section 5 . From the other species allied to $O$. parvipennis, $O$. smetanai is distinguished by darker colour, longer antennae, and by the primary and secondary sexual characters (see diagnoses below), from $O$. hamatus and $O$. aequabilis in addition by larger size. $O$. praecisus and $O$. collapsus, which are of similar size and general appearance, differ in the pronotal punctation pattern, the apical processes of the lateral tergal sclerites IX, and the shape and internal structures of the aedeagus.

Distribution and bionomics: $O$. smetanai has become known only from the type locality (Peitawushan) in Pingtung Hsien, the southernmost Taiwanese locality where Othius has been found (Map 1, p. 85). The holotype was slightly teneral; apart from the details indicated on the label, no ecological data are available.

\subsection{Othius aequabilis sp. $\mathrm{n}$.}

Figs 31 a-g, Map 1 (p. 85)

\section{Types}

Holotype $\sigma^{*}$ : Taiwan, Nantou Hsien, Yushan N. P., 1.8km W Pai-Yun Hut, 3375m, 17.V.91, A. Smetana [T 85] (cSme). Paratypes: $29 \%$ [1 9 with mature egg in ovaries], same data as holotype (cSme, cAss).

\section{Diagnosis}

Measurements and ratios (range, $\mathrm{n}=3$ ): $\mathrm{HL}: 1.25-1.31$; HW: $1.10-1.22 ; \mathrm{PW}: 1.27-1.34$; PL: 1.59 - 1.65; EL: 0.95; TiL: 1.10 - 1.19; TaL: 0.82 - 0.88; TL: 8.7 - 9.4; HL/HW: 1.08 - 1.14; HW/PW: $0.87-0.91$; PL/PW: $1.23-1.25$; EL/PL: $0.57-0.60$; TiL/TaL: $1.33-1.37$. 

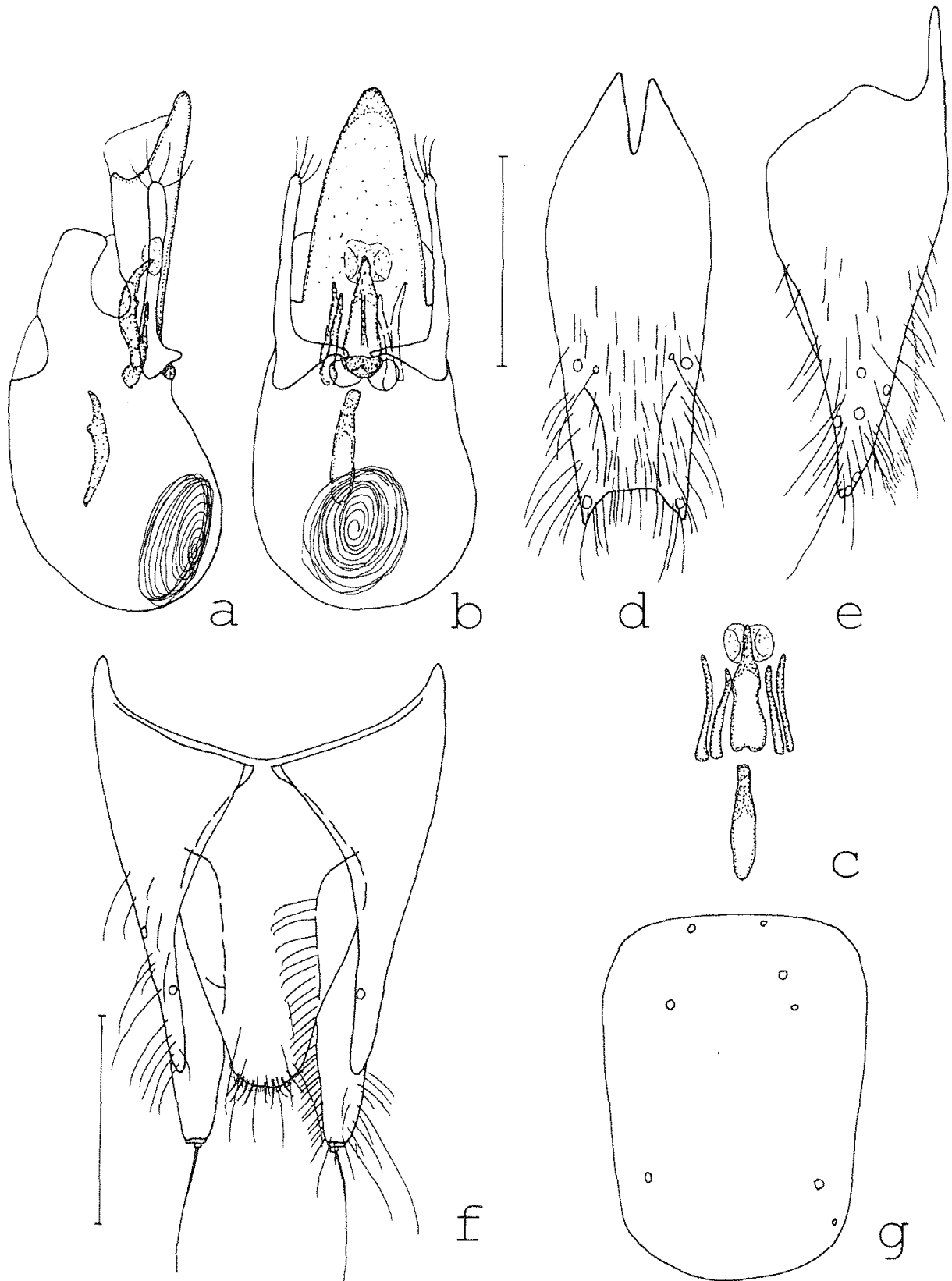

Figs 31 a - g: $O$. aequabilis sp. $\mathrm{n}$ : aedeagus in lateral and in ventral view (a, b); internal structures in ventral view (c); $\sigma^{*}$ sternum $\mathrm{IX}(\mathrm{d})$; $\sigma^{*}$ lateral tergal sclerite $\mathrm{IX}$ and tergum $\mathrm{X}$ in lateral view (e); 9 terminalia (f); schematic representation of pronotal punctation pattern of PT (left) and of HT (right) (g); long setae partly or completely omitted in $\mathrm{d}-\mathrm{f}$. Scales: $0.5 \mathrm{~mm}$; $\mathrm{g}$ without scale. 
Externally highly similar to $O$. parvipennis, but distinguished from this species as follows:

Colour on the whole slightly darker, \pm uniformly dark brown, legs and antennal base reddish brown; body smaller than in $O$. parvipennis (see measurements).

Head with microsculpture predominantly composed of short transverse and isodiametric meshes; posterior pair of frontal punctures relatively large; antennae distinctly shorter than in $O$. parvipennis, antennomeres V - X (PT) or VI - X (HT) clearly transverse.

Pronotum with microsculpture composed of transverse meshes and transverse striae; position of posterior discal puncture as in $O$. parvipennis and $O$. smetanai; position of anterior punctures apparently variable (Fig. $31 \mathrm{~g}$ ).

Elytra of similar shape as in the related species, but punctation finer; scutellum with more distinct microsculpture composed of transverse meshes of variable length and with several punctures.

Abdomen with similar microsculpture and shine as in $O$. parvipennis, but punctation somewhat finer.

$\sigma^{*}:$ protarsomeres I - IV slightly less dilated than in $O$. parvipennis; sternum V and VI centrally with large circular callosities with tomentose, dense brownish pubescence, the callosities of similar size and almost equally delimited as in $O$. parvipennis; sternum VII posteriorly weakly concave and weakly flattened; hind margin of sternum VIII \pm weakly convex, without marginal pubescence, pubescence on the whole similar to $O$. smetanai; sternum IX of similar shape and pubescence as in $O$. parvipennis, but much less strongly concave posteriorly (Fig. 31d); lateral tergal sclerites of segment IX apically as in $O$. parvipennis, but slightly longer, reaching beyond tergum $\mathrm{X}$ (Fig. 31 ); aedeagus with ventral process slender, apically less acute than in $O$. parvipennis; apical folds indistinct, basal carina weak, not sclerotized; parameres apically weakly dilated; internal sac with 6 sclerotized structures: a median basal and an approximately equally long median apical, and two pairs of almost equally long and \pm straight lateral pieces; near apex of median apical structure with membranous structure, which is less dark and distinct than in $O$. parvipennis; pair of dark basal membranous structures apparently absent; flagellum thin and with ca. 15 coils (Figs $31 \mathrm{a}-\mathrm{c}$ ).

$q$ : protarsomeres I - IV dilated, but distinctly less so than in $0^{*}$; sternum VIII convex, posteriorly with marginal row of yellow setae; lateral tergal sclerites IX apically rounded; tergum X posteriorly with several rather short and apically weakly curved modified setae; inner margins of styli with fringe of long, rather stout setae, which are anteriorly shorter and less curved than in $O$. taiwanus (Fig. 31f).

Derivatio nominis: The name (lat: similar, of similar shape) refers to the characteristic set of almost equally long sclerotized internal structures of the aedeagus.

Comparative notes: $O$. aequabilis is distinguished from the closely related $O$. parvipennis, $O$. smetanai, $O$. hamatus, $O$. acutus, and $O$. reticulatus, by the apically weakly pointed ventral process and by the presence of a basal median structure in the internal sac of the aedeagus, from all these species, except for $O$. hamatus, in addition by its smaller size and shorter antennae.

Distribution and bionomics: The species is known only from Yushan, Nantou Hsien, in central Taiwan (Map 1, p. 85), where it was collected at an altitude of $3375 \mathrm{~m}$ in May. The ovaries of a dissected 9 contained a mature $\mathrm{egg}$.

\subsection{Othius hamatus sp. $\mathrm{n}$.}

Figs 32 a - f, Map 1 (p. 85)

Types: Holotype o: Taiwan, Kaohsiung Hsien, Peinantashan trail, 2250m, 4.VII.93, A. Smetana [T 137] (cSme). Paratypes: 1 [ [with mature egg in ovaries]: same data as holotype (cSme); 19 , Taiwan, Kaohsiung Hsien, Peinantashan trail, 2390-2490m, 5.VII.1993, A. Smetana [T 138] (cAss). 

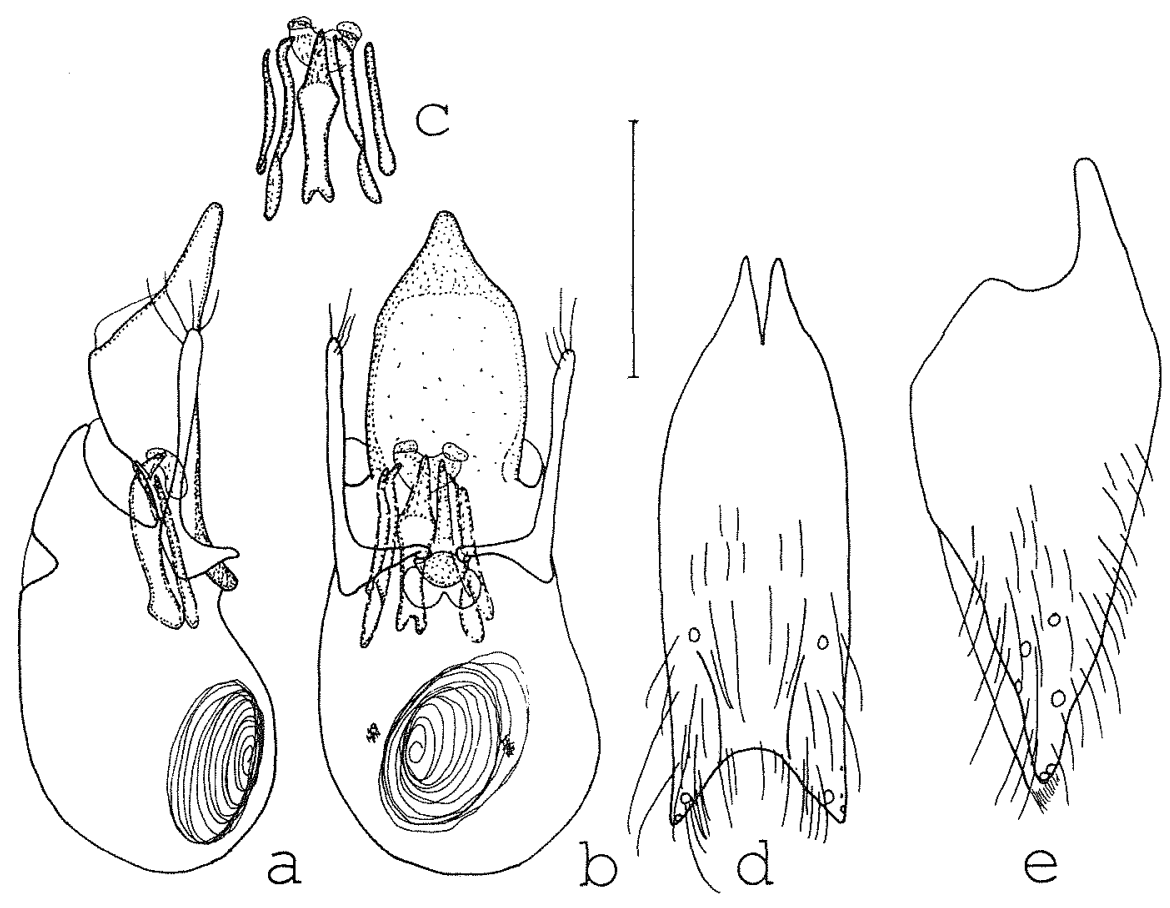

Figs 32 a - f: $O$. hamatus sp. $\mathrm{n} .:$ aedeagus in lateral and in ventral view $(\mathrm{a}, \mathrm{b})$; internal structures in ventral view (c); o sternum IX (d); $\sigma^{*}$ lateral tergal sclerite IX and tergum $X$ in lateral view (e); $\odot$ tergum $X(f) ;$ long setae partly or completely omitted in d - e. Scales: $0.5 \mathrm{~mm}$.

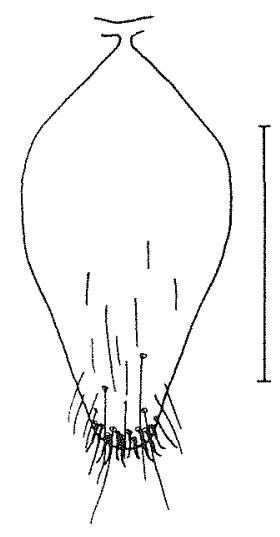

f

\section{Diagnosis}

Measurements and ratios (range, $\mathrm{n}=3$ ): $\mathrm{HL}: 1.25-1.31 ; \mathrm{HW}: 1.07-1.16$; PW: $1.22-1.28 ; \mathrm{PL}$ : 1.53 - 1.62; EL: 0.82 - 0.88; TiL: 1.08 - 1.13; TaL: $0.79-0.92$; TL: 8.2 - 9.4; HL/HW: $1.13-1.17$; HW/PW: 0.85 - 0.91; PL/PW: 1.25 - 1.27; EL/PL: 0.54 - 0.55; TiL/TaL: 1.23 - 1.37.

Externally most similar to $O$. aequabilis, but more closely related to the somewhat larger (see measurements) and darker $O$. smetanai and to $O$. acutus (see below).

Colour and size as in $O$. aequabilis. 
Head more distinctly oblong (cf. ratio) and with slightly smaller eyes than in the related species, eyes $0.31-0.33 x$ the length of postgenae in lateral view; microsculpture similar to $O$. aequabilis, i. e. predominantly composed of short transverse and isodiametric meshes; posterior pair of frontal punctures relatively large; antennae with basal 3 antennomeres ferrugineous, distally only weakly infuscate, of similar length and proportions as in $O$. aequabilis, distinctly shorter, less massive and with more transverse antennomeres than in $O$. smetanai and $O$. parvipennis.

Pronotum with microsculpture composed of a mixture of transverse and isodiametric meshes, and transverse striae; discal punctation pattern similar to $O$. parvipennis and $O$. smetanai.

Elytra with punctation as in $O$. smetanai, slightly finer and less dense than in $O$. aequabilis; microsculpture similar to $O$. aequabilis, more distinct than in $O$. smetanai.

Abdomen with similar microsculpture and shine as in $O$. aequabilis.

o: dilatation of protarsomeres I - IV as in O. smetanai; sternum V and VI as in O. smetanai centrally with small suboval callosities with tomentose, dense brownish pubescence; sternum VII posteriorly weakly concave and weakly flattened; unlike $O$. smetanai, sternum VIII not distinctly bicoloured; hind margin of sternum VIII \pm truncate, without marginal pubescence, pubescence on the whole similar to $O$. smetanai; sternum IX of similar shape as in $O$. smetanai, but pubescence less dense (Fig. 32d); lateral tergal sclerites IX relatively short, not reaching hind margin of tergum X (Fig. 32e); aedeagus of similar morphology as in $O$. smetanai, but ventral process broader in ventral view, and in lateral view apically narrower; apical folds absent, basal carina distinctly sclerotized; parameres apically weakly dilated; internal sac with sclerotized structures as in $O$. smetanai, but apical median piece more strongly curved and lateral pieces stouter; near apex of median apical structure with membranous structure, its shape slightly different from that in $O$. smetanai; flagellum thin and with ca. 15 coils (Figs $32 \mathrm{a}-\mathrm{c}$ ).

q: protarsomeres I - IV dilated, but distinctly less so than in $\sigma^{*}$; sternum VIII convex, posteriorly with marginal row of rather dense yellow setae; lateral tergal sclerites IX apically acute, with two terminal setae, but without apical process; tergum $X$ posteriorly with several rather short and apically weakly curved modified setae (Fig. 32f); styli with fringe of dense, stout, not or only weakly curved setae, posteriorly decreasing in length.

Derivatio nominis: The name (lat: hook-shaped) refers to the shape of the median sclerotized structure in the internal sac of the aedeagus, a character distinguishing $O$. hamatus from the similar O. smetanai.

Comparative notes and phylogenetics: For a distinction from $O$. acutus and $O$. smetanai see the comparative notes below the former species and the diagnosis above, respectively. From the externally highly similar $O$. aequabilis, $O$. hamatus is separated by the shorter elytra, and by the different primary and secondary sexual characters. The species is characterized by a set of autapomorphies: the slender head and pronotum, the reduced eye size, and the short antennae. For further remarks on phylogenetic affiliations see section 5 .

Distribution and bionomics: Like the closely related species, $O$. hamatus seems to have a very restricted area of distribution. It is known only from Peinantashan, Kaohsiung Hsien, in southern central Taiwan (Map 1, p. 85), where it was collected at an altitude of $2250-2490 \mathrm{~m}$ in July, together with the following species. The ovaries of a dissected $q$ contained a mature egg.

\subsection{Othius acutus sp. $\mathrm{n}$.}

Figs 33 a - e, Map 1 (p. 85)

Type

Holotype ơ: (Kuanshan Yakou) Taitung, Taiwan, Aug. 21st, 1987, Y. Shibata leg. (TUA). 


\section{Diagnosis}

Measurements and ratios (HT): HL: 1.53; HW: 1.34 ; PW: 1.53 ; PL: 1.81 ; EL: 1.01 ; TiL: 1.31; TaL: 1.01 ; TL: 10.3; HL/HW: 1.14; HW/PW: 0.88; PL/PW: 1.19; EL/PL: 0.56; TiL/TaL: 1.30. Closely related and externally similar to $O$. parvipennis and allied species.

Whole body \pm uniformly reddish brown, with the elytra and the legs yellowish brown.

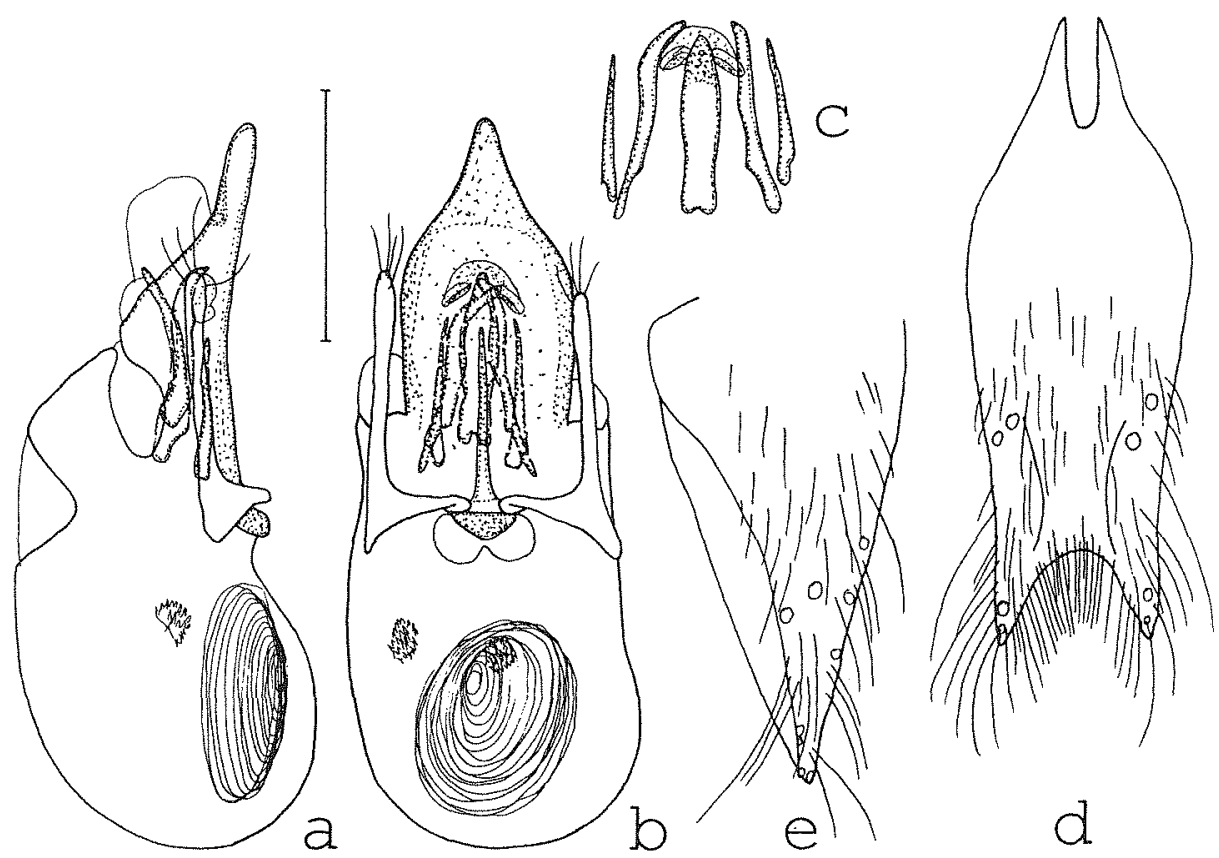

Figs 33 a - e: $O$. acutus sp. $n$. aedeagus in lateral and in ventral view $(a, b)$; internal structures in ventral view (c); $o^{*}$ sternum IX (d); $o^{*}$ lateral tergal sclerite IX and tergum X in lateral view (e); long setae partly or completely omitted in d - e. Scale: $0.5 \mathrm{~mm}$.

Head of similar shape and proportions as in O. parvipennis, less oblong than in O. hamatus (cf. ratios); relative size of eyes as in $O$. parvipennis; macropunctation similar to $O$. parvipennis, but slightly sparser, about as dense as in $O$. smetanai; posterior pair of frontal punctures present; anterior frontal punctures accompanied by $2-3$ additional punctures; frontal furrows distinctly sulcate; micropunctation present on whole dorsal surface, also on frons; microsculpture predominantly isodiametric, but shallower than in $O$. reticulatus (see below), surface therefore more shining than in that species; antenna similar to $O$. parvipennis, but slightly shorter, longer and more massive than in $O$. hamatus; antennomeres IV subquadrate and $\mathrm{V}$ - $\mathrm{X}$ increasingly transverse.

Pronotum of similar shape and punctation as in $O$. parvipennis, broader and posteriorly more distinctly tapering than in $O$. hamatus; microsculpture predominantly composed of transverse meshes.

Elytra with somewhat uneven surface, near scutellum and suture with irregular, ill-defined or confluent punctation and partly with microsculpture; scutellum with several punctures and transverse microsculpture; hind wings reduced.

o": dilatation of protarsomeres I - IV as in O. parvipennis; sternum V and VI with ovoid flattened areas with tomentose dark pubescence and dense punctation, their size only slightly smaller than 
in O. parvipennis; sternum VII posteriorly weakly concave and weakly flattened; sternum VIII of similar shape, colour and pubescence as in $O$. hamatus, but hind margin of sternum VIII weakly convex and with scattered short marginal pubescence; sternum IX and lateral tergal sclerites IX of similar shape and pubescence as in O. parvipennis (Figs 33d, e); aedeagus of similar morphology as in $O$. hamatus, ventral process apically acutely pointed, without pair of long median folds, but with long and distinctly sclerotized basal carina; parameres apically weakly dilated; internal sac with sclerotized structures similar $O$. hamatus, but apical median structure apically shorter and basally less distinctly constricted; near apex of median apical structure with membranous structure; basal membranous structure with two small areas with distinctly sclerotized spines; flagellum long and thin, and with ca. 25 coils (Figs $33 \mathrm{a}-\mathrm{c}$ ).

o: unknown.

Derivatio nominis: The name (lat.: acute) refers to the pointed apex of the median lobe.

Comparative notes and phylogenetics: The species is distinguished from $O$. hamatus, which has a similar morphology of the aedeagus, by larger size, a broader head and pronotum, larger eyes, more massive and longer antennae, lighter colour, the larger tomentose areas on the $\sigma^{*}$ sterna $\mathrm{V}$ and VI, an apically more strongly pointed median lobe and the different shape of the apical median structure in the internal sac. From $O$. parvipennis it is separated by smaller size, shorter antennae, different microsculpture of the head, the absence of a pair of median folds on the ventral process and the apically different shape of the aedeagus, and by the different shapes of the internal structures, especially the apical median structure. In $O$. smetanai, the antennae are distinctly longer, the colour is darker, the microsculpture of head and pronotum is transverse, and the $\sigma^{7}$ primary and secondary sexual characters (shape and internal structures of the aedeagus, modifications of sterna V and VI) are different. In $O$. aequabilis the basal median structure in the internal sac is absent. For distinction from $O$. reticulatus see below that species.

The similar morphology of the aedeagus (shape of ventral process, reduction of pair of median folds, shape of internal structures) suggests that $O$. acutus may be most closely allied to $O$. hamatus. A sister species relationship is also supported by the vicinity of the localities, from which the two species are known. The presence of distinct micropunctation on the head, the punctation and sculpture of the elytra (if they are constant characters), and the broad shape of the apical median structure in the internal sac of the aedeagus appear to be autapomorphic.

Distribution and bionomics: $O$. acutus is known only from Kuanshan - Yakou, Taitung, in southern central Taiwan (Map 1, p. 85), where it was collected in August. No further data are available.

\subsection{Othius reticulatus sp. $\mathrm{n}$.}

Figs 34 a - f, Map 1 (p. 85)

\section{Types}

Holotype ơ: (Near Tsifeng) Nantou - Hsien, Taiwan (2200m), Aug. 25th, 1974, Coll. Y. Shibata (TUA). Paratype $q$ : (Sungchuankang) Nantou, Taiwan, March 27th, 1987, Y. Shibata leg. (cAss).

\section{Diagnosis}

Measurements and ratios (HT, PT): HL: 1.43, 1.53; HW: 1.30, 1.45; PW: $1.43-1.53$; PL: 1.80 , 1.86; EL: 1.01, 1.01; TiL: 1.28, 1.37; TaL: 0.98 - 1.01; TL: 9.0, 10.3; HL/HW: 1.11, 1.05; HW/PW: $0.90,0.95$; PL/PW: $1.26,1.22$; EL/PL: 0.56, 0.54; TiL/TaL: $1.31,1.36$.

Closely related and externally similar to $O$. parvipennis, $O$. smetanai and $O$. hamatus, approximately as large as $O$. smetanai, but lighter in colour. 

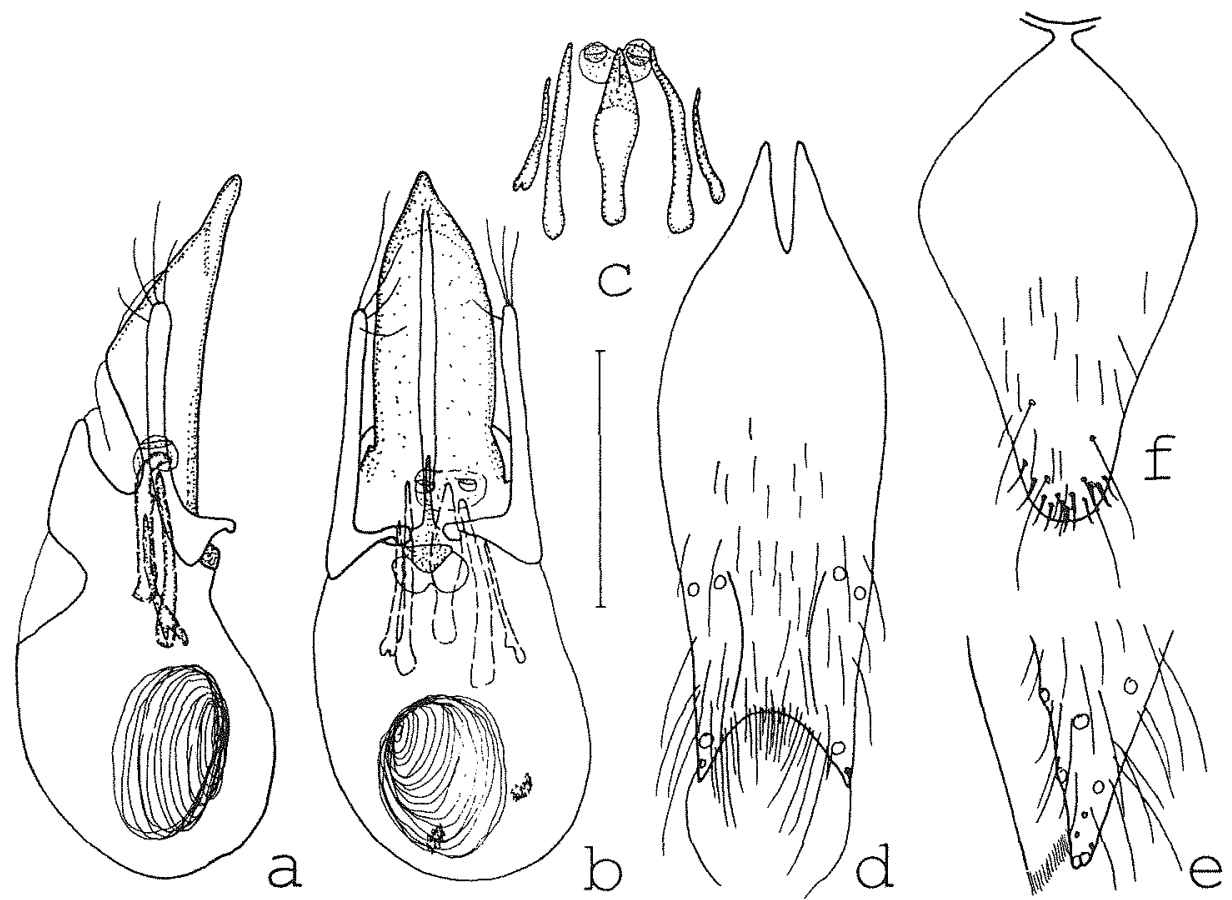

Figs 34 a - f: $O$. reticulatus sp. $n$.: aedeagus in lateral and in ventral view $(\mathbf{a}, \mathbf{b})$; internal structures in ventral view (c); on sternum IX (d); apices of $\sigma^{*}$ lateral tergal sclerite IX and tergum X in lateral view (e); 우 tergum X (f); long setae partly or completely omitted in d - e. Scale: $0.5 \mathrm{~mm}$.

Head dark brown, pronotum and antennae slightly lighter; abdomen brown, elytra and legs yellowish brown.

Head of similar shape and proportions as in $O$. parvipennis, but microsculpture much more distinct and isodiametric on whole surface; punctation very extensive, present on all of posterior half, and denser than in $O$. smetanai; posterior pair of frontal punctures present, but small and surrounded by additional punctures; anterior frontal punctures accompanied by $3-4$ additional punctures; frontal furrows very shallow, not distinctly sulcate; antennae similar to $O$. parvipennis, but antennomere IV subquadrate; antennomeres V - X increasingly transverse.

Pronotum with microsculpture similar to that of head, distinctly isodiametric; shape and punctation similar to $O$. parvipennis.

Elytra, and abdomen as in $O$. parvipennis; microsculpture of scutellum slightly more distinct, composed of transverse and isodiametric meshes.

$\sigma^{*}$ : dilatation of protarsomeres I - IV similar to O. parvipennis; sternum V and VI as in $O$. parvipennis centrally with large flattened or shallowly impressed, well-defined callosities, their size almost as in $O$. parvipennis; that of sternum $\mathrm{V}$ subcircular with tomentose dark and suberect pubescence and with rasp-like punctation, that of sternum VI slightly smaller, ellipsoid, and with less dense pubescence and punctation; sternum VII posteriorly weakly concave and and shallowly impressed; sternum VIII not distinctly bicoloured, shape similar to $O$. parvipennis; hind margin of sternum VIII weakly concave, without marginal pubescence, pubescence along median line and near middle of hind margin \pm absent; sternum IX of similar shape as in $O$. parvipennis (Fig. $34 d$ ); lateral tergal sclerites IX relatively short, not reaching hind margin of tergum X (Fig. 34e); 
aedeagus of similar morphology as in $O$. parvipennis, also with distinct pair of long median folds on ventral process, but in ventral view more slender; basal carina distinctly sclerotized; parameres apically weakly dilated; internal sac with sclerotized structures similar to $O$. parvipennis, but apical median piece shorter and in ventral view wider, and long lateral structures more slender; near apex of median apical structure with membranous structure; basal membranous structure with two small areas with distinctly sclerotized spines; flagellum similar to $O$. parvipennis, with $\mathrm{ca} .25$ coils (Figs $34 \mathrm{a}-\mathrm{c}$ ).

$q$ : terminalia similar to $O$. parvipennis, but tergum $\mathrm{X}$ posteriorly distinctly membranous and with shorter modified setae (Fig. 34f).

Derivatio nominis: The name (lat.) refers to the distinct microreticulation of the head and pronotum, an external character distinguishing $O$. reticulatus from its most closely related congeners.

Comparative notes and phylogenetics: From all the closely related species allied to $O$. parvipennis, $O$. reticulatus is distinguished by the distinct microreticulation of head and pronotum. From $O$. hamatus and $O$. aequabilis it is also separated by larger body size, by the shape of the ventral process of the aedeagus, the presence of a pair of distinct median folds on the ventral process, and by the internal structures of the aedeagus. From $O$. smetanai, it is additionally distinguished by the lighter colour, by the shorter antennae, by the the larger and more clearly delimited tomentose areas on the $0^{x}$ sterna V and VI, by the more distinct pair of median folds of the ventral process of the median lobe, and by the shape of the internal structures of the aedeagus. From the similar $O$. parvipennis it differs also in the shorter antennae, the more slender ventral process of the aedeagus and the shape of the internal structures, especially the much shorter apical median structure. In $O$. acutus, the ventral process of the aedeagus is much broader and more strongly pointed apically, and it lacks a pair of distinct median folds.

$O$. reticulatus shares several conspicuous characters with $O$. parvipennis, i. e. the relatively broad head and pronotum, the similar modifications of the $\sigma^{*}$ sterna $\mathrm{V}$ and $\mathrm{VI}$, the presence of a pair of distinct median folds on the ventral process of the aedeagus as well as a long flagellum in the internal sac. Since these characters, however, are likely to represent the plesiomorphic states, it is uncertain whether both species are in fact adelphotaxa.

Distribution and bionomics: $O$. reticulatus is known from two localities in the north of Nantou Hsien (Map 1, p. 85), where it was collected in March and August, and the northernmost representative of the $O$. parvipennis species complex in Taiwan. Like the related taxa, it seems to occur at altitudes above $2000 \mathrm{~m}$.

\subsection{Othius praecisus $\mathrm{sp} . \mathrm{n}$.}

Figs $35 \mathrm{a}-\mathrm{f}$

\section{Types}

Holotype o": Taiwan, Kaohsiung Hsien, Peinantashan trail, 2500m, 4.VII.93, A. Smetana [T 136] (cSme). Paratypes: 1 우 [teneral], same data as holotype (cSme); $10^{\circ}, 2$ 우 [1 $0^{\circ}, 1$ 우 teneral], Taiwan, Kaohsiung Hsien, Peinantashan trail, 2390-2490m, 5.VII.1993, A. Smetana [T 138] (cSme, cAss).

\section{Diagnosis}

Measurements and ratios (range, $\mathrm{n}=5$ ): $\mathrm{HL}: 1.46-1.74$; HW: $1.34-1.62$; PW: $1.49-1.74$; PL: 1.77 - 2.01; EL: 1.04 - 1.13; TiL: 1.25 - 1.46; TaL: 0.98 - 1.10; TL: 9.5 - 12.3; HL/HW: 1.06 1.09; HW/PW: 0.86 - 0.96; PL/PW: 1.16 - 1.19; EL/PL: 0.56 - 0.59; TiL/TaL: 1.26 - 1.33. 

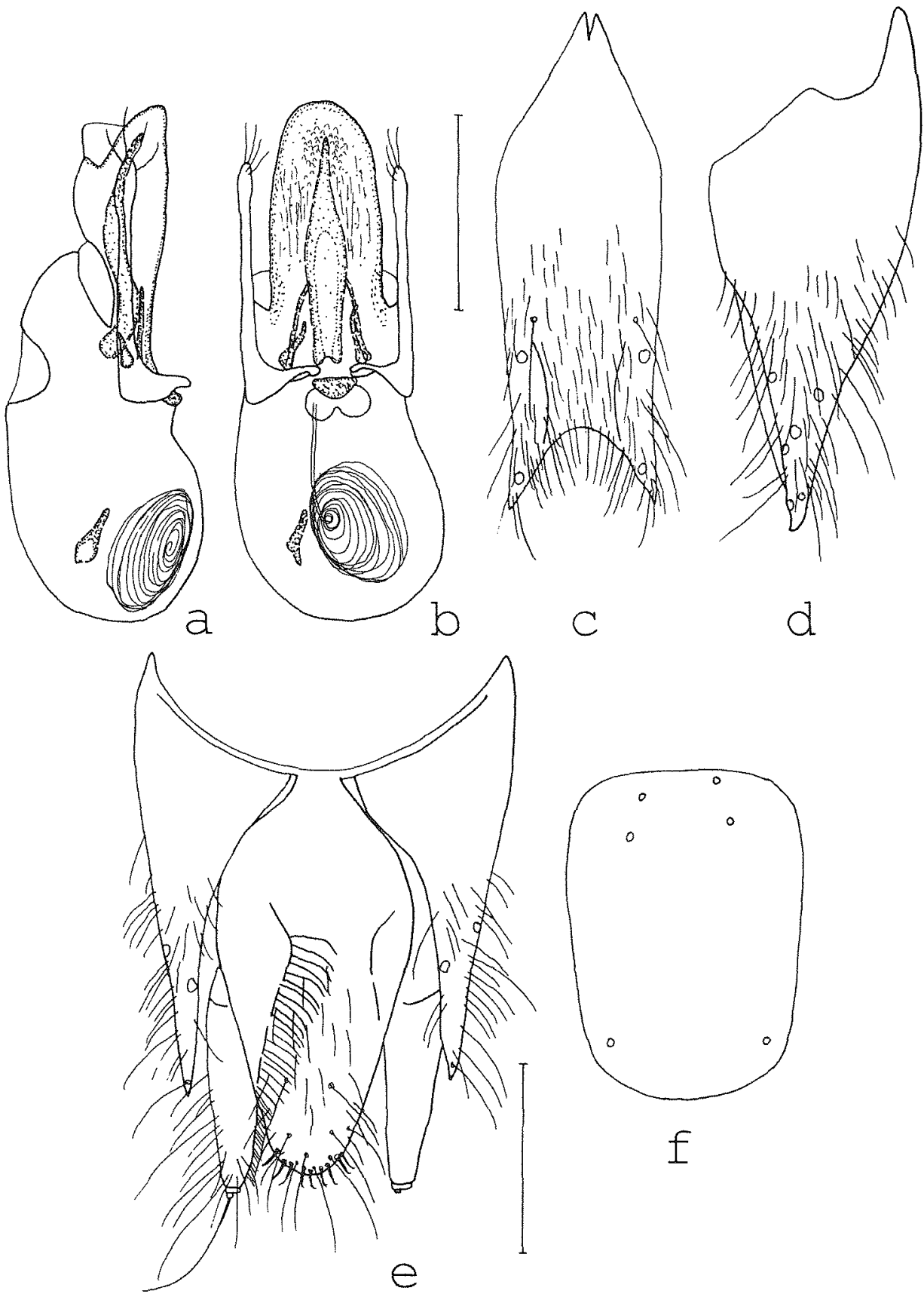

Figs 35 a - f: $O$. praecisus sp. n.: aedeagus in lateral and in ventral view (a, b); $o^{x}$ sternum IX (c); $o^{*}$ lateral tergal sclerite IX and tergum $\mathrm{X}$ in lateral view (d); $q$ terminalia (e); schematic representation of pronotal punctation pattern (f); long setae partly or completely omitted in c - e. Scales: $0.5 \mathrm{~mm}$; $\mathrm{f}$ without scale. 
Externally highly similar to $O$. parvipennis and especially $O$. smetanai, but distinguished from these species as follows:

Colour as in $O$. smetanai, but basal three antennomeres mostly reddish brown; body size similar to $O$. smetanai,

Head posteriorly \pm distinctly dilated; microsculpture similar to $O$. parvipennis, anteriorly composed of more transverse and posteriorly predominantly of isodiametric and short transverse meshes; posterior pair of frontal punctures small.

Pronotum with posterior discal puncture closer to hind angles than in $O$. parvipennis and related species (Fig. 35f).

Elytra of similar shape as in O. parvipennis, but punctation less coarse and surface with less shine due to shallow, \pm irregular micropunctation and microstriae; scutellum with distinct, predominantly transverse microsculpture and with several punctures.

Abdomen with punctation, microsculpture and shine similar to $O$. smetanai.

$\sigma^{*}$ : dilatation of protarsomeres I - IV similar to $O$. parvipennis; sternum V and VI centrally with suboval callosities with tomentose brownish pubescence, the callosities of similar size as in $O$. smetanai or somewhat larger; sternum VII posteriorly weakly concave, not distinctly flattened; hind margin of sternum VIII \pm weakly convex, pubescence similar to $O$. parvipennis, but poster iorly \pm condensed on either side of median line and with scattered, short and yellowish marginal setae; sternum IX of similar shape and pubescence as in $O$. parvipennis and $O$. smetanai, but anteriorly only weakly bifid (Fig. 35c); lateral tergal sclerites of segment IX long, slightly reaching beyond tergum $X$, and apically with short, stout and weakly curved process (Fig. 35d); tergum X posteriorly with broad membranous appendage; aedeagus with ventral process of characteristic shape, in ventral view apically not acute, but broadly rounded; apical folds indistinct, basal carina weak, not sclerotized; surface of ventral process with a mixture of longitudinal and scale-like microsculpture and punctures; parameres apically distinctly dilated and with broad bases; internal sac with 6 sclerotized structures: a small median basal (absent in $O$. parvipennis and O. smetanai), a very large median apical, a pair of short and basally dilated lateral, and a pair of longer thin lateral pieces; flagellum slightly wider than in the related species and with ca. $15-20$ coils, inner coils widened and slightly darker (Figs $35 \mathrm{a}-\mathrm{b}$ ).

ㅇ: protarsomeres I - IV dilated, but somewhat less so than in o", sexual dimorphism moderate; sternum VIII convex, posteriorly with marginal row of yellow setae (similar to O. aequabilis); lateral tergal sclerites IX with short and acute apical process (much shorter than in O. medius); tergum $\mathrm{X}$ posteriorly with several rather short, apically curved modified setae; inner margins of styli with fringe of dense, anteriorly long and stout, and posteriorly thin and rather short setae (Fig. 35e).

Derivatio nominis: The name (lat: : cut off, broken off, shortened) refers to the characteristic shape of the ventral process, which lacks the acute apex of the related species.

Comparative notes and phylogenetics: see below the following species.

Distribution and bionomics: $O$. praecisus is known only from the Peinantashan, Kaohsiung Hsien, in southern central Taiwan (Map 1, p. 85), where it was collected at an altitude of 2390 $2500 \mathrm{~m}$ in July, together with $O$. hamatus. Three of the five type specimens were teneral.

4.29. Othius collapsus sp. n.

Figs 36 a - e, Map 1 (p. 85)

Types

Holotype $\sigma^{*}$ : (Near Tsifeng) Nantou - Hsien, Taiwan (2300m), Aug. 2nd, 1977, Y. Shibata leg. (TUA). 

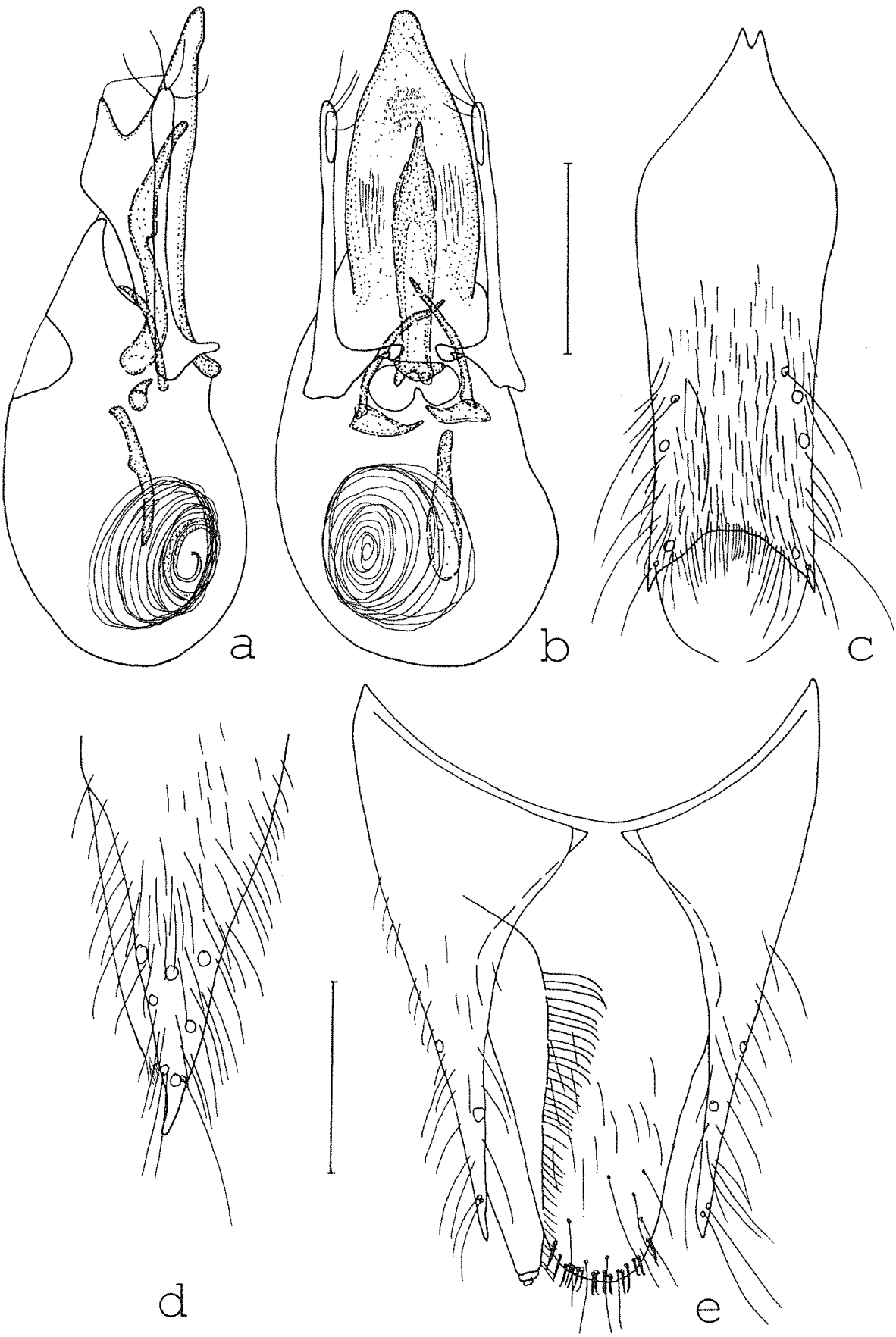

Figs 36 a - e: $O$. collapsus sp. $\mathrm{n}$.: aedeagus in lateral and in ventral view (a, b); $\sigma^{*}$ sternum IX (c); $\sigma^{*}$ lateral tergal sclerite IX and tergum X in lateral view (d); 7 terminalia (e); long setae partly or completely omitted in c - e. Scales: $0.5 \mathrm{~mm}$. 
Paratypes: $2 \circ \%$ [1우 teneral], same data as holotype (cShY, cAss); $10^{\prime}, 1$ 우 [teneral], (Near Tsifeng) Nantou - Hsien, Taiwan (2300m), Aug. 22nd, 1973, Coll. Y. Shibata (cShY, cAss); $10^{\prime \prime}, 1 \%$ [teneral], same data, but Aug. 23rd (cShY).

\section{Diagnosis}

Measurements and ratios (range, $\mathrm{n}=7$ ): $\mathrm{HL}: 1.80-2.04 ; \mathrm{HW}: 1.74-1.92$; PW: $1.83-2.01$; PL: 2.26 - 2.47; EL: 1.40 - 1.65; TiL: 1.68 - 1.89; TaL: 1.25 - 1.43; TL: 10.8 - 12.8; HL/HW: 1.02 1.08; HW/PW: 0.92 - 0.98; PL/PW: 1.19 - 1.25; EL/PL: 0.62 - 0.68; TiL/TaL: 1.22 - 1.41 .

Colour somewhat variable, in mature specimens dark brown to blackish brown, with the elytra slightly lighter, brown to dark brown; antennae ferrugineous to blackish, the basal antennomeres at most slightly lighter than the terminal joints; legs ferrugineous to dark brown; body larger than in $O$. praecisus (see measurements).

Head posteriorly weakly dilated; microsculpture predominantly composed of transverse meshes of variable length; posterior pair of frontal punctures small; antennae more massive and longer than in $O$. praecisus; antennomeres IV weakly oblong, V subquadrate, and VI - X weakly transverse. Pronotum with pronotal punctation pattern similar to $O$. praecisus (cf. Fig. $35 \mathrm{f}$ ).

Elytra with distinctly more shine than in O. praecisus, interstices usually without microsculpture; scutellum with distinct isodiametric and transverse microsculpture, and with several punctures. Abdomen with punctation and microsculpture similar to $O$. praecisus.

$\sigma^{7}$ : protarsomeres I - IV strongly dilated; sternum V and VI centrally with subcircular or ovoid callosities with dense and dark pubescence, that of sternum VI large (approximately as large as in $O$. parvipennis), more distinctly delimited from surrounding sternal area, \pm impressed, strongly microsculptured, that of sternum $\mathrm{V}$ either similar, or smaller, more weakly delimited, with relatively sparse pubescence and with weaker microsculpture; sternum VII posteriorly weakly concave, flattened and with \pm dense dark pubescence directed postero-mediad; hind margin of sternum VIII \pm truncate; sternum IX of similar shape and pubescence as in $O$. praecisus, also anteriorly weakly bifid, but posteriorly less deeply concave (Fig. 36c); lateral tergal sclerites of segment IX long, slightly reaching beyond tergum $X$, and apically with long, spine-like process (Fig. 36d); tergum $X$ posteriorly with broad membranous appendage (cf. Fig. 37e); aedeagus much larger than in $O$. praecisus; ventral process of somewhat variable width, apically pointed, without apical folds, basal carina indistinct, microsculpture as in $O$. praecisus; parameres apically distinctly dilated; internal sac with arrangement of sclerotized structures similar to $O$. praecisus: a smaller median basal, a very large and long median apical, a pair of \pm transverse, short, basally dilated and apically acute lateral, and a pair of longer thin lateral structures; flagellum with ca. 30 coils, inner 2 coils widened and darkened (Figs 36 a - b).

q: protarsomeres distinctly dilated, but less so than in $\sigma^{\circ}$, sexual dimorphism moderate; sternum VIII posteriorly convex and with numerous yellowish marginal setae; lateral tergal sclerites IX apically with acute process (similar to $O$. medius); hind margin of tergum $\mathrm{X}$ broadly convex and with several relatively short and apically weakly bent modified setae; inner margin of styli with fringe of numerous long setae, which are very stout anteriorly and thin posteriorly (Fig. 36e).

Derivatio nominis: The name (lat: collapsed) refers to the characteristic position of the short lateral structures in the internal sac of the aedeagus.

Comparative notes and phylogenetics: For distinction from $O$. praecisus see diagnosis. From all other brachypterous Taiwanese congeners, $O$. collapsus, $O$. praecisus, and the following two species are distinguished by the following characters: posterior pronotal punctures nearer to the posterior angles, pronotum relatively broader (PL/PW: $<1.26$ ), lateral tergal sclerites IX with short apical process (which is reduced in $O$. coniceps), ventral process of aedeagus without distinct 
median folds and without distinct basal carina, internal sac with six (in $O$. coniceps with five) sclerotized structures of characteristic shape, parameres apically distinctly dilated (exception: $O$. coniceps). For further remarks on phylogenetics see section 5.

Distribution and bionomics: $O$. collapsus is one of the northernmost brachypterous representatives of the genus in Taiwan (Map 1, p. 85). It is known from the surroundings of Tsifeng (Nantou Hsien), where it was collected at an altitude of $2300 \mathrm{~m}$. All the specimens were taken in August; most of them were teneral.

\subsection{Othius contumax sp. $\mathrm{n}$.}

Figs 37 a - e, Map 1 (p. 85)

\section{Types}

Holotype o: Taiwan, Nantou Hsien, Nenkaoshan, Tenchi Hut, 2890m, 7.V.1992, A. Smetana [T 119] (cSme). Paratypes: 10*, Taiwan, Nantou Hsien, Nenkaoshan trail, Yuenhai Hut, 2350m, 4.V.1992, A. Smetana [T 112] (cSme); 10", Taiwan, Nantou Hsien, Nenkaoshan, Tenchi Hut, $2900 \mathrm{~m}, 5$. V.1992, A. Smetana [T 114] (cAss).

\section{Diagnosis}

Measurements and ratios (range, $\mathrm{n}=3$ ): HL: $1.74-1.83$; HW: $1.65-1.71$; PW: $1.77-1.86$; PL: 2.14 - 2.26; EL: 1.25 - 1.37; TiL: 1.40 - 1.26; TaL: 1.13 - 1.19; TL: 11.1 - 12.5; HL/HW: 1.06 1.07; HW/PW: 0.92 - 0.93; PL/PW: 1.17 - 1.21; EL/PL: 0.59 - 0.61; TiL/TaL: 1.18 - 1.30.

External morphology (colour, proportions, punctation, microsculpture) as in $O$. collapsus, from which it differs as follows:

Antennae slightly shorter, antennomeres IV subquadrate, and V - X weakly transverse. Legs shorter (cf. measurements TiL and TaL).

$\sigma^{\prime \prime}$ : dilatation of protarsomeres I - IV and sternum V, VI and VII as in $O$. collapsus; sternum VIII \pm truncate posteriorly, pubescence slightly condensed on either side of median line; sternum IX of similar shape and pubescence as in $O$. collapsus, but posteriorly more weakly concave (Fig. 37c); lateral tergal sclerites of segment IX long, slightly reaching beyond tergum $X$, on the whole similar to $O$. collapsus, but apically somewhat truncate and with much shorter process (Fig. 37d); tergum $\mathrm{X}$ posteriorly with broad membranous appendage (Fig. $37 \mathrm{e}$ ); aedeagus of similar morphology as in $O$. collapsus, but long apical median structure more abruptly narrowed apically and less acute in ventral view, basal median structure slightly shorter, and short lateral structures of different shape, more distinctly sclerotized and in less transverse position; ventral process of somewhat variable width; flagellum with ca. 30 coils, inner 2 coils widened and darkened (Figs 37 $\mathrm{a}-\mathrm{b})$.

ㅇ: unknown.

Derivatio nominis: The name (lat.: obstinate, stubborn) alludes to the time and effort that was required to finally realize that $O$. contumax is in fact distinct from $O$. collapsus.

Comparative notes and comments: For distinction from $O$. collapsus, from other brachypterous Taiwanese congeners, and for remarks on phylogenetics see diagnosis, the comments below $O$. collapsus, and section 5 , respectively.

The vicinity of the type localities of $O$. collapsus and $O$. contumax, their similar external appearance, and the basically similar morphology of the aedeagus would suggest that they are not specifically distinct, but belong to one variable species. Nevertheless, they are here hypothesized to represent distinct species for the following reasons: In the three males available of both species, the indicated differences were constant. 

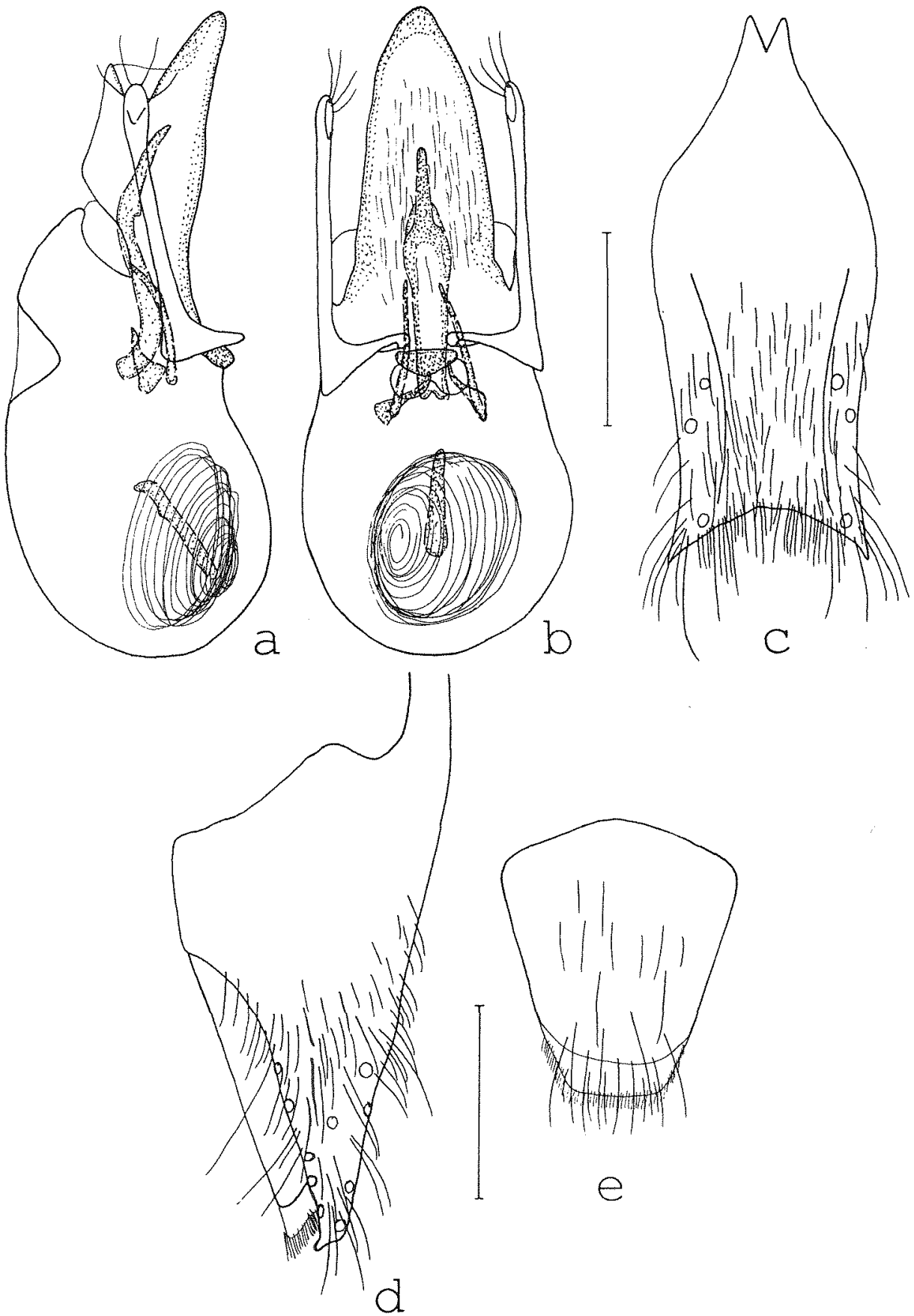

Figs 37 - e: $O$. contumax sp. $n$.: aedeagus in lateral and in ventral view (a,b); $\sigma^{*}$ sternum IX (c); $\sigma^{*}$ lateral tergal sclerite $\mathrm{IX}$ and tergum $\mathrm{X}$ in lateral view $(\mathbf{d})$; $\sigma^{*}$ tergum $\mathrm{X}$ (e); long setae partly or completely omitted in $\mathrm{c}-\mathrm{d}$. Scales: $0.5 \mathrm{~mm}$. 
In addition, distinguishing characters are often not very pronounced also in other groups of brachypterous and more or less endemic Othius species, e. g. in the species allied to O. parvipen$n i s$, and in the Western Palaearctic $O$. intermedius subgroup and the $O$. crassus subgroup. The modifications of the lateral tergal sclerites IX have proved to be very constant and of great diagnostic value especially in the $O$. crassus subgroup (ASSING, 1997a, 1998b; ASSING \& SOLODOVNIKOV, 1998).

Distribution and bionomics: $O$. contumax is known only from the Nenkaoshan in northern Nantou, only some $20 \mathrm{~km}$ away from the type locality of $O$. collapsus (Map 1, p. 85), where it was collected at an altitude of $2350-2900 \mathrm{~m}$ in May.

\subsection{Othius coniceps sp. n.}

Figs 38 a - d, Map 1 (p. 85)

Type

Holotype o : (Near Hohuanshan) Nantou - Hsien, Taiwan (3100m), July 31st, 1983, Y. Shibata leg. (TUA).

\section{Diagnosis}

Measurements and ratios (HT): HL: 1.53; HW: 1.46; PW: 1.59; PL: 1.89; EL: 1.10; TiL: 1.31; TaL: 1.07; TL: 10.3; HL/HW: 1.04; HW/PW: 0.92; PL/PW: 1.19; EL/PL: 0.58; TiL/TaL: 1.23.

Head and pronotum dark brown, abdomen brown, elytra and legs light brown; antennae dark reddish brown, apically weakly infuscatewe; body similar to $O$. praecisus (see measurements).

Head posteriorly distinctly dilated; eye size as in $O$. praecisus and allied species; macropunctation finer and sparser than in the related species; microsculpture predominantly composed of a mixture of transverse and isodiametric meshes; posterior pair of frontal punctures small; antennae with antennomeres IV subquadrate and V - X weakly transverse.

Pronotum of similar shape, and with similar pronotal punctation pattern as in $O$. praecisus and allied species (cf. Fig. 35f).

Elytra with shine, punctation and microsculpture as in $O$. praecisus; scutellum with distinct isodiametric and transverse microsculpture, and with several punctures.

Abdomen with punctation as in O. praecisus; microsculpture similar, too, but less distinct; microsculpture near anterior tergal margins not different from that of posterior tergal surface.

ơ: protarsomeres I - IV strongly dilated; sternum V and VI centrally with weakly delimited (especially on sternum VI) subcircular areas with condensed dark pubescence; sternum VII posteriorly weakly concave, impressed and with dense dark pubescence directed postero-mediad; hind margin of sternum VII truncate; sternum IX of similar shape and pubescence as in $O$. collapsus, but anteriorly more strongly bifid and hind angles less acute (Fig. 38c); lateral tergal sclerites of segment IX, slightly reaching beyond tergum $X$, broad and apically without acute process (Fig. 38d); tergum $\mathrm{X}$ posteriorly with broad membranous appendage; aedeagus with ventral process of similar shape as in $O$. collapsus, without apical folds, but with weak lateral elevations; basal carina indistinct; microsculpture as in $O$. praecisus; parameres apically weakly dilated; internal sac with 5 sclerotized structures: a very large and long median apical, a pair of short, basally dilated and apically acute lateral, and a pair of longer thin lateral pieces; basal median structure absent; flagellum with ca. 30 coils, inner 2 - 3 coils widened and darker (Figs 38 $a-b)$.

q: unknown.

Derivatio mominis: The name (lat.) refers to the remarkably coniform shape of the head. 


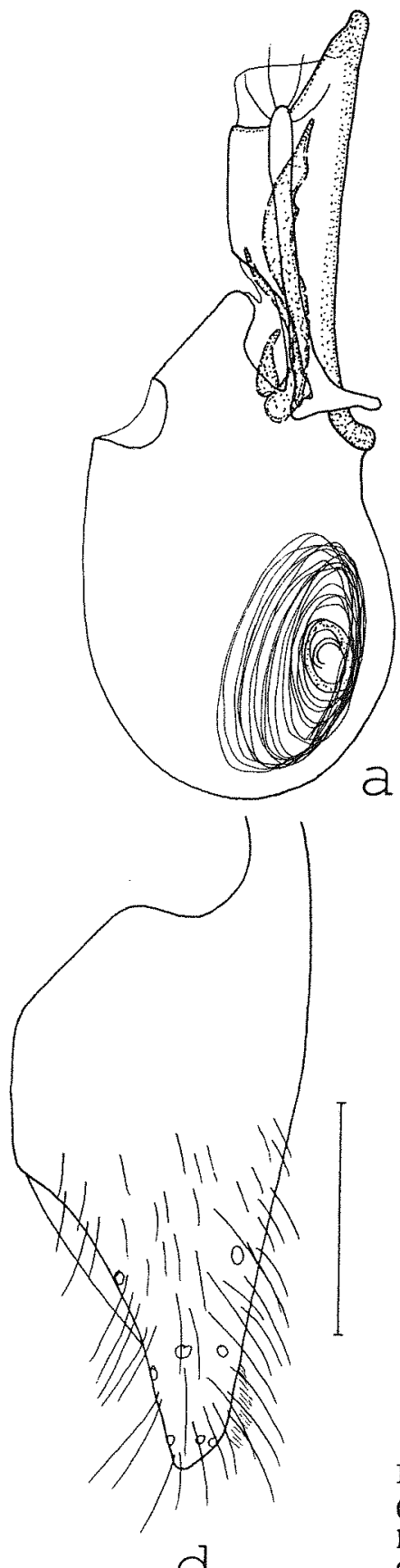

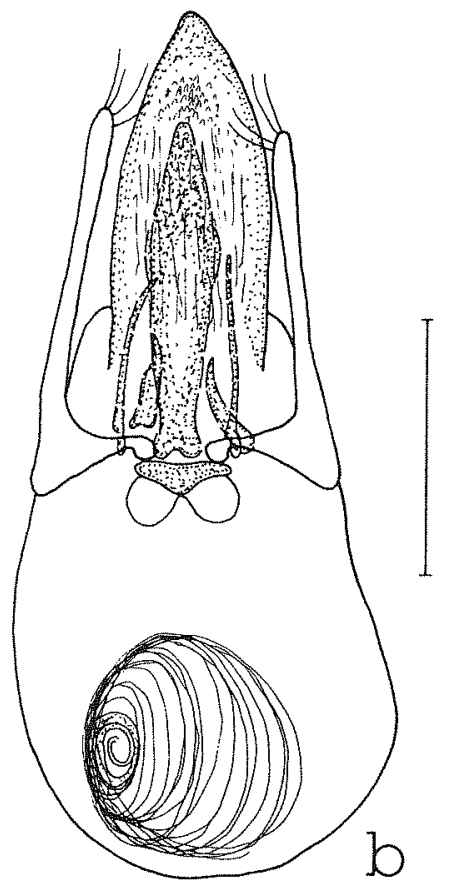

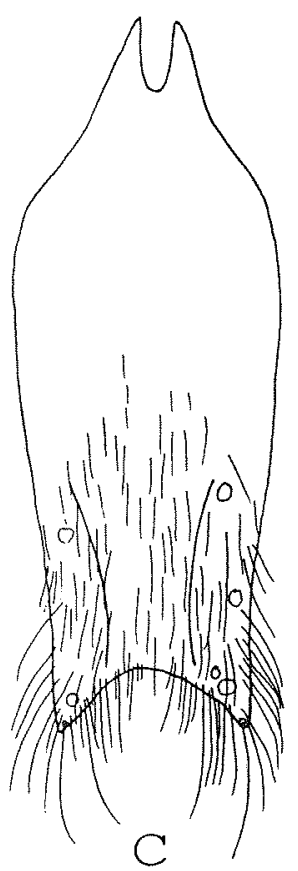

Figs $38 \mathrm{a}-\mathrm{d}$ : O. coniceps sp. $\mathrm{n}$.: aedeagus in lateral and in ventral view $(\mathbf{a}, \mathrm{b})$; $\sigma^{n}$ sternum IX (c); $\sigma^{n}$ lateral tergal sclerite IX and tergum X in lateral view (d); long setae partly or completely omitted in $c-d$. Scales: $0.5 \mathrm{~mm}$.

Comparative notes and phylogenetics: $O$. coniceps is readily distinguished from $O$. praecisus and allied species by the posteriorly distinctly dilated head, the reduced apical processes of the 
lateral tergal sclerites IX, and particularly by the absence of a basal median structure in the internal sac. For remarks on phylogenetics see comments below $O$. collapsus and section 5 .

Distribution and bionomics: The species is known only from the Hohuanshan, northern Nantou Hsien in Taiwan (Map 1), where it was taken at an altitude of $3100 \mathrm{~m}$ at the end of July.

Map 1: Distribution of Othius species in Taiwan: O. punctatus BERNHAUER (1); O. taiwanus Iто (2); O. shibatai Iто (3); $O$. yushanus ITO (4); O. parvipennis (SHBBATA) (5); O. smetanai sp. n. (6); $O$. aequabilis sp. n. (7); O. hamatus sp. n. (8); O. acutus sp. n. (9); O. reticulatus sp. n. $(\mathbf{1 0}) ; O$. praecisus sp. $\mathrm{n}$. (11); $O$. collapsus sp. n. (12); O. contu$\max$ sp. n. (13); O. coniceps sp. n. (14); scale: $40 \mathrm{~km}$. Map redrawn from map 1 in SMETANa (1995).

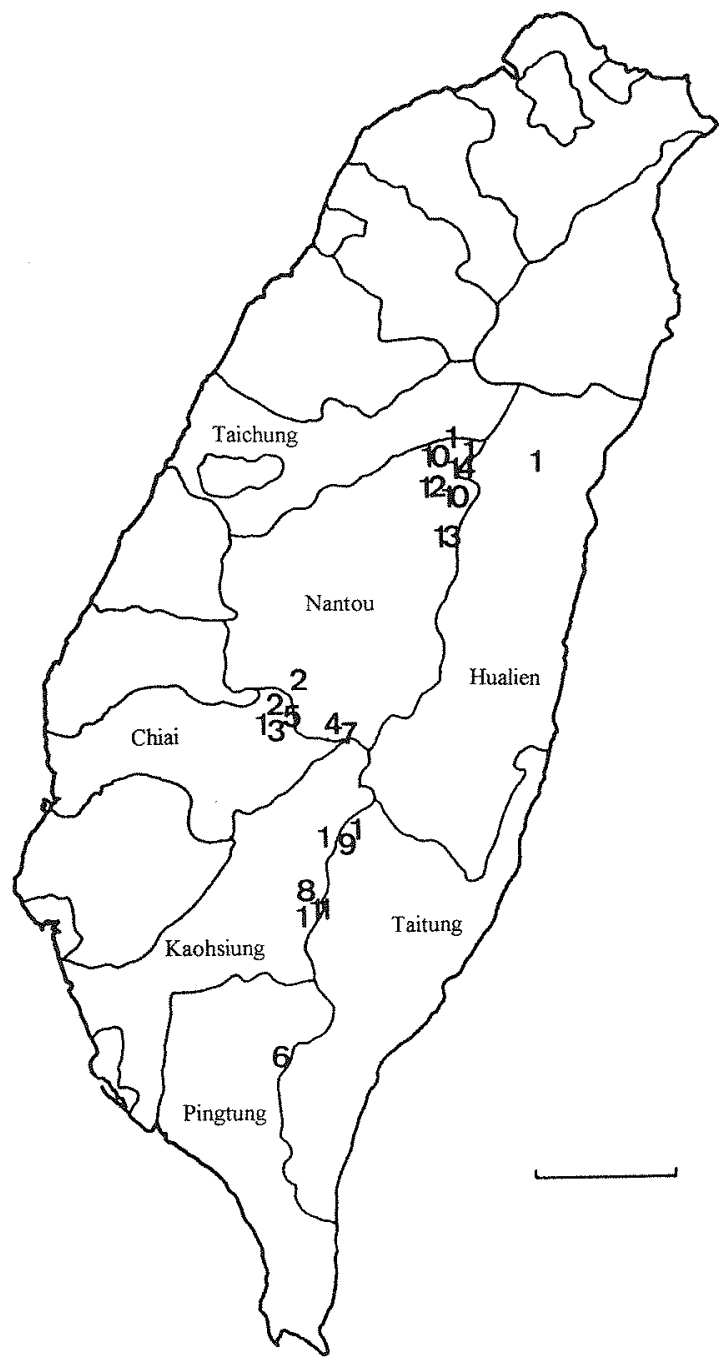

5. The Othius species of Taiwan: diversity, phylogenetics and colonization

Altogether 14 species are now known to occur in Taiwan; only one of them, O. punctatus BERNHAUER, is widespread and present also in mainland China. The long elytra and hind wings, the relatively large eyes, and the presence of a palisade fringe on the hind margin of tergum VII in $O$. taiwanus ITO suggest that this species, too, is capable of flight and may be more widely distributed, 
but as yet it has not been recorded from outside Taiwan. The remaining 12 species are not only certain to be island endemics, as can be inferred from their external morphology (i. e. the reduction of elytra, hind wings, eye size, and palisade fringe), they apparently even have a very restricted distribution within the island. All of them are known only from a single mountain or mountain range; only $O$. reticulatus was collected in two localities, but they are only some $20 \mathrm{~km}$ apart (Map 1). As can be concluded from the altitudes indicated on the labels, these local endemics inhabit the cool and the cold temperate coniferous forest zones, and the subalpine coniferous forest zone sensu SMETANA (1995).

Of the total of 36 specimens of brachypterous Othius from Taiwan examined, 34 belonged to 12 species, 9 of them described here for the first time, and several species are represented only by single specimens. The remaining two females could not be attributed to any of the species, since no corresponding males were available, and may well represent two undescribed taxa. Therefore, it seems safe to assume that the inventory of Taiwanese Othius species is far from complete and that, with respect to Othius, Taiwan is among the most diverse areas of the Palaearctic region, probably more so than the Atlantic islands with 13 known endemics (AssING, 1998b), the Caucasus with 12 endemic taxa (ASSING, 1997a; AssING \& SolODOVNIKOV, 1998), and exceeded only by the Himalayas with 24 known endemics (AssING, 1998a). The Othius fauna of the mountain ranges of Sichuan and Yunnan appears to be very diverse, too; these areas have only been poorly studied and are likely to be inhabited by a far greater number of species than are presently known.

The Taiwanese Othius fauna can be subdivided into five species groups. Two of them are represented by a single species each, $O$. punctatus and $O$. taiwanus. The former is widespread and also present in mainland China, so that - by geological standards - a recent colonization can be assumed. Judging from external characters (body shape and proportions, punctation, microsculpture, male secondary sexual characters etc.) and the shape and internal structures of the aedeagus, the species seems to be most closely related to $O$. rufipennis.

Like $O$. punctatus, $O$. taiwanus does not show the morphological adaptions - i. e. reductions of characters associated with flight activity - usually found in Othius species with a restricted distribution, especially island endemics (see AssING, 1998b), which also suggests a comparatively recent colonization. Among the known Eastern Palaearctic congeners, there is no obvious adelphotaxon. On the one hand, there is some similarity with $O$. fibulifer from Sichuan in the morphology of the aedeagus and the shape of the internal structures, especially the median structures, but on the other hand the possibility that these character states represent homoplasies cannot be ruled out, particularly since both species differ in many external characters and $O$. fibulifer is apparently more closely related to $O$. wrasei.

The three remaining species groups are monophyla whose respective ancestors seem to have colonized Taiwan in earlier geological periods. The monophylum $O$. shibata $+O$. yushanus is constituted by several distinct synapomorphies, the reduced eyes, the light colour, the slender pronotum, the very short elytra, the absence of conspicuous pubescence on the o sterna V and VI, and the presence of clusters of dark long spines in the internal sac. There is no obvious adelphotaxon among the Eastern Palaearctic congeners. The only apomorphy suggesting a closer relationship to the species allied to $O$. parvipennis (SHIBATA) is the position of the posterior dorsal puncture of the pronotum, a character state, however, which may well be homoplastic and which also occurs in other Eastern Palaearctic species groups.

Together with $O$. smetanai $\mathrm{sp} . \mathrm{n}$., $O$. hamatus sp. n., O. reticulatus, $O$. acutus and $O$. aequabilis sp. n., O. parvipennis forms a monophyletic group supported by the following hypothesized synapomorphies: the pronotal punctation pattern with the posterior punctures clearly distant from the posterior angle, the presence of an apical membranous structure of characteristic shape in the internal sac, the \pm reduced number of coils of the flagellum, and the very narrow basis of the i 
tergum X. Within this group, a closer relationship of $O$. parvipennis, $O$. reticulatus, $O$. smetanai, $O$. acutus and $O$. hamatus can be inferred from the apomorphic absence of the median basal structure and the presence of a basal pair of small membranous structures covered with \pm sclerotized short spines in the internal sac. The phylogenetic affinities among the species of this group, however, are difficult to assess, partly because of the low degree of character divergence in these apparently extremely closely related species, a situation also encountered in the Othius intermedius subgroup of the Canary Islands (AssING, 1998b). In addition, most of the hypothesized apomorphies are either autapomorphies of single species or in conflict with other synapomorphies. Finally, the species treated here are very likely to represent only a fraction of the actual number of species present in the mountain ranges of Taiwan. Close affinities between $O$. acutus and $O$. hamatus are suggested by the strongly pointed ventral process of the aedeagus, the similar shape of the internal structures and especially by the apomorphic reduction of the pair of median folds of the aedeagus. The sister taxon of the group of species allied to $O$. parvipennis seems to be $O$. rost $i$ BERNHAUER from the northeast of the Eastern Palaearctic region (Japan, Russian Far East). Hypothesized synapomorphies supporting the sister group relationship are the presence of an apical membranous structure in the internal sac, the absence of a basal median structure, the reduced number of flagellar coils, and the remarkably narrow basis of the + tergum X.

Of the numerous characters shared by $O$. praecisus, $O$. collapsus, $O$. contumax and $O$. coniceps, at least the broad membranous appendage of tergum $X$, the anteriorly weakly bifid sternum IX, the remarkably large median apical structure, the characteristic shape of the short lateral structures of the internal sac, and the somewhat darkened and widened inner coils of the flagellum can be considered synapomorphies supporting the monophyly of the four taxa. Like the species related to $O$. parvipennis, they apparently have a very limited area of distribution and are confined to higher altitude habitats. $O$. collapsus, $O$. contumax, and $O$. coniceps share a long flagellum and an apically pointed ventral process; in $O$. praecisus, $O$. collapsus, and $O$. contumax, on the other hand, the tergal sclerites IX have a distinct apical process, and the internal sac contains a basal median structure. These character states, however, are not very conclusive, as they are very likely to be plesiomorphic. $O$. collapsus and $O$. contumax are without doubt adelphotaxa, not only because of their similar outward appearance and their probably synapomorphic large size, but also because of the very similar morphology of the internal structures of the aedeagus, especially of the basal median structure. In addition, a close relationship is supported by the vicinity of the localities where they were collected. It is somewhat more difficult to decide whether the monophylum $O$. collapsus $+O$. contumax is more closely allied to $O$. praecisus or to $O$. coniceps. Although biogeographic evidence would favour the latter, the former hypothesis $(O$. coniceps $+(O$. praecisus $+(O$. collapsus $+O$. contumax $)))$ appears to be more likely, as it is supported by two probable synapomorphies, i. e. the anteriorly more weakly bifid ơ sternum IX, and the apically distinctly dilated parameres. Both $O$. praecisus and $O$. coniceps are characterized by several obvious autapomorphies: the former by the rounded apex of the ventral process of the aedeagus and the shorter and wider flagellum, the latter by the posteriorly distinctly dilated head, the reduced apical processes of the lateral tergal sclerites IX, and particularly by the absence of a basal median structure in the internal sac. $O$. collapsus and allied species are apparently the sister group of $O$. medius $+O$. bordonii. The monophyly of these two species groups is supported by the presence of an apical process on the lateral tergal sclerites IX, a character which is absent in all other known species of Othius and therefore very likely to represent a synapomorphy.

Based on the phylogenetic observations and conclusions, at least four, probably five successful colonization events can be assumed for Taiwanese Othius. At least one of them, the ancestor of $O$. parvipennis and allied species, is likely to have originated from the northeast. The probably most recent addition to the Othius fauna of Taiwan, O. punctatus, almost certainly came from mainland 
China, since this species does not seem to occur in Japan and the islands linking Japan and Taiwan. Although there is some doubt as to the origin of the remaining three species groups, either because no obvious sister group could be identified $(O$. shibatai $+O$. yushanus, $O$. taiwanus) or because the hypothesized adelphotaxon is widespread ( $O$. collapsus and allied species), a colonization from mainland China would seem more likely, not only due to the relatively low distance, but also because of the greater number of species present and the probably larger populations.

\section{Key to the species of Othius of the Eastern Palaearctic region east of the Himalayas}

The species from southern China and Taiwan are here considered Palaearctic elements and included below (see section 1). Note that three of the species described by ZHENG (1995) - $O$. quadratus, $O$. goui, and $O$. rudis - had to be neglected and are not accounted for in the key, because the types were not available and the original descriptions are inadequate for a safe identification of the species (see remarks in the introduction to section 4). For explanations of abbreviations and measurements see section 3 .

1. Palisade fringe at hind margin of tergum VII absent; brachypterous species with \pm completely reduced hind wings and usually relatively smaller eyes. $\ldots \ldots \ldots \ldots \ldots \ldots \ldots$

- Palisade fringe at hind margin of tergum VII present; hind wings usually present, though

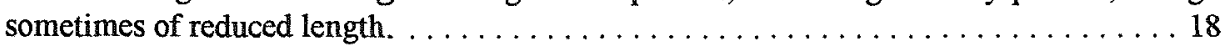

2. Species endemic to Taiwan. . . . . . . . . . . . . . . . . . . . . 3

- Species endemic to mainland China (Sichuan, Yunnan). . . . . . . . . . . 14

3. Eyes reduced, composed of few (ca. 15 - 30) ommatidia, $0.15-0.25 x$ the length of postgenae in lateral view; pronotum slender, PL/PW: $>1.32$, not narrower than head; body colour \pm

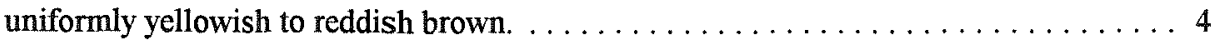

- Eyes distinctly larger, composed of $>50$ ommatidia, $>0.3 x$ the length of postgenae in lateral view; pronotum wider, PL/PW: $<1.27$, narrower than head; body colour darker.

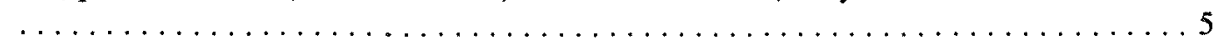

4. Slightly larger species: HL: $>1.3$; HW: $>1.1$; PW: $>1.05$; PL: $>1.4$; eyes more strongly reduced, with $<20$ ommatidia, $0.15 x$ the length of postgenae in lateral view.

0 : sternum V and VI centrally with more distinct modifications; lateral tergal sclerites IX apically rounded, not reaching hind margin of tergum $X$ in lateral view (Fig. 27e); aedeagus with rather short parameres; ventral process in lateral view more slender (Fig. 27b); internal sac with internal structures as in Figs 27c.

Taiwan: Alishan.

O. shibatai ITO

- Smaller species: HL: $<1.25 ; \mathrm{HW}:<1.1$;W: $<1.05 ; \mathrm{PL}:<1.4$; eyes less strongly reduced, with $>20$ ommatidia, $0.20-0.24 \mathrm{x}$ the length of postgenae in lateral view.

$0^{*}$ : modifications of sternum $\mathrm{V}$ and VI very weak, reduced to subcircular areas with dense microsculpture and therefore less shine than the surrounding sternal area; lateral tergal sclerites of segment IX apically more acute (Fig. 28e); aedeagus smaller, apex of ventral process in lateral view broader and in ventral view of different shape, parameres relatively longer; internal sac with differently shaped clusters of long dark spines, apically more acute and basally more dilated median apical piece, and with basally more dilated dark lateral pieces (Figs 28 a - c).

Taiwan: Yushan.

O. yushanus ITO 
5. Posterior pronotal punctures nearer to posterior angles (Fig. 35f); pronotum relatively broader (PL/PW: <1.25); lateral tergal sclerites IX with apical process, which may be reduced, in which case the sclerites are apically \pm truncate.

0 : ventral process of aedeagus without distinct pair of median folds and without distinct basal carina, internal sac in most species with six sclerotized structures of characteristic shape; apical median structure strongly enlarged; inner $1-2$ coils of flagellum widened and darkened.

Posterior pronotal puncture more distant from posterior angles (cf. Fig. 30f); pronotum often more slender; lateral tergal sclerites IX apically without process, acute and with 1 . 2 terminal setae.

$\sigma^{7}$ : aedeagus in all but one species with five sclerotized structures (basal median piece absent); apical median structure distinctly smaller; with membranous structure near apex of median structure; inner coils of flagellum unmodified. . . . . . . . . . . . 9

6. Head distinctly dilated posteriorly.

0 : lateral tergal sclerites IX without distinct apical process, apically \pm truncate (Fig. 38d); aedeagus without basal median structure in internal sac (Fig. $38 \mathrm{a}-\mathrm{b}$ ).

Taiwan: Hohuanshan (Nantou). . . . . . . . . . . . . . oniceps sp. $n$. Head at most only weakly dilated posteriorly.

8 : lateral tergal sclerites IX with distinct and \pm acute apical process; aedeagus with basal median structure in internal sac. $\ldots \ldots \ldots \ldots \ldots \ldots \ldots \ldots \ldots \ldots$

7. On average smaller species: HL: $<1.8$; HW: $<1.7$; PW: $<1.8$; PL: $<2.1$; elytra with shallow microsculpture and therefore less shine.

0 : sternum IX posteriorly more strongly concave (Fig. 35c); aedeagus with ventral process apically rounded; basal median internal structure small; flagellum wider and with fewer (ca. 15) coils (Figs 35 a - b).

Taiwan: Peinantashan. .................. praecisus $\mathbf{s p . ~} \mathbf{n}$.

On average larger species: $\mathrm{HL}:>1.7 ; \mathrm{HW}:>1.6 ; \mathrm{PW}:>1.7 ; \mathrm{PL}:>2$; elytra without distinct microsculpture, interstices shining.

$\sigma^{*}$ : sternum IX posteriorly moderately concave; aedeagus with ventral process apically pointed; basal median internal structure larger; flagellum with ca. 30 coils.

Taiwan: Northern Nantou Hsien. . . . . . . . . . . . . . . . . . . . . . . . 8

8. On average larger species; antennae slightly longer, antennomere IV weakly oblong; legs longer (TiL: $>1.6$; TaL: $>1.2$ ).

$0^{n}$ : lateral tergal sclerites IX with long and very acute apical process (Fig. 36d); internal structures of aedeagus of different shape: apical median structure apically gradually tapering, basal median structure slightly longer, and short lateral structures less distinctly sclerotized and in transverse position (Figs $36 \mathrm{a}-\mathrm{b}$ ).

Taiwan: Tsifeng.

O. collapsus sp. $\mathrm{n}$.

On average smaller; antennae slightly shorter, antennomere IV subquadrate; legs shorter (TiL: <1.5; TaL: <1.2).

$0^{\prime}$ : lateral tergal sclerites IX with short apical process (Fig. 37d); internal structures of aedeagus: apical median structure apically \pm abruptly narrowed, basal median structure slightly shorter, and short lateral structures more sclerotized and in less transverse position (Figs $37 \mathrm{a}-\mathrm{b}$ ).

Taiwan: Nenkaoshan.

O. contumax sp. $\mathrm{n}$. 
9. Larger species: $\mathrm{HL}:>1.4 ; \mathrm{HW}:>1.3 ; \mathrm{PW}:>1.4 ; \mathrm{PL}:>1.75$. Antennae longer, antennomere $\mathrm{VI} \pm$ subquadrate, $\mathrm{X}$ weakly transverse $\ldots \ldots \ldots \ldots \ldots \ldots \ldots \ldots \ldots \ldots$ Smaller species: HL: $<1.4$; HW: $<1.3$; PW: $<1.4$; PL: $<1.7$. Antennae shorter, antennomere VI (often also $\mathrm{V}$ ) distinctly, $\mathrm{X}$ strongly transverse. . . . . . . . . . . . 13

10. Colour darker, dark brown to blackish, with the legs and part of the basal two antennomeres light brown or reddish; antennae very long; microsculpture of head and pronotum very shallow and predominantly transverse.

ơ: protarsomeres I - IV moderately dilated; sternum V and VI centrally with small areas with condensed pubescence; aedeagus with slender ventral process, pair of median folds short and not very pronounced; flagellum thin and with only ca. 12 coils (Figs $30 \mathrm{a}-\mathrm{c}$ ). Taiwan: Peitawushan. . . . . . . . . . . smetanai sp. $n$. Colour of body brown to dark brown, with the elytra, the hind margins of abdominal segments VII and VIII, parts of segments IX and X, and the legs light brown to yellowish brown; antennae shorter; microsculpture of head and pronotum more pronounced and less distinctly transverse.

$\sigma^{*}$ : protarsomeres I - IV often more strongly dilated; central subcircular callosities on sternum $\mathrm{V}$ and VI larger, usually more distinctly delimited from surrounding sternal area; median folds of ventral either very distinct or \pm absent; flagellum with more coils.

11. Microsculpture of head and pronotum pronounced and distinctly isodiametric.

$\sigma^{*}$ : ventral process of aedeagus slender and with distinct median folds (Fig $34 \mathrm{a}-\mathrm{b}$ ); internal structures as in Fig. 34c.

Taiwan: Tsifeng (Nantou). . . . . . . . . . . . . . . . reticulatus $\mathrm{sp.} n$. Microsculpture of head and pronotum less pronounced and - at least on pronotum - not distinctly isodiametric.

$\sigma^{*}$ : primary sexual characters different.

Species with more southern distribution in Taiwan. . . . . . . . . . . 12

12. Microsculpture of head predominantly isodiametric.

$\sigma^{*}$ : ventral process of aedeagus more strongly pointed apically and without distinct median folds; apical median structure in the internal sac shorter and less slender (Figs 33 $a-c)$.

Taiwan: Kuanshan Yakou (Taitung).

O. acutus sp. n.

Microsculpture of head with predominantly transverse meshes and transverse striae.

o": ventral process of aedeagus less strongly pointed apically and with distinct median folds; apical median structure in the internal sac longer and more slender (Figs $29 \mathrm{a}-\mathrm{c}$ ). Taiwan: Alishan.

O. parvipennis (Shibata)

13. Eyes smaller than in other species allied to O. parvipennis; elytra relatively shorter (EL/ PL: $<0.56$ ).

ơ: sternum V and VI centrally with small suboval callosities; lateral tergal sclerites IX relatively short, not reaching hind margin of tergum X; sternum IX posteriorly strongly concave (Fig. 32d); ventral process of aedeagus in ventral view with curved lateral margins, pointed apex distinctly sclerotized basal carina; internal sac with 5 sclerotized structures and near apex of median apical structure with distinct membranous structure (Figs $32 \mathrm{a}-\mathrm{c}$ ).

Taiwan: Peinantashan

O. hamatus sp. $\mathrm{n}$. 
- $\quad$ Eyes larger and elytra relatively longer (EL/PL: $>0.57$ ).

$\sigma^{x}$ : stemum V and VI centrally with large circular callosities; lateral tergal sclerites of segment IX slightly longer, reaching beyond tergum X (Fig. 31e); sternum IX posteriorly moderately concave (Fig. 31d); ventral process in ventral view with \pm straight lateral margins, less pointed apex and indistinct basal carina; internal sac with 6 sclerotized structures, membranous structure very indistinct (Figs $31 \mathrm{a}-\mathrm{c}$ ).

Taiwan: Yushan.

a. aequabilis sp. $\mathrm{n}$.

14. Posterior pair of frontal punctures absent or minute; very large species $(\mathrm{HL}:>2.3$, $\mathrm{HW}$ : $>2.0 ; \mathrm{PW}:>2.1$; PL: $>2.6$ ); elytra mat and with very characteristic microsculpture, which is mostly composed of fine and dense rugae of variable length and direction.

q: terminalia as in Fig. 21 a.

China: Sichuan. .................... o. sculptipennis $\mathrm{sp} . \mathrm{n}$.

Posterior pair of frontal punctures present; distinctly smaller species (HL: <2.0, HW: $<2.0$; PW: $<2.1$; PL: $<2.4$ ); elytra with at least subdued shine and less distinct microsculpture.

15. Small species (HL: $<1.3$; HW: $<1.0 ;$ PW: $<1.2$; PL: $<1.7$ ); head very slender (HL/ HW: ca. 1.3; HW/PW: ca. 0.8 ); body colour lighter, pronotum and elytra brown; pronotal punctation pattern characteristic (Fig. 19f).

$0^{7}$ : shape and internal structures of aedeagus as in Fig. 19 a - c.

China: Sichuan. . . . . . . discrepans $\mathrm{sp} . \mathrm{n}$. Larger species (HL: $>1.4$; HW: $>1.2$; PW: $>1.3$; PL: $>1.7$ ); head less slender (HL/HW: $<1.2$; HW/PW: $>0.8$ ); body darker, pronotum and elytra dark brown to blackish; pronotal punctation pattern and on primary sexual characters different. . . . . . . . . 16

16. Head more oblong (HL/HW: $>1.1$ ) and distinctly narrower than pronotum (HW/PW: ca. 0.85 ), posteriorly not widened; elytra without distinct microsculpture.

$\sigma^{\pi}$ : sternum IX posteriorly very deeply concave (Fig. 20d); shape and internal structures of aedeagus as in Figs $20 \mathrm{a}-\mathrm{C}$.

China: Sichuan.

O. excisus sp. $\mathrm{n}$.

Head as wide as or slightly narrower than pronotum (HW/PW: $>0.94$ ), either much shorter (HL/HW: $<1.0$ ) or posteriorly distincty widened; elytra without distinct microsculpture.

$\sigma^{7}$ : primary and secondary sexual characters different or unknown.

17. Head posteriorly distinctly widened; elytra without shallow protuberances, but with distinct microsculpture composed of irregular and partly confluent micropunctation and microrugae; size smaller and pronotum more slender (PL/PW: $>1.23$ ).

$\sigma^{*}:$ primary and secondary sexual characters as in Figs 25 a $-\mathrm{e}$.

\%: lateral tergal sclerites IX shorter and apically less acute; tergum X less oblong and apically less distinctly pointed (Fig. 25f).

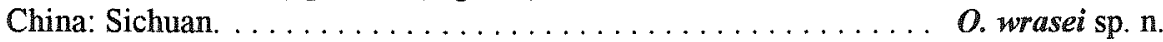

Head posteriorly not distinctly widened; elytra with shallow protuberances, microsculpture less distinct and composed of wide \pm isodiametric or scale-shaped meshes; size larger and pronotum less slender (PL/PW: <1.2); pronotal punctation pattern as in Fig. $23 \mathrm{~b}$.

$0^{*}$ : unknown.

\%: lateral tergal sclerites IX long and apically very acute; tergum X more oblong and apically distinctly pointed (Fig. 23a).

China: Yunnan.

O. tuberipennis $\mathrm{sp} . \mathrm{n}$. 
18. Head with posterior pair of frontal punctures absent; elytra with distinct, well-defined and \pm evenly spaced dense micropunctation.

China: Yunnan. . . . . . . . . . . . . . . . . . . . . . . . . 19

- Head with posterior pair of frontal punctures present; elytra either without or with illdefined, irregularly spaced micropunctation. (In O. taiwanus, the posterior frontal punctures may occasionally be absent or reduced to one puncture, but the elytra are shining and without distinct microsculpture. Rarely, these punctures may also be absent in $O$. medius, a species which is always readily identified by the long spine-like apical processes of the lateral tergal sclerites IX in both sexes.). . . . . . . . . 20

19. Body \pm uniformly blackish; punctation of head less dense and less extensive; head broader (HL/HW: ca. 1.1; HW/PW: >0.92) and elytra shorter (EL/PL: <0.76).

o: unknown.

$:$ : terminalia as in Fig. 22a.

o. opacipennis CAMERON

Body bicoloured, elytra dark reddish and distinctly lighter than head and pronotum; punctation of head denser and more extensive; head more slender (HL/HW: $>1.2 ; \mathrm{HW} /$ PW: $<0.9)$ and elytra longer $(E L / P L:>0.77)$.

$\sigma^{x}$ : aedeagus of unique shape (similar to that of Atrecus); internal structures minute and weakly sclerotized (Figs $12 \mathrm{a}-\mathrm{c}$ ).

q: unknown.

O. atavus sp. $\mathrm{n}$.

20. Elytra with distinct microsculpture composed of unevenly spaced, \pm irregular micropunctation and microrugae; hind wings of reduced length, palisade fringe at hind margin of tergum VII weakly developed.

o: sternum IX posteriorly of characteristic shape, hind angles rounded (Fig. 24d); shape and internal structures of aedeagus as in Figs $24 \mathrm{a}-\mathrm{c}$.

q: terminalia as in Fig. 24f.

China: Sichuan.

O. fibulifer sp. $\mathrm{n}$.

Elytra without conspicuous microsculpture; palisade fringe distinct.

0 : primary and secondary sexual characters different. . . . . . . . . 21

21. Whole body \pm uniformly brownish; pronotum very characteristic, slender (PL/PW: $>1.3$ ), weakly narrowed posteriorly, posterior angles very distinct, hind margin only weakly convex, and dorsally flattened, so that the full length of both lateral margins is visible when viewed from above; posterior pronotal puncture near lateral margin, but distinctly distant from hind angles (Fig. 18b); antennae very long and slender.

$:$ tergum $X$ posteriorly without modified setae (Fig. 18a).

China: Sichuan. ........................ badius ZHENG

- At least head, pronotum and/or abdomen of darker colour; pronotum of different shape and dorsally not distinctly flattened, lateral margins not visible near anterior angles in dorsal view.

\%: hind margin of tergum $X$ usually with modified setae. . . . . . . . . 22

22. Lateral tergal sclerites IX apically with spine-like process (this process may be broken off in older material). . . . . . . . . . . . . . . . . . . . 23

- Lateral tergal sclerites IX without such process. . . . . . . . . . . . . . 24

23. Spine-like process of lateral tergal sclerites IX longer (Figs If, h); punctation of elytra and abdomen denser and less coarse.

$\sigma^{*}$ : aedeagus with ventral process basally \pm constricted; internal structures, especially apical median structure of characteristic shape (Figs 1a - d). 
क: lateral tergal sclerites IX longer and more acute, reaching hind margin of tergum $\mathrm{X}$, the latter posteriorly \pm rounded (Fig. 1h).

Widespread in the Japanese archipelago, South Korea, and China. . O. medius SHARP Spine-like process of lateral tergal sclerites IX shorter (Figs 4e, f); punctation of elytra and abdomen coarser and less dense.

$\sigma^{\text {*: }}$ aedeagus with ventral process basally not constricted; internal structures, especially apical median structure of different shape (Figs $4 \mathrm{a}-\mathrm{c}$ ).

ㅇ: lateral tergal sclerites IX shorter and less acute, not reaching the more strongly pointed hind margin of tergum X (Fig. 4f).

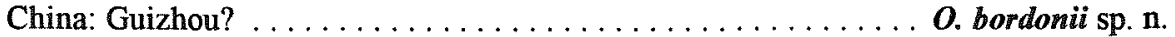

24. Elytra lighter than head and pronotum, reddish or reddish brown, in $O$. rosti often \pm extensively darkened near scutellum and suture. . . . . . . . . . . . 25 Elytra of approximately the same colour as head and pronotum, dark brown to black, sometimes with the margins slightly lighter. . . . . . . . . . . . . . . 27

25. Elytra relatively long (EL/PL: $>0.72$ ); eyes approximately $0.5 x$ the length of postgenae in lateral view or even larger; head on average more slender (HL/HW: $>1.21$ ).

ơ: lateral tergal sclerites apically very long and acute; aedeagus with distinctly pointed ventral process; internal structures of characteristic shape, longer lateral structures bifid (Figs $16 \mathrm{a}-\mathrm{e}$ ).

†: unknown.

Japan, China. . . . . . . . . rufipennis SHARP Elytra relatively shorter (EL/PL: $<0.68)$; eyes smaller; head on average less slender (HL/HW: <1.22).

$0^{\text {: }}$ lateral tergal sclerites apically shorter and less acute; aedeagus with ventral process and internal structures of different shape. . . . . . . . . . . . . . . 26

26. Larger species (HL: $>1.9$; HW: $>1.7$; PW: $>1.9$; PL: $>2.2$ ); head broader (HL/HW: $<1.13$ ).

$\sigma^{*}$ : median area of sterna $\mathrm{V}$ and $\mathrm{VI}$ without tomentose pubescence; lateral tergal sclerites IX apically \pm broadly truncate (Fig. 70); aedeagus much larger, internal sac with 6 sclerotized structures; apical median and lateral structures shorter and stouter; flagellum thin and with ca. 20 coils (Fig. $7 \mathrm{~g}$ ).

o: terminalia as in Fig. 7 t.

China: Gansu. . . . . . . . . . . . . . . . O. latus gansuensis ssp. $n$.

Smaller species (HL: $<1.7$; HW: $<1.5$; PW: $<1.75$; PL: $<2.2$ ); head more slender (HL/HW: >1.09).

$\sigma^{*}:$ median area of sterna V and VI with tomentose pubescence; lateral tergal sclerites IX apically pointed (Fig. 5e); aedeagus smaller, internal sac with apical membranous structure of characteristic shape, without basal median structure, and with apical median and lateral structures longer and thinner; flagellum wider than in any other Eastern Palaearctic species, distally distinctly darkened, and with only $6-7$ coils (Figs 5 a - c).

o: terminalia as in Fig. 5 f.

Ussuri region, Sakhalin, Kuril Islands, Japan.

O. rosti BERNHAUER

27. Very large species (HL: $>2.2$; HW: $>1.9$; PW: $>1.9$; PL: $>2.4$ ); head and pronotum of \pm equal width; pronotum slender (PL/PW: $>1.2$ ) and elytra relatively long (EL/PL: $>0.7)$. $\sigma^{*}$ : sterna $\mathrm{V}$ and VI with areas with tomentose pubescence; aedeagus large and slender, internal sac with sclerotized structures, especially basal median structure of characteristic shape (Figs $26 a-b$ ). 
q: tergum $\mathrm{X}$ as in Fig. 26e.

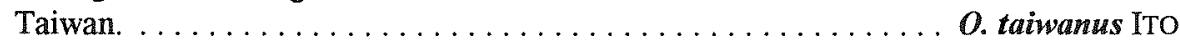
Either distinctly smaller species, or large species with less slender pronotum; elytra often shorter.

$\sigma^{2}$ : sterna V and VI modified only in distinctly smaller species; aedeagus and internal structures of different shape.

Except for one distinctly smaller species absent from Taiwan.

28. Smaller species (HL: $<1.7$; HW: $<1.5$; PW: $<1.6$; PL: $<2.0$ ); head and pronotum mostly narrower (HL/HW: $>1.2$; PL/PW: $>1.15$ ); elytra relatively long (EL/PL: $>0.6)$.

$\sigma^{\prime \prime}$ sterna V and VI centrally with denser or tomentose pubescence. . . . . . . . . 29 Larger species $(\mathrm{HL}:>1.45 ; \mathrm{HW}:>1.35 ; \mathrm{PW}:>1.55 ; \mathrm{PL}:>1.8)$; head and pronotum mostly wider (HL/HW: $<1.15 ;<1.25$ ); elytra often shorter.

$\sigma^{*}:$ sterna $V$ and VI centrally without such modifications. . . . . . . . . . . 30

29. Head larger (HL: $>1.4 ; \mathrm{HW}:>1.2 ; \mathrm{HL} / \mathrm{HW}:<1.25$ ); legs on average more extensively infuscate; posterior pronotal puncture very close to hind angles (Fig. 16h); lateral margins of pronotum posteriorly usually concave.

$0^{7}$ : ventral process of aedeagus apically of broadly triangular shape; internal structures characteristic, inner lateral structures bifid (Figs 16 a - c).

q: terminalia as in Fig. 16g.

China: Sichuan.

O. maculativentris ZHENG

Head smaller (HL: $<1.45 ; \mathrm{HW}:<1.2 ; \mathrm{HL} / \mathrm{HW}:<1.25$ ); legs on average lighter; posterior pronotal puncture more distant from hind angles (Fig. 131); lateral margins of pronotum posteriorly usually \pm straight.

$\sigma^{\prime}$ : ventral process of aedeagus apically distinctly pointed and with sinuate margins in ventral view; internal structures different (Figs 13 a - g).

q: terminalia as in Figs 13j, $\mathrm{k}$.

Widespread: China (Sichuan, Gansu, Shaanxi, Hunan, Zhejiang), Taiwan.

o. punctatus BERNHAUER

30. On average smaller species. Eyes larger, ca. $0.6 \mathrm{x}$ the length of postgenae in lateral view. $\sigma^{*}$ : lateral tergal sclerites IX longer and apically more acute (Fig. 17f); ventral process of aedeagus apically distinctly pointed and with sinuate lateral margins in ventral view; internal structures characteristic: basal median structure very long; inner lateral structures \pm bifid and much longer than external lateral structures (Figs $17 \mathrm{a}-\mathrm{d}$ ).

q: tergum X posteriorly with long unmodified setae (Fig. $17 \mathrm{~g}$ ).

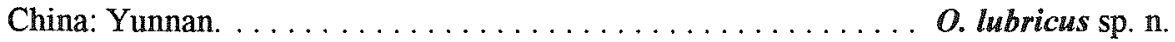

- Larger species. Eyes less than $0.5 x$ the length of postgenae in lateral view.

$\sigma^{*}$ : lateral tergal sclerites IX shorter and apically less acute; ventral process of aedeagus apically of \pm triangular shape, lateral margins in ventral view not distinctly sinuate; internal structures different: basal median structure much shorter; lateral structures not bifid and subequal in length.

q: tergum $\mathrm{X}$ posteriorly with modified setae.

Distribution different.

31. Colour of legs distinctly reddish; body on average smaller; head on average relatively shorter, and eyes on average somewhat larger. 
$\sigma^{\text {: }}$ : posterior margin of sternum VII weakly concave, with shallow median impression and less dense pubescence; sternum VIII with convex hind margin; lateral tergal sclerites of segment IX longer, more slender and apically more acute (Fig. 10f); sternum IX more slender and with different pubescence (Fig. 10e); aedeagus smaller and more slender, ventral process longer, and basally more constricted; sclerotized internal structures of characteristic shape (Figs $10 \mathrm{a}-\mathrm{d}$ ).

$\%$ : tergum $X$ as in Fig. $10 \mathrm{~g}$.

Japan: Amami Islands. . . . . . . . amamianus ITO Highly variable species; colour of legs reddish brown to brown; body on average larger; head on average relatively longer, eyes usually relatively smaller.

o': sternum VII with broad but shallow median impression increasing in depth and width posteriorly and with weakly concave hind margin, the impression with dense and long, almost tomentose pubescence; hind margin of sternum VIII moderately concave and laterally with long dark setae (Fig. 7r); lateral tergal sclerites of segment IX short an broad in lateral view, apically obtusely rounded (Figs $7 \mathrm{n}-\mathrm{p}$ ); sternum LX broader and with pubescence as in Fig. $7 \mathrm{~h}$; aedeagus larger and wider, ventral process shorter; sclerotized internal structures of different shape (Figs $7 \mathrm{a}-\mathrm{f}$ ).

o : terminalia as in Fig. $7 \mathrm{t}$.

Widespread from Sakhalin and Japan to China (Zhejiang, Hunan, Sichuan). . . . . . .

O. latus latus SHARP

\section{Acknowledgements}

I am much indebted to the colleagues indicated in section 2 for arranging the loan of type and non-type material, and in addition to several of the private collectors (especially T. ITO, A. PÜTZ, G.-M. DE RoUGEMONT, M. SCHÜLKE, Y. SHBBATA, A. SMETANA, D. WRASE) for the generous gift of specimens, which are so indispensable for my future studies. TATEO ITO, MUNETOSHI MARUYAMA and MICHAEL SCHÜLKE helped by clarifying localities which I was unable to find in the sources available to me. GUILLAUME M. DE ROUGEMONT kindly translated part of ZHENG's (1995) paper. Finally, I am grateful to LOTHAR ZERCHE for providing me with some older hard-to-get literature articles and for critically reviewing the manuscript.

\section{References}

Assing, V. 1997a: A revision of Othius STEPHENS, 1829. III. The species of the Western Palaearctic region exclusive of the Atlantic Islands (Coleoptera, Staphylinidae: Xantholininae). - Nova Suppl. Entomol., Berlin 10: 3-130.

ASSING, V. 1997b: The species of Othius STEPHENS, 1832 [recte: 1829] of the Canary Islands (Coleoptera, Staphylinidae, Xantholininae). - Vieraea 25 (1996): 103-115

Assing, V. 1998a: A revision of Othius STEPHENs. V. The species of the Himalayan region (Coleoptera: Staphylinidae, Xantholininae) - - Beitr. Ent. 48: 293-342.

Assing, V. 1998b: A revision of Othius STEPHENS of the Atlantic Islands. III: Further records, new species, phylogenetics, and colonization (Insecta, Coleoptera, Staphylinidae: Xantholininae). - Reichenbachia 32: 213-224.

Assing, V. \& SolodovnIKov, A. 1998: Three new species of Othius STEPHENs from the Caucasus (Coleoptera, Staphylinidae: Xantholininae). - Zoosystematica Rossica 7(2): 299-305.

Assing, V. \& WUNDERLE, P. 1995: A revision of the Madeiran species of the genus Othius STEPHENS (Coleoptera: Staphylinidae). - Bol. Mus. Mun. Funchal 45 (1993): 53-65.

BERNHAUER, M. 1907: Zur Staphylinidenfauna von Japan. - Verh. zool.-bot. Ges. Wien 57: 371-414.

BERNHAUER, M. 1916: Neue Staphyliniden der palaearktischen Fauna. - Neue Beitr. syst. Insektenk. 1: 26-28.

BERNHAUER, M. 1922: Neue Staphyliniden der palaearktischen Fauna. - Koleopterol. Rundsch. 10: 122-128. 
BERnHAUER, M. 1931: Neue Staphyliniden aus China von der STÖTZNER'schen Expedition. - Entomol. Nachr.bl. 5 (1): 1-3.

BERNHAUER, M. \& SCHUBERT, K. 1914: Staphylinidae IV. - In: JUNK, W. \& S. SCHENKIING (eds.): Coleopterorum Catalogus, pars 57, Berlin: 289-408.

CAMERON, M. 1937: Fauna Javanica. The Staphylinidae collected by Mr. F. C. Drescher, Part II. - Tijdschr. Ent. 80: 1-37.

CAmeron, M. 1939a: Fauna Javanica. The Staphylinidae collected by Mr. F. C. Drescher, Part III. Tijdschr. Ent. 82: 1-29.

CAMERON, M. 1939b: New species of Asiatic Staphylinidae (Col.). - The Entomologist's Mon. Mag. 75: 162-163.

CoIfFArT, H. 1974: Staphylinides récoltés en Ussuri (Asie Orientale) par S. M. KHNZORIAN-IABLOKOFF. Nouv. Rev. Ent. 4: 197-204.

Crowson, R. A. 1980: On amphipolar distribution patterns in some cool climate groups of Coleoptera. Entomol. Gener. 6: 281-292.

Grant, P. R. (ed.) 1998: Evolution on islands. - Oxford, New York, Tokyo: 334 pp.

ITO, T. 1989: Notes on the species of Othius from Taiwan (Coleoptera, Staphylinidae). - Ent. Rev. Japan 44: 25-30.

Iro, T. 1993: Notes on the species of Staphylinidae from Japan, II (Coleoptera). - Ent. Rev. Japan 48: 141-149.

KLIMASZEWSKI, J; NeWTON JR., A. F. \& THAYER, M. K.: A review of the New Zealand rove beetles (Coleoptera: Staphylinidae). - New Zealand J. Zool. 23: 143-160.

SHARP, D. 1874: The Staphylinidae of Japan. - Trans. ent. Soc. London 1874: 1-103.

SHIBATA, Y. 1973: The subfamily Xantholininae from Taiwan, with descriptions of three new species (Coleoptera: Staphylinidae). - Trans. Shikoku Ent. Soc. 11: 121-132.

SHIBATA, Y. 1986: A list of genera and species new to Taiwan and new data on distribution of the Staphylinidae discovered from Taiwan since 1973 (Insecta: Coleoptera). - Ann. Bull. Nichidai Sanko No. 24: 109-128.

SmetanA, A. 1995: Revision of the tribes Quediini and Tanygnathinini. Part III. Taiwan. (Coleoptera: Staphylinidae). - National Museum of Natural Science Taichung, Special publication number 6: 1-145.

WATANABE, Y. 1994: New record of staphylinid species from Rebun-tô Island, northeast Japan. - Elytra, Tokyo 22: 114.

WATANABE, Y. 1995: Additional records of staphylinid species from Okushiri-tô Island, off southwestern Hokkaido. - Elytra, Tokyo 23: 256.

WATANABE, Y. 1996: Staphylinid beetles (Coleoptera) found in caves and mines of Japan. - J. speleol. Soc. Japan 20: 8-18.

ZHENG, F. 1995: New species and new record of the genus Othius STEPHENS from China (Coleoptera: Staphylinidae, Xantholininae). - Acta Entomol. Sinica 38: 340-346.

\section{Author's address:}

VOLKER ASSING

Gabelsbergerstraße 2

D- 30163 Hannover, Germany

vassing.hann@t-online.de 